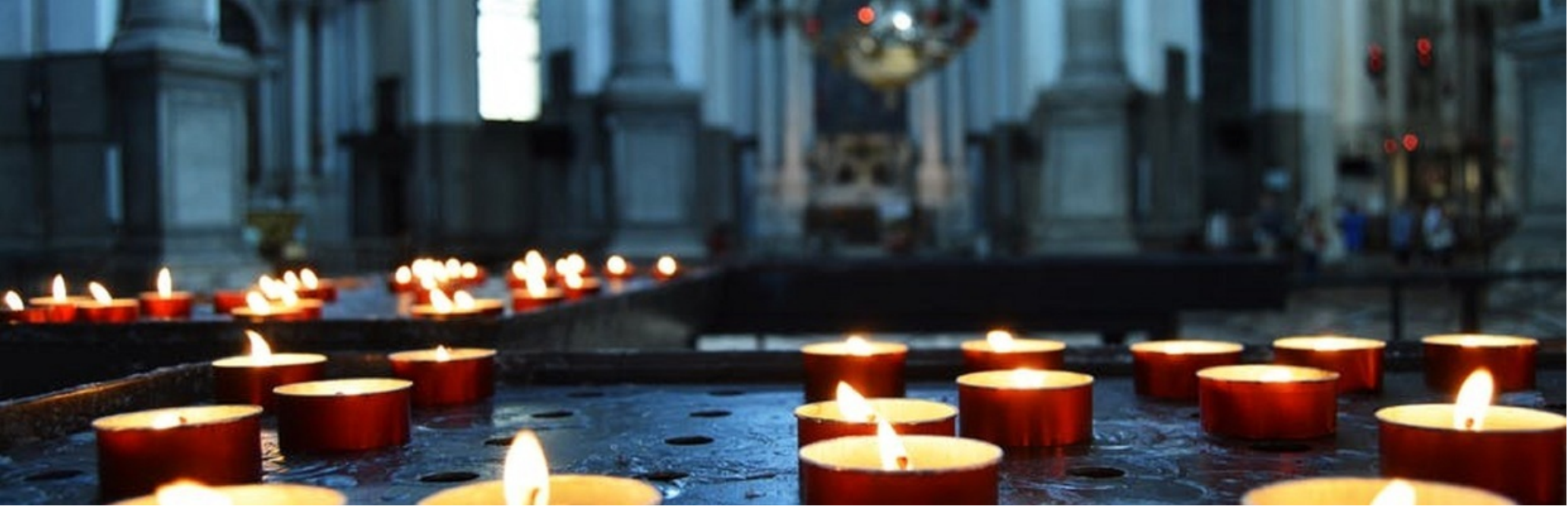

\title{
Demetrios Preis 2018: "A comparison of the religiosity of Christian and Muslim youth in Germany"
}

Authors: $\quad$ Nora Marie Leps

Submitted:

28. September 2018

Published:

Volume:

Issue:

28. September 2018

5

7

Affiliation:

Languages:

Keywords:

\section{Abstract:}

Albert-Ludwigs-university of Freiburg

German

Demetrios Preis 2018, Master, Theology, Religion, Catholicism, Muslim religion, Germany

DOI: $\quad$ 10.17160/josha.5.7.473

This is one of the four works that have been selected by our JOSHA-editors as a winner of our Demetrios Preis 2018! The Thesis was presented by Nora Marie Leps from Germany. Religion and religious education are once again playing an important public role in the integration debate in the face of demographic change in Europe because religion, among other things, provides for integration and orientation. According to Schambeck, religious education, in particular, should aim to teach the students in, from, through and about religion. How can this be achieved so that young people can behave in the face of multiculturalism in Germany?

\section{JOSHA Joumana ossancese Humanities and Arts}


Nora Marie Leps

\section{Ein Vergleich der Religiosität christlicher und muslimischer Jugendlicher in Deutschland}

Wissenschaftliche Arbeit 


\title{
ALBERT-LUDWIGS-UNIVERSITÄT FREIBURG KATHOLISCH-THEOLOGISCHE FAKULTÄT
}

\author{
AB Religionspädagogik \\ Prof. Dr. Mirjam Schambeck sf
}

16. Februar 2018

\section{Ein Vergleich der Religiosität christlicher und muslimischer Jugendlicher in Deutschland}

\author{
Wissenschaftliche Arbeit
}

Eingereicht von:

Nora Marie Leps

13. Semester Katholische Theologie / Spanische Philologie Zur Bitzenmatte 5 79249 Merzhausen

Tel.: 015759294539 E-Mail: noramar@gmx.de 


\section{Inhaltsverzeichnis}

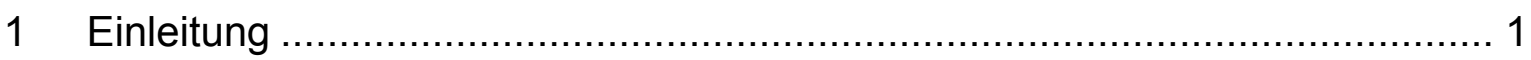

2 Die Rolle der Religion bei der Identitätskonstruktion Jugendlicher.................. 4

2.1 Kontext von Religion - Religiosität ..................................................... 4

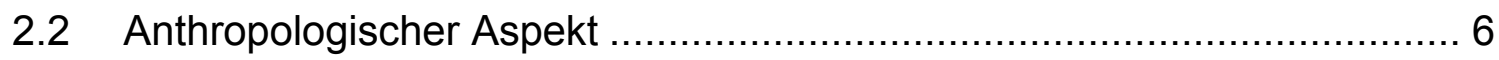

2.3 Sozialpsychologischer und theologischer Identitätsbegriff ...................... 8

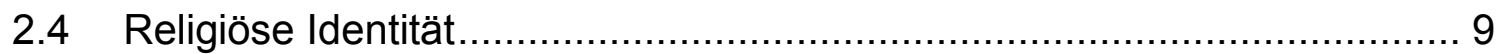

3 Fünf repräsentative Studien zur Religiosität christlicher und muslimischer Jugendlicher im deutschsprachigen Raum ........................................................ 11

3.1 Shell-Jugendstudie 2015 \& Sinus Studie 2016 u 18 „Wie ticken

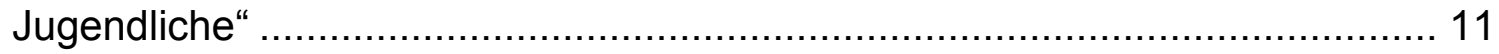

3.2 Deutsches Jugendforschungsinstitut „Radikaler Islam im Jugendalter“ .. 11

3.3 Forschungsprojekt "Tell me your story" .............................................. 12

3.4 Forschungsprojekt zur Religiosität der Muslime in Österreich von 2012 -

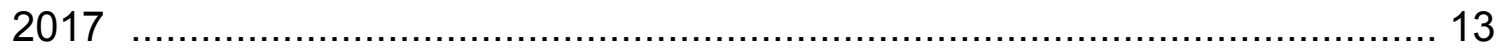

4 Die Religiosität christlicher und muslimischer Jugendlicher in Deutschland.. 14

4.1 Ausgewählte Ergebnisse der fünf Studien......................................... 14

4.1.1 Glaube als Wertorientierung …............................................. 14

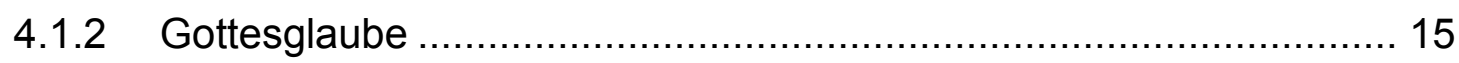

4.1.3 Glaube und Religion im Alltag...................................................... 16

4.1.4 Konfessionalität und Kirche/Glaubensgemeinschaft ....................... 18

4.1.5 Leben und Umgang mit religiöser Vielfalt .................................... 19

4.2 Eigene empirische Studie mit zwei Jugendlichen pro Religion............... 22

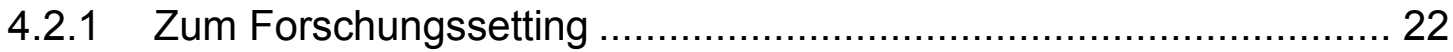

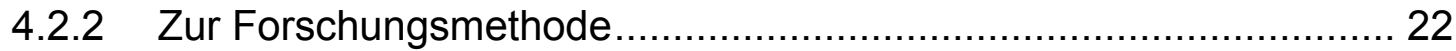

4.2.3 Klassifizierung und Interview-Leitfaden ...................................... 24

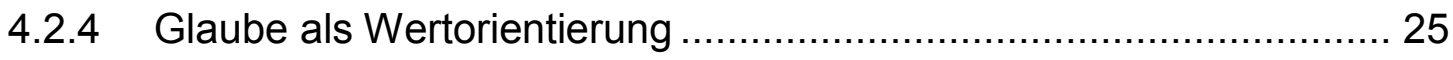




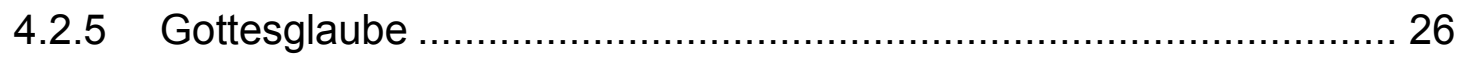

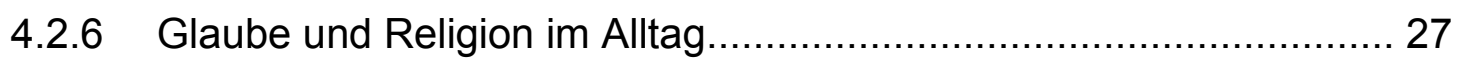

4.2.7 Konfessionalität und Kirche/Glaubensgemeinschaft........................ 27

4.2.8 Leben und Umgang mit religiöser Vielfalt ..................................... 28

5 Kennzeichen/Charakteristika jugendlicher Religiosität................................ 29

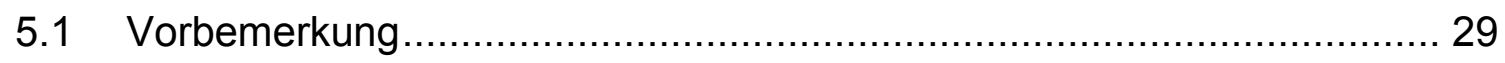

5.2 Allgemeines Kennzeichen jugendlicher Religiosität .............................. 29

$5.3 \quad$ Funktion und Aneignung von Religiosität .......................................... 30

5.4 Vier spezifische Eigenschaften der Religiosität muslimischer Jugendlicher im Vergleich zu christlichen Jugendlichen ............................................... 32

5.5 Modi der Aneignung von Religion ……….......................................... 33

5.6 Identität, Identitätsbildung und religiöse Bildung …………................... 34

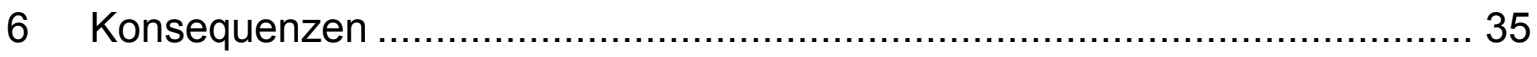

6.1 Aktueller Zustand des christlich-islamischen Dialogs ............................ 35

6.2 Umsetzung der Wünsche der Schülerinnen und Schüler gegenüber

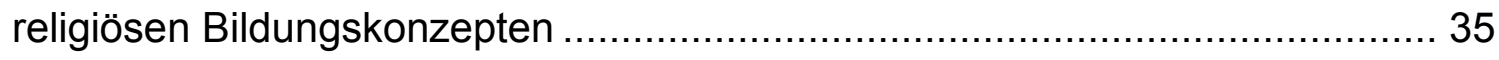

6.3 Religiöse Bildung im Kontext von Integration ....................................... 36

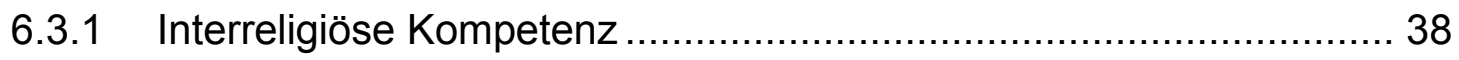

6.3.2 Wertebildung nach christlicher und muslimischer Perspektive - Der Beitrag von religiöser Wertebildung zur Integration..................................... 39

6.3.3 Didaktische Überlegungen und ein Beispiel für die praktische Umsetzung im Religionsunterricht......................................................... 43

6.3.4 Pluralitätsfähige religiöse Erziehung im Islamischen Religionsunterricht. Grundlagen und Perspektiven. ................................... 45

6.3.5 Konstruktiver Vorschlag an die Bildungspolitik ............................. 47

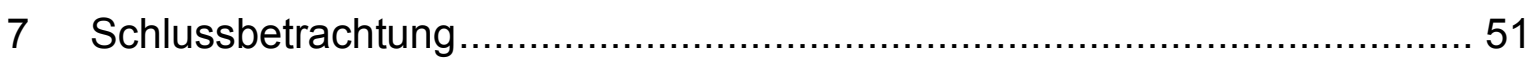

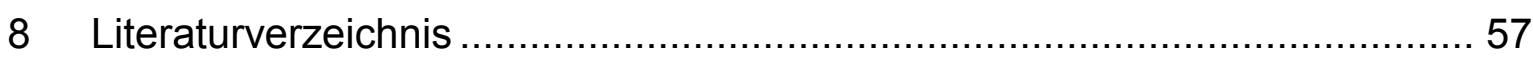

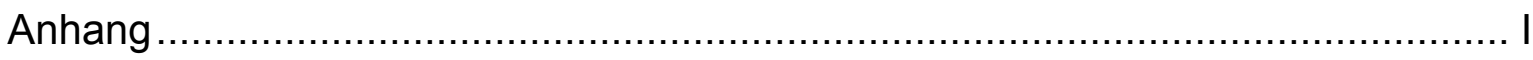




\section{Einleitung}

Terror und Islam. Diese beiden Worte werden in Deutschland vielleicht allzu schnell in ein und denselben Satz gepackt. Aber was steckt dahinter? Im Jahr 2017 riss ein britischer Selbstmordattentäter lybischer Herkunft Kinder und Jugendliche im Namen des Islamischen Staates in den Tod. In der Nähe von Kairo töteten islamische Extremisten mehr als 24 koptische Christen. Parallel dazu warnte einer der höchsten Autoritäten des sunnitischen Islams, der Großimam der Azhar-Universität in Kairo, dass dem Islam ein Rückfall ins Mittelalter drohe, wenn dieser sich weiterhin dem fundamentalistischen Terrorismus hingebe. Für al Tayyeb seien die Attentäter keine Muslime mehr, vielmehr fordere er ein Ende der Gewalt im Namen von Religionen. Immer mehr islamische Religionsgelehrte müssen sich eingestehen, dass "der Islam in einer Sackgasse steckt und ein Problem mit der Gewalt hat" ${ }^{\text {"1 }}$. Um mehr Licht in diese scheinbare Einbahnstraße zu bringen, ist ein großer Schwerpunkt dieser Arbeit die Religiosität muslimischer Jugendlicher in Deutschland genauer unter die Lupe zu nehmen und auf deren Bedürfnisse zu blicken. Gleichermaßen wird diese Untersuchung auch auf der Seite christlicher Jugendlicher geschehen. In einem weiteren Schritt werden beide Jugendgruppen einander gegenübergestellt und verglichen.

Eines ist sich Rainer Hermann jedoch jetzt schon sicher: „[...] dass die Muslime wieder einen Umgang mit ihrer Religion finden, wie er lange üblich war: mehrere Lesarten des Korans zuzulassen und $z u$ akzeptieren, dass sich das Normensystem nach Zeit und Ort verändert [...] [und sie den Koran] anders lesen als im 7. Jahrhudert, wie es der IS macht. ${ }^{\text {2 }}$ Zudem steht er theologischen Erneuerungen des Islams unter heutigen Bedingungen in der arabischen Welt eher pessimistisch gegenüber. Wie müsse sich der Religionsunterricht und vor allem die muslimische Religionspädagogik angesichts dieser Umstände weiter entwickeln, damit islamistischer Terror bereits im Keim, also bei den leicht zu manipulierbaren Kindern und Jugendlichen, erstickt würde und der Religionsunterricht zukunftsfähig die Schülerinnen und Schüler zu demokratischen Mitbürgerinnen und Mitbürgern erziehe?

Unsere Gesellschaft steht angesichts von Migration unter großen Herausforderungen. Aber nicht nur das Aufnahmeland versucht den

\footnotetext{
${ }^{1}$ Hermann, Rainer, Terror und Islam.

${ }^{2}$ Ebd.
} 
demographischen Wandel zu bewältigen, sondern auch die Geflüchteten kämpfen in der Fremde um ihre eigene Identität. Für die Identitätssicherung und Identitätsstiftung spielt Religion eine entscheidende Rolle. Dies wird in der politischen als auch soziologischen Debatte der letzten Jahre vermehrt anerkannt. „Religion beeinflusst die menschliche Identität, gibt ihr Richtung und Sinn. Dass sich unter Migrationsbedingungen religiöse bzw. konfessionelle Identitäten verändern, dass sie erstarken oder fragiler werden, verwundert daher nicht. “3 Gleichzeitig kann religiöse Identitätsstiftung sowohl zu gesellschaftlicher Integration beitragen als auch Desintegration hervorrufen. Diese vorliegende Arbeit hat es sich zur Aufgabe gemacht diese Spannung zu untersuchen, die Religiosität christlicher und muslimischer Jugendlicher in Deutschland konkret zu analysieren und auf muslimischer Seite genauer zwischen deutschen Jugendlichen mit Migrationshintergrund von der ersten, zweiten, oder drittem Generation und Geflüchteten der letzten Jahre zu sprechen. Daher ist Integration ein entscheidender zu diskutierender Faktor in dieser Arbeit. Zudem wird die Frage gestellt, was Multikulturalität und Multireligiosität, wie es im Jahr 2017 in Deutschland ersichtlich der Fall ist, für religiöse Bildungsprozesse bedeutet, wie gleichzeitig der Religionsunterricht zukunftsfähig bleibt und wie zu einem friedlichen Miteinander zwischen unterschiedlichen Kulturen und Religionen beigetragen werden kann.

Ein wichtiges Ziel dieser Arbeit ist es klischeehafte Vorurteile ${ }^{4}$ über Jugendliche mit Migrationshintergrund abzubauen und Skandalisierungen sowie Dramatisierungen entgegenzuwirken. Fakt ist, dass bei muslimischen Jugendlichen Religion und Integration tendenziell eine weitaus wichtigere Rolle spielen als es bei ihren christlichen Altersgenossen der Fall ist. Mit meiner eigenen Studie soll vor allem untersucht werden, welche Rolle die Familie, die Freundschaften, persönliche Netzwerke, ethnische oder andere Zugehörigkeiten für die vier Jugendlichen spielen. Cordula Weissköppel ist der Ansicht, dass verschiedene „[...] religiöse Identitäten im Einwanderungsland zur Ressource [werden], um die spezifische Herkunftskultur fortzusetzen, sie als ein Element vertrauter Alltagspraxis in den neuen Lebenskontext $\mathrm{zu}$ integrieren und

\footnotetext{
${ }^{3}$ Schambeck/Rahner: Zwischen Integration und Ausgrenzung (2011): S.3.

${ }^{4} \mathrm{Im}$ öffentlichen Diskurs wird oftmals die Meinung vertreten, dass Migrantenjugendliche sich eher als die Einheimischen für Gewalthandlungen und Fundamentalismus öffnen, sich tendenziell mehr abschotten und Parallelgesellschaften bilden. Vgl. dazu Yildiz, Aslan, Ein Ausflug in die Alltagspraxis migrantischer Jugendlicher, 115.
} 
demzufolge möglichst auch die Kinder mit diesen Kompetenzen, Gewohnheiten

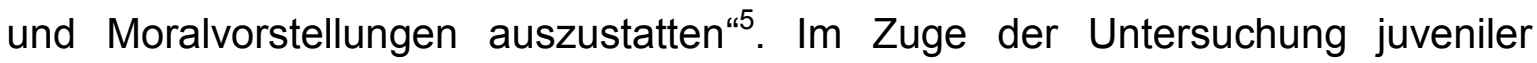
muslimischer Religiosität wird deshalb auch ein Schwerpunkt auf religiöser Bildung im Kontext von Integration liegen.

Das folgende Zitat von Bundesinnenminister Thomas de Maizière vom 20. September 2016 beim 2. Zukunftskongress "Integration und Migration“ führt geradewegs zum Thema dieser Arbeit und zeigt dessen Relevanz auf:

„Wir haben die Bedeutung von Religion unterschätzt. [...] Wir haben auf unser säkularisiertes Land geschaut und gedacht, die große christliche Erzählung ist nicht mehr so wichtig. Was wir aber vielleicht zu wenig sahen, ist, dass überall auf der Welt die Bedeutung von Religion gerade nicht abnahm, sondern anstieg. Nicht nur in der arabischen Welt, auch in Südamerika. [...] Wir werden uns deshalb auch mehr mit uns und unserem Glauben beschäftigen müssen. Wir werden über Religion mehr lernen müssen. [...] und wir sollten uns mehr dafür interessieren, woher unsere Traditionen eigentlich kommen. [...] Von den Flüchtlingen, die zu uns kommen, verlangen wir Neugier und wir wollen, dass sie Fragen stellen zu unseren Traditionen und Lebensweisen. Aber sind wir in der Lage, diese Fragen zu beantworten?"6

Es geht um den Menschen. Alles religionskundliche und religionspädagogische Wissen braucht eine Rückbindung an die Menschen und ihre Bedürfnisse, Sorgen, Wünsche, etc. Dem soll mit dieser Arbeit Rechnung getragen werden.

In der vorliegenden Arbeit wird ein Vergleich der Religiosität muslimischer und christlicher Jugendlicher, besonders zwischen den 14- und 18-Jährigen in Deutschland vorgenommen. Unter muslimischen Jugendlichen wird der Fokus auf die zweite und dritte Generation der Einwanderer sowie auf erst in den letzten Jahren nach Deutschland Geflüchtete gelegt. Zunächst wird die Rolle der Religion bei der Identitätskonstruktion Jugendlicher untersucht. Anschließend werden fünf große empirische Studien zur Religiosität Jugendlicher im deutschsprachigen Raum vorgestellt und deren Ergebnisse bezüglich des Themas dieser Arbeit zusammengefasst. Darauf aufbauend wird meine eigene empirische Studie mit je zwei Jugendlichen pro Religion vorgestellt und mit den Ergebnissen der fünf Studien in Bezug auf die Religiosität Jugendlicher verglichen. Nach der

\footnotetext{
${ }^{5}$ Weissköppel, Die Kultur der Väter verstehen, 159.

${ }^{6}$ Thomas de Maziére, Integration und Migration.
} 
Auswertung werden allgemeine Charakteristika und Kennzeichen juveniler Religiosität zusammengefasst und Konsequenzen im Bereich des christlichislamischen Dialoges und der Erwartung von Seiten der Schülerinnen und Schüler aus den Ergebnissen geschlossen. In einem weiteren Schritt wird religiöse Bildung im Kontext von Integration diskutiert. Abschließend werden die Ergebnisse auf den Religionsunterricht des 21. Jahrhunderts übertragen und ein Vorschlag an den zukünftigen Religionsunterricht herangebracht.

\section{Die Rolle der Religion bei der Identitätskonstruktion Jugendlicher}

\subsection{Kontext von Religion - Religiosität}

Die These von Religion als einer anthropologischen Konstante und Abkopplung von der Institution Kirche hat seit den 90er Jahren zu intensiver empirischer Forschung angeregt. ${ }^{7}$ Innerhalb der analytischen Untersuchungen lässt sich besonders die anthropologische Frage nach Identität in zwei Aspekte aufteilen. Zum einen ist wichtig zu erörtern, welche Funktion Religion für die Stabilität und Entwicklungsdynamik der Gesellschaft hat. Denn laut Wippermann ist Religion gesellschaftliche Moral und hat die Aufgabe, Individuen in die soziale Ordnung konstant und stabil einzupassen. ${ }^{8}$ Andererseits wird nach der Bedeutung der Religion für das Individuum gefragt. Wie gestalten Menschen unter den Strukturbedingungen und Wandlungsprozessen der Postmoderne typischerweise ihre Religiosität? Welche Rolle spielt Religion für die Lebensführung und Identität? In dieser Arbeit soll der Schwerpunkt auf Letzterem liegen, nämlich auf heutigen Formen der Gestaltung und Selbstwahrnehmung von der Religiosität Jugendlicher in Deutschland. Spezifisch wird hier zwischen christlichen und muslimischen Jugendlichen unterschieden. Als Aufgabe der Religion sieht Wippermann ganz klar die Bewältigung von Komplexität und Kontingenzen existentieller Erfahrungen, wie Geburt, Leid, Tod, etc. Aktuell gesehen habe die christliche Religion und die christlichen Kirchen für immer weniger Menschen eine essentielle Bedeutung für die eigene Lebensgestaltung und Identitätskonstruktion. ${ }^{9}$ In aktuellen Debatten

\footnotetext{
${ }^{7}$ Vgl. Wippermann, Religion, Identität und Lebensführung, 11.

${ }^{8}$ Vgl. ebd.,12.

${ }^{9}$ Vgl. ebd.: 14.
} 
wird sogar von einem Bedeutungsverlust der Religion für die Identität gesprochen; und dies beziehe sich nicht nur allein auf das Christentum. ${ }^{10}$

Es gibt heutzutage keine einheitliche Definition von dem vieldeutigen Verständnis von Religion. Deshalb bietet es sich an von Weltanschauung zu sprechen und diese gleichzeitig von der Frage der Religiosität zu trennen. Interessanterweise unterscheidet Wippermann Religion als eine soziale und Religiosität als personale Kategorie.

Folglich ist für inn Religiosität keine anthropologische Grundbefindlichkeit, sondern eine Disposition, welche das (kognitive) Verhältnis des Einzelnen zu seiner Weltanschauung beschreibt. Religiosität ist daher ein relationaler Begriff. Die Religion bzw. Weltanschauung hat im Leben der Jugendlichen erst dann eine Bedeutung, wenn diese sich aktiv und bewusst mit der Weltanschauung auseinandersetzen, das heißt diese zu ihrer Welt- und Selbstbedeutung machen. Nichtsdestotrotz betont er, dass jeder Mensch zwar eine gewisse unaufhebbare religiöse Veranlagung in sich trage, soziologisch relevant jedoch sei, was der Einzelne aus ihr mache. Allein eine bestimmte Weltanschauung zu haben, sei damit noch nicht religiös. ${ }^{11}$

Der Modernisierungsprozess prägt die Formen der Selbst- und Weltdeutung der Jugend in einer von Individualisierung, Pluralisierung und Säkularisierung geprägten Alltagswelt erheblich ${ }^{12}$ und dies gilt es in den vorgelegten Studien hervorzuheben. In einem weiteren Schritt ist zu fragen, ob die heutige Gestaltung von juveniler Religiosität für die Identität des Einzelnen noch subjektiv entscheidend und funktional ist. Gelingt es einer religiösen Konfiguration „Identität zu stabilisieren und die Regeln der Lebensführung zu gestalten“"13? Anhand der empirischen Studien soll dies diskutiert und beleuchtet werden. Im Anschluss daran geht die empirische Rekonstruktion der Religiositätsprofile der christlichen und muslimischen Jugendlichen der Frage nach, welche Relevanz die Ergebnisse der Studien für die Bildungspolitik und den Religionsunterricht haben und was für Konsequenzen man daraus schließen müsse, so dass der Religionsunterricht zukunftsfähig bleibe.

\footnotetext{
${ }^{10}$ Wippermann geht davon aus, dass im Jahr 1998 jeder vierte Jugendliche und junge Erwachsene der Meinung sei, dass „Religion und modern-sein nicht zusammenpassen“. Ebd., 15.

${ }^{11} \mathrm{Vgl}$. ebd., 220.

${ }^{12}$ Vgl. ebd., 13.

${ }^{13}$ Ebd.: 13.
} 
P. Mecheril und O. Thomas-Olalde sprechen in ihrem Aufsatz "Die Religion der Anderen" über Subjektivierungspaxen der Gegenwart bezüglich Religion. Entgegen aller vermuteten Säkularisierungstendenzen rückt Religion scheinbar wieder näher in den Mittelpunkt. Das Religiöse kehrt als Entinstitutionalisierung und Neuformierung religiöser Handlungsmuster und Selbstverständnisse zurück. Gleichzeitig beschreiben Mecheril und Thomas-Olalde das Religiöse als Individualisierung und Entprivatisierung der religiösen Erfahrung. Mit den Stichworten Pluralisierung, Popularisierung und (De-)Privatisierung wird im Kontext der gegenwärtigen gesellschaftlichen Debatte über Religiosität gedacht. ${ }^{14}$ Außerdem unterscheiden sie zwischen Jugendlichen, die sich Religion aus einem pluralen religiösen Sinnangebot gemäß ihren Erfahrungen und Bedürfnissen selbst aneignen und denen, die dem Paradigma der schicksalhaften religiösen Identität angehören. ${ }^{15}$ Damit meinen sie beispielsweise den Islam als „Religion der Anderen“. Diese Ausdrucksweise soll dazu dienen das "Nicht-Muslimisch-Sein des Westens" hervorzubringen und somit ein neues Feindbild des Westens (islamische Welt) benannt zu haben. Die Angst vor einer Islamisierung Europas lässt sich von diesem Verständnis von der Aneignung der Religion und religiöser Identität ableiten. Der Islam als "das Andere" stehe der „modernen/säkularen/christlichen/demokratischen/emanzipierten/liberalen/abendländischen Welt auf eine bedrohliche Art und Weise“16 gegenüber.

\subsection{Anthropologischer Aspekt}

Die Frage nach der Identität Jugendlicher in einer modernen Gesellschaft lässt sich nicht so einfach stellen, da sie durch Prozesse der Globalisierung und Integration sowie zunehmender Regionalisierung beeinflusst wird. Die traditionell national bzw. ethisch orientierte Suche nach der eigenen Identität wird von internationalen und regionalen Perspektiven überlagert.

Das Thema „Identität" wird vor allem im Jugendalter als Entwicklungsaufgabe gesehen und als Prozess der Identitätskonstruktion verstanden. In jugendlichen Lebenswelten wird Identität häufig auf eine noch unbestimmte Zukunft hin entworfen.

\footnotetext{
${ }^{14}$ Vgl. Mecheril, Thomas-Olalde, Die Religion der Anderen, $35 f$.

${ }^{15}$ Vgl. ebd. 38-39.

${ }^{16}$ Ebd. 43.
} 
Der heutige Forschungsstand ist sich darüber einig, dass die Identitätsfindung aus einem Zusammenspiel aus mehreren Faktoren besteht, die in einer Wechselwirkung auf den Jugendlichen einwirken. Dieser befindet sich nämlich in einem sozialen Geflecht aus Familie, Schule, Beruf, Freizeit, Kultur und Religion und muss sich zu den verschiedenen Faktoren in seiner eigenen Identitätsarbeit verhalten lernen. Man muss zwischen religiöser und nicht-religiöser Selbstdefinition der Identität der Jugend unterscheiden. Junge Erwachsene aus Ost- und Westdeutschland sehen sich selbst in ihrer Lebenswelt meist weit entfernt von Religion. Im Umkehrschluss bedeutet dies jedoch nicht, dass Jugendliche sich nicht auch mit religiösen Fragen auseinandersetzen oder kulturell angebotene religiöse Deutungsmuster für sich in Anspruch nehmen. ${ }^{17}$

An dieser Stelle muss genannt werden, dass es die ständige religionsdidaktische Aufgabe ist, die Beziehung zwischen der Alltagswelt der Schülerinnen und Schüler und der christlichen Überlieferung in einem wechselseitig-kritischen Verhältnis wiederherzustellen.

Zu den häufigsten Nennungen bei der Frage nach dem eigenen Glauben zählt die Familie. Zuallererst werden im Raum der Familie Kohärenzerfahrungen, wie Geborgenheit und Zusammenhalt gemacht , $[\ldots]$ die familiär vermittelten, grundlegenden Orientierungen bestimmen positiv oder negativ Richtungen für die Erarbeitung eigener retrospektiver und prospektiver Identitätsperspektiven. “18

Ein Zusammenhang zwischen Religion und Familie lässt sich erkennen, wenn man von einem eigenen mikrokosmischen Familiensystem ausgeht, welches eine sich selbst tragende Welt erschafft, in der auf Immanenz ausgerichtete Sinndeutungsmuster bereitgestellt werden. Die Rekonstruktion familiärer Identität ist somit nicht weniger als die Identität des Subjekts zu komplexen Organisationsund Deutungsprozessen. ${ }^{19}$ Die Erfahrung von Trost und Unterstützung wird von jungen Erwachsenen der Familie zugeschrieben, oftmals in Blickrichtung der religiösen Institutionen, die innen dies nicht vermitteln können; wohl aufgrund fehlender religiöser Alltagspraxis. Wie für den Bereich „Familie“, gilt es auch für "Liebe" aus der Sicht junger Erwachsener, dass es sich um einen Bereich existentieller Sinnvergewisserung ${ }^{20}$ handelt. Liebe steht hier für den Inbegriff für

\footnotetext{
${ }^{17}$ Vgl. Oertel, „Gesucht wird Gott?“, 388f.

${ }^{18}$ Ebd. 389.

${ }^{19}$ Vgl. ebd., 390.

${ }^{20}$ Ebd., 393.
} 
das Sinnstiftende im Leben und als Chiffre für Glück. Somit identifizieren sich Jugendliche vor allem über Familie und Liebe in ihrem Leben.

Dem in nichts hinterherstehend ist auf mindestens gleicher Ebene der Glaube an sich selbst und das Bewusstsein des eigenen Ichs für Jugendliche entscheidend. ${ }^{21}$ An dieser Stelle kommt die Frage auf, in wie fern Religion für Jugendliche neben, oder gerade durch die Bereiche Familie, Liebe und Selbstfindung noch ins Spiel kommt. Dieser Gedanke wird in den folgenden Kapiteln weiterhin verfolgt werden.

\subsection{Sozialpsychologischer und theologischer Identitätsbegriff}

Hier gilt es zwischen religiöser oder nicht-religiöser Selbstdefinition zu unterscheiden. Die humanwissenschaftlichen Ansätze sprechen von Selbstthematisierung und Selbstfindung.

Die theologische Perspektive betont dem Gegenüber, dass der Mensch seine Identität allein von Gott aus gewinnt und nicht nur durch ein „ausgewogenes Selbst- und Sozialverhältnis (Beziehungsstruktur des Personenbegriffs)“22. Hier wird erkennbar, dass das theologische Verständnis von Identität im Widerspruch zu dem zu sehen ist, was Menschen heute allgemein unter „Identität“ verstehen. Von der Identität eines Menschen lässt sich theologisch nur dann sprechen, wenn sie im Hinblick auf Gott erfolgt. ${ }^{23}$ Wie nämlich M. Meyer-Blanck formulierte, dass der Mensch keine eigene Identität habe, sondern sich erst durch die Beziehung auf Gott und von dort ausgehend auch auf die Beziehung auf andere, auf sich selbst und die Welt definieren könne. ${ }^{24}$ Identität gewinnt der christliche Jugendliche durch die Gottesebenbildlichkeit, „verwiesen auf die Gnade, das Heil und die Bestimmung zur Selbstvergessenheit der Liebe, in der sie sich lebenspraktisch vollzieht“ ${ }^{\star 25}$.

(Christlich-) Religiöse Bildung ist aus den oben genannten Gründen der Identitätsfindung in der Adoleszenz grundlegend zur Förderung adoleszenter Entwicklungsprozesse.

\footnotetext{
${ }^{21}$ Vgl. ebd., 394

22 Ebd., 82.

${ }^{23}$ Vgl. ebd., 78.

${ }^{24}$ Vgl. ebd., 79.

25 Ebd., 82.
} 


\subsection{Religiöse Identität}

Stefan Altmeyer stellt sich die Frage, wie Religion, Identität und Bildung zueinanderstehen und gibt $z u$, dass die theoretischen Positionen, phänomenologischen Bezüge und methodischen Zugänge dazu zu vielfältig und teilweise divergierend sind, um einheitliche Aussagen über die Rolle der Religion bei der Identitätskonstruktion Jugendlicher machen zu können.

Jeder Mensch nimmt sich selbst wahr und wird von anderen wahrgenommen. Mit diesem Verständnis ist die Frage nach der eigenen Identität untrennbar mit der Frage nach soziokulturellen Beziehungen verbunden. Ein wichtiger Faktor ist die moderne Gesellschaft. Denn erst in ihr wurde es für die Masse möglich nach der individuellen Positionierung, dem eigenem Lebensentwurf und der religiösen Orientierung fragen zu können. Je krisenhafter die Gegenwart wahrgenommen wird, desto stärker scheinen sich Identitätsfragen $\mathrm{zu}$ stellen. Dies ist im Jugendalter, aber auch für die vielen Flüchtlinge in einer Umbruchsituation sicherlich der Fall.

Einerseits lässt sich fragen, welche Rolle die Religion für die Identitätsprozesse der Menschen spielt, die positiv aber auch kritisch bewertet werden kann, andererseits kann Religion als konstitutiver Bestimmungsgrund von Identität verstanden werden. Die Suche nach Identität selbst kann sogar schon als religiöses Phänomen bezeichnet werden, indem sie sich auf ein immer neues Transzendieren des vor sich Befindenden ausrichtet. Auf gleiche Weise kann Religion bereits als konstitutiver Bestimmungsgrund von Identität verstanden werden. $^{26}$

Religiöse Identität lässt sich folglich als Religionszugehörigkeit oder eigene religiöse Selbstbeschreibung verstehen, so Altmeyer. Es sind die auf die Identitätsfrage antwortenden Identifizierungspraktiken. Sinnvollerweise muss an dieser Stelle zwischen religiösen und nicht-religiösen Formen des Identifizierens unterschieden werden, wie es in Kapitel 2.2 bereits weiter ausgeführt wurde.

Erst dann stellt sich die Frage nach religiöser Identität, wenn der Einzelne nach religiösen Aspekten in der Selbst- und Fremdwahrnehmung und der daraus resultierenden Lebensform fragt. Dies gilt nicht nur im individuellen Sinn, sondern auch im sozial-kulturellen Sinn. Also nicht nur individuell und aktiv, sondern auch kollektiv und passiv kann die Frage danach gestellt werden.

\footnotetext{
${ }^{26} \mathrm{Vgl}$. Altmeyer, religiöse Identität.
} 
Altmeyer plädiert dafür Identität prozessual zu denken, kurzum „Identität als Resultat von Identifizierungspraktiken im Balancieren von Selbst- und Fremdwahrnehmung ${ }^{27}$ zu sehen. Daran anknüpfend fragt er, wie sich in den menschlichen Formen des Identifizierens religiöse Muster artikulieren können und wie diese dann mit institutionalisierten Formen von Religion korrespondieren. In den folgenden Studien wird genau dieses Phänomen analysiert und in einem zweiten Schritt besonders zwischen der Religiosität muslimischer und christlicher Jugendlicher unterschieden. Altmeyer schlussfolgert, dass sich die religiöse Identität auf die Lebensform der Jugend bezieht, in der vor allem im (Selbst-) Empfinden, Fühlen, Denken, Erzählen und Zeigen Bezüge zu individueller Religiosität und sozial-kultureller Religion vorhanden sind.

Was bedeutet das auf den Alltag der Jugend angewendet? Konkret bedeutet dies zum Beispiel, dass sich religiöse Identität eines Teenagers bereits im Tragen eines Kreuzes oder Kopftuches zeigen kann (Zeigen). Zugleich kann Religiosität als Gefühl der besonderen Nähe zu Gott oder zu einer Glaubensgemeinschaft verstanden werden (Fühlen). Das Erzählen der eigenen Biographie, z.B. von der Firmung, kann Ausdruck der eigenen religiösen Identität sein (Erzählen). Wo religiöse Traditionen in der Deutung und Beschreibung des eigenen Lebens fruchtbar werden, spielt Religion eine entscheidende Rolle (Denken). Im Geschmack für das Unendliche und einem das Leben tragenden Urvertrauens ein religiös getöntes Empfinden (Empfinden) ${ }^{28}$ Zusammenfassend kann man sagen, dass sich das religiöse Identitätsmuster im Leben der Jugend auf diese genannten Arten ausdrücken kann.

\footnotetext{
${ }^{27}$ Altmeyer, religiöse Identität.

${ }^{28} \mathrm{Vgl}$. ebd. in der Linie von Schleiermacher und Ericson dazu.
} 


\section{Fünf repräsentative Studien zur Religiosität christlicher und muslimischer Jugendlicher im deutschsprachigen Raum}

\subsection{Shell-Jugendstudie 2015 \& Sinus Studie 2016 u 18 „Wie ticken Jugendliche“"}

Die SHELL-Jugendstudie $2015^{29}$ (Daten erhoben Frühjahr 2015, im Folgenden kurz: „SHELL-Studie“) betrachtet repräsentativ alle 12-25-Jährigen in Deutschland und wertet die Daten differenziert nach Geschlecht, Schulform, Ost-West aus. Die SINUS-Studie 2016 „Wie ticken Jugendliche“30 (im Folgenden kurz: „SINUSStudie“) untersucht dahingegen nur den minderjährigen Anteil der Jugend, nämlich die 14-17-Jährigen. Sie ist eine qualitative Studie mit 72 Jugendlichen, bei der die durch sie gewonnenen Erkenntnisse und Klassifizierungen in Werte- und Lebensweltmodelle interpretiert werden. Mit den gewonnenen LebensweltModellen der „Konservativ-Bürgerlichen“, „Adaptiv-Pragmatischen“, „Prekären“, „Materialistischen Hedonisten“, „Experimentalistischen Hedonisten“, „Sozialökologischen“ und „Expeditiven“ sollen die unterschiedlichen Realitäten der Jugendlichen dargestellt und kategorisiert werden. Meistens sind diese jedoch banaler als die Begriffe selbst und die Übergänge fließender. Nichtsdestotrotz bestätigt diese Studie im Wesentlichen ihren Vorgänger (SHELL-Studie) bezüglich des Werte-Glaube-Kirche-Themas. Der Aussagewert der Daten beider Studien im Vergleich ist so gut wie gleichrangig und aktuell, da die Befragungen nur ein Jahr auseinander liegen. „Wichtiger/weniger wichtig“ oder „mehr/weniger geworden“ beziehen sich in der SHELL-Jugendstudie normalerweise auf den Vergleich mit den Daten der selbigen Studie von 2010 und bei der SINUS-Jugendstudie auf die Daten von 2012.

\subsection{Deutsches Jugendforschungsinstitut „Radikaler Islam im Jugendalter“}

Diese Studie konzentriert sich auf radikale muslimische Jugendliche in Deutschland und deren Religiosität. Integration, Diskriminierung und Radikalisierung, sowie deren Zusammenspiel, bildeten den Hintergrund der

\footnotetext{
${ }^{29}$ Vgl. Shell Deutschland Holding (Hg.), Jugend 2015. Eine pragmatische Generation im Aufbruch (17. Shell Jugendstudie).

${ }_{30}$ Vgl. Calmbach, Borgstedt, Borchard, u.a., Wie ticken Jugendliche 2016? Lebenswelten von Jugendlichen im Alter von 14 bis 17 Jahren in Deutschland.
} 
qualitativen Interviewstudie. Untersucht wurde die Einstellung und Wahrnehmung der in Deutschland lebenden Musliminnen und Muslime in Bezug auf den islamistischen Terrorismus und die Beziehung zwischen der muslimischen und der „westlichen Welt“. Ein besonderes Augenmerk lag auf „intergenerationalen Dynamiken sowie Transmissionsprozesse[n] “31. Die Interviews wurden zwischen Dezember 2009 und September 2010 mit insgesamt 18 Personen aus sechs Familien durchgeführt. In jeder Familie wurde auch jeweils ein Mitglied der dritten Einwanderergeneration interviewt, welches im Schnitt 17 Jahre alt war. Befragt wurden eine alevitische und fünf sunnitische Familien. Im Hintergrund wurde unter anderem die Lebenswelt der befragten muslimischen Familien Deutschlands thematisiert. Hier wurde nach ihrer Bindung an die Herkunftskultur und an Deutschland gefragt. ${ }^{32}$

\subsection{Forschungsprojekt "Tell me your story"}

Sie ist die aktuellste der in dieser Arbeit vorgestellten Studien und steht unter der Leitung von Prof. Dr. Mirjam Schambeck sf. Hier wird versucht zu erörtern, was für eine Bedeutung Religion in den Biographien von jugendlichen Geflüchteten und Migrant/-innen hat und welche religionspädagogischen Konsequenzen man daraus ziehen müsse. Unterschieden wird hierbei die Rolle von Religion während der Fluchtgeschichte und andererseits während dem Leben im Aufnahmeland Deutschland. Es werden „halboffene, leitfadengestützte Interviews geführt, durch soziodemographische Daten ergänzt und eine Fragebatterie zur Einschätzung der eigenen Religiosität erweitert“33. Die Studie zieht aus den Bedeutungen von Religion in den individuellen Biographien inhaltliche Zusammenhänge und arbeitet dabei typische Phänomene heraus. Dazu bedient sie sich dem Verfahren der empirisch begründeten Typenbildung nach Susanne Kluge ${ }^{34}$. In dieser Studie werden nur Jugendliche zwischen 16-27 Jahren befragt. Herkunftsland und

\footnotetext{
31 Vgl. Schiefer, Möllering, Geschke, Muslimisch-deutsche Lebenswelten in Zeiten von Terrorismus(-verdacht): Eine Mehrgenerationenfallstudie, 125-139.

${ }^{32} \mathrm{Vgl}$. ebd., 126.

${ }^{33}$ Schambeck, „Warum ein religiöses Wir-Gefühl nicht nur beruhigt“, 55.

${ }^{34} \mathrm{Vgl}$. Kluge, Susanne: Empirisch begründete Typenbildung. Zur Konstruktion von Typen und Typologien in der qualitativen Sozialforschung.
} 
Religionszugehörigkeit ist beliebig; einzige Grenze ist, dass die geflüchteten jungen Menschen bereits nicht länger als fünf Jahre in Deutschland leben. ${ }^{35}$

\subsection{Forschungsprojekt zur Religiosität der Muslime in Österreich von 2012 $-2017$}

Dieses Projekt unter der Leitung von Ednan Aslan, Jonas Kolb und Erol Yildiz ging über eine Zeitspanne von fünf Jahren. Es beleuchtet die Lebenswelt der Muslime in Österreich und gewährt Einblick in die Vielschichtigkeit und Variationsbreite ihrer religiösen Alltagspraxis, sowie ihrer Lebenswirklichkeiten. Im Fokus stehen Muslime, die keine aktiven Mitglieder von islamischen Organisationen sind und somit die überwiegende Mehrheit von Muslimen in Österreich darstellen. Die drei Autoren möchten mit dieser Studie eine wissenschaftlich fundierte Grundlage bieten, um angemessen auf die Herausforderungen einer pluralen Gesellschaft und der Debatte um die Präsenz der Muslime im europäischen Raum reagieren zu können. Weiterführend nennen sie praktische Handlungsempfehlungen. Die quantitativen und qualitativen Analysen stellen den Ausgangspunkt für eine differenzierte Beurteilung von Integrationsprozessen, Migrationspolitik und eine Verbesserung der religionspädagogischen Angebote dar. Zudem plädieren sie für ein Überdenken der islamischen Theologie im westeuropäischen Abendland. Wie unterschiedlich die religiöse Praxis von Muslimen in Österreich ist und wie stark Säkularisierungstendenzen unter Muslimen verbreitet sind, hat diese erarbeitete Studie des Instituts für Islamische Studien der Universität Wien erhoben. Zu der Studie haben die Autoren ein Buch mit dem Titel „Muslimische Diversität. Ein Kompass zur religiösen Alttagspraxis in Österreich" veröffentlicht. Die Ergebnisse sind hier von besonderem Interesse, da Muslime jeden Alters befragt wurden und bewusst außerhalb von Moscheegemeinden und religiösen Organisationen, nämlich beispielsweise in Parks, Fitnessstudios und Geschäften gesprächsbereite Personen für die Studie gefunden wurden. Das religiöse Alltagsleben von Muslimen in Österreich ist vielfältiger als es der öffentliche Diskurs vermuten lässt. So tragen etwa 77 Prozent der Musliminnen kein Kopftuch. Die Studie setzt es sich damit zum Ziel ein vollständigeres Bild der Religiosität muslimischer

\footnotetext{
${ }^{35} \mathrm{Vgl}$. Schambeck, Was religiöse Wertebildung zur Integration beitragen kann. Überlegungen aus der Religionspädagogik, 118-138.
} 
Jugendlicher und deren Umfeld, ihrer Familien, Freunde und Moscheegemeinden abzubilden. Unterschiedliche Bildungsniveaus, Nationalitäten, Geschlechter und Ethnien sowie die verschiedenen islamischen Rechtsschulen wurden beachtet und mit hineingenommen. Sechs Prozent der Befragten waren Konvertiten. Insgesamt werteten sie 719 Befragungen aus, 71 ausführliche Interviews von einer bis drei Stunden Dauer (qualitative Untersuchung) und 648 standardisierte Fragebögen (quantitative Untersuchung).

Die Autoren unterscheiden zwischen fünf Formen von Religiosität:

„Pragmatische“ und „kulturelle“ Religiosität, „ungebundene Restreligiosität“, "offene" und "bewahrende" Religiosität. Mit fast 30 Prozent ist die größte Gruppe die der „pragmatischen“ (29,6 Prozent), gefolgt von 26,6 Prozent, die als Menschen mit „kultureller Religiosität" bezeichnet werden. 15 Prozent gehören der Gruppe der „ungebundenen Restreligiosität" an, 14,8 Prozent leben eine "offene“ und 14,1 Prozent eine „bewahrende Religiosität“. ${ }^{36}$

\section{Die Religiosität christlicher und muslimischer Jugendlicher in Deutschland}

\subsection{Ausgewählte Ergebnisse der fünf Studien}

\subsubsection{Glaube als Wertorientierung}

Die meisten Jugendlichen Deutschlands sehen in guter Gemeinschaft und Beziehungen zu Familie und Freunden den höchsten Sinn im Leben. Fest steht, dass das Interesse an Sinnfragen unabhängig von der Zugehörigkeit zu einer Glaubensgemeinschaft bei der Jugend stark besteht. Für christliche und nichtreligiöse Jugendliche ist die Frage nach dem Tod und dem Ursprung von allem entscheidend. Für muslimische Jugendliche ist dahingegen das Streben nach Gerechtigkeit und moralischem Verhalten besonders wichtig ${ }^{37}$. Unter allen „Werten" steht auch der "Gottesglaube" mit seiner Wichtigkeit für die Lebensführung, kaum verändert zu 2010, wenn auch leicht sinkend: er ist 33\%

\footnotetext{
${ }^{36}$ Vgl. Aslan, Kolb, Yildiz, Muslimische Diversität. Ein Kompass zur religiösen Alltagspraxis in Österreich.

${ }^{37}$ Vgl. SINUS-Studie, 342.
} 
der Befragten wichtig, für $17 \%$ teils-teils und für $46 \%$ unwichtig. ${ }^{38}$ Wenn man die Konfessionen näher betrachtet, fällt auf, dass noch 53\% der evangelischen und $58 \%$ der katholischen Jugendlichen den Glauben an Gott für ihr Leben als wichtig oder zumindest einigermaßen wichtig einstufen. Dahingegen ist er für $83 \%$ der Jugendlichen anderer Konfessionen wie beispielsweise des Islam oder orthodoxen Kirchen essentiell. ${ }^{39}$ Tendenziell lässt sich beobachten, dass von der Seite der katholischen Jugendlichen her der Verlust der Wichtigkeit des Glaubens höher ist als auf evangelischer Seite; bei den „Anderen“ hat sich die Gewichtigkeit nur gering von „wichtig“ zu „teils-teils“ verschoben.

Auf demographischer Ebene kann man betrachten, dass noch ca. zwei Drittel der Jugendlichen zwischen 12 und 25 Jahren den beiden Landeskirchen angehören, wohingegen sich das letzte Drittel vor allem in Konfessionslose und Muslime unterteilt. $^{40}$

Die dritte Generation der muslimischen Jugend in Deutschland sieht in der Zugehörigkeit zum Islam eher eine soziale Funktion als besondere Wertevorstellungen und Prinzipien. Nichtsdestotrotz identifizieren auch sie sich noch stark mit dem Islam und verstehen die Wichtigkeit der eigenen Zugehörigkeit zur muslimischen Gemeinschaft.

\subsubsection{Gottesglaube}

Der Gottesglaube wird anhand der SHELL-Studie und SINUS-Studie eigenen Kriterien definiert und bemessen. Hierbei wird folgendermaßen nach den Inhalten der Religiosität gefragt und unterschieden: Glaube an einen persönlichen Gott bejahen $26 \%$ aller Jugendlichen zwischen 12 und 25 Jahren, an eine überirdische Macht glauben 21\%, dahingegen sind sich 24\% religiös unsicher (,ich weiß nicht was ich glauben soll“) und „ich glaube nicht, dass es einen persönlichen Gott oder eine überirdische Macht gibt“ äußerten 27\% laut der SHELL-Studie. Mit 47\% sind die überhaupt Gläubigen in der Minderheit. Damit wird bestätigt, dass die evangelischen und katholischen Jugendlichen eher relativ „ungläubig“ im Vergleich zu muslimischen und „anderen Christen“ sind. Nur 27\% der evangelischen Jugendlichen glauben an Gott als Person, wohingegen 67\% der

\footnotetext{
${ }^{38}$ Vgl. SHELL-Studie, 243.

${ }^{39} \mathrm{Vgl}$. ebd., 151.

${ }^{40}$ Vgl. ebd., 253, 256.
} 
muslimischen Jugendlichen von einem persönlichen Gottesbild ausgehen. ${ }^{41}$ Ergänzend dazu stellt die SINUS-Studie fest, dass für muslimische Jugendliche der Glaube und die Religionszugehörigkeit weniger trennbar voneinander gesehen werden können als es bei den Christen der Fall ist, für die der Glaube etwas Individuelles ist. Dennoch sind auch sie von religiöser Praxis im Alltag eher entfernt. ${ }^{42}$ Ein weiterer nennenswerter Aspekt ist die Zuwanderung: 2015 wohnten $11,5 \%$ islamische Jugendliche und orthodoxe Christen in Deutschland, wohingegen 2002 dies nur $6,5 \%$ waren. $^{43}$

\subsubsection{Glaube und Religion im Alltag}

Immer weniger Jugendliche kommen aus einem religiösen Elternhaus $(27 \%)^{44}$, dementsprechend sinkt die sog. religiöse Praxis. Beispielsweise beten nur noch $15 \%$ der evangelischen und $20 \%$ der katholischen Jugendlichen ${ }^{45}$ gegenüber $46 \%$ der „sonstigen“ Religionen (muslimisch, orthodox), deren Anhänger mindestens einmal in der Woche zu beten scheinen. ${ }^{46}$ Dazu passend stellt die SINUS-Studie fest, dass gerade die kirchentreuen Jugendlichen ihre Motivation an erster Stelle aus Jugendarbeit und Gemeinschaftserfahrungen schöpfen. ${ }^{47}$ Seinen Glauben zu leben bedeutet für viele Jugendliche zunächst die Einhaltung von Regeln, aber auch positive Gemeinschaftserlebnisse. ${ }^{48}$ Beispielsweise nennen muslimische Jugendliche den Koran-Unterricht, regelmäßige Gebete, den Ramadan, das Zucker- und Opferfest als aktive Mitwirkung in ihrer Glaubensgemeinschaft. ${ }^{49}$ Laut der Studie zur Religiosität muslimischer Familien in Deutschland ist das Thema Religion durchaus auch diskursfähig innerhalb der Familien und im Freundeskreis als selbstverständlicher Teil des Alltags. Die Jugend der dritten Generation in Deutschland bevorzugt jedoch eher jugendrelevantere Themen als Glaubensgespräche. Als Beispiel gehören hier jedoch auch Moscheebesuche zum Gesprächsthema. Die Eltern der Jugendlichen finden es zwar wichtig ihr Zöglinge im muslimischen Glauben zu unterweisen. Tendenziell wurde durch die Studie

\footnotetext{
${ }^{41}$ Vgl. SHELL-Studie, 254-255.

${ }^{42}$ Vgl. SINUS-Studie, 341, 355.

${ }^{43} \mathrm{Vg}$. SHELL-Studie, 254.

${ }^{44}$ Vgl. ebd., 157.

${ }^{45}$ gefragt war nach Regelmäßigkeit = einmal im Monat.

${ }^{46}$ Vgl. SHELL-Studie, $256 f$.

${ }^{47}$ Vgl. SINUS-Studie, 351.

${ }^{48}$ Vgl. ebd., 356.

${ }^{49}$ Vgl. SINUS-Studie, 341.
} 
aber bestätigt, dass sich die jüngere Generation von einer muslimischtraditionellen Lebensweise abwendet, und sich verstärkt von einer westlich orientierten postmodernen Lebensweise angezogen fühlt. Außerdem wurde aufgezeigt, dass die tatsächliche Religionspraxis und die Ausführung der Regeln des Korans genauso stark von Familie zu Familie variieren, wie auch das Wissen über die eigene muslimische Religion.

Die drei Wissenschaftler Ednan Aslan, Jonas Kolb und Erol Yidiz berichten, dass die Mehrheit der in Österreich lebenden Muslime Säkularisierungstendenzen aufweist. Dies gilt nicht nur für Erwachsene, sondern gleichermaßen für junge Musliminnen und Muslime. Im Alltag bedeutet dies konkret, dass „pragmatisch“ lebende Muslime die im Islam vorgeschriebenen fünf täglichen Gebete so verrichten, wie es der Arbeitsplatz, die Freizeitgestaltung und andere äußere Einflüsse es ihnen ermöglichen. Sie werden auch als „moderat konservativ“ beschrieben. Dem gegenüber stehen „Kulturelle“ oder „Kulturmuslime“. Sie sind aus Gewohnheit Muslime und üben ihre religiösen Praxis hauptsächlich zu bestimmten Anlässen, wie etwa dem Fastenmonat Ramadan aus. Außerhalb dieser traditionellen Vorgaben wird die Religion jedoch eher als Relikt gesehen.

Mit den sogenannten „Taufscheinchristen“ könne man diejenigen Muslime benennen, die eine weltoffen Haltung haben und ihren Glauben individualisiert verstehen. Der Glaube an Gott und das Paradies ist durchaus ausgeprägt, findet aber keinerlei Entsprechung im Alltag. Trotzdem verstehen sich diese 15 Prozent der muslimischen Bevölkerung in Österreich als Muslime laut Aslan.

Liberale und weltoffene Muslime leben sehr selbstbestimmt. Zum Beispiel beten sie nicht nach Vorschrift sondern nach persönlichem Bedürfnis und wohnen mit dem Partner bereits vor dem Eheschluss zusammen.

Laut der österreichischen Studie sind die „Bewahrenden“ die kleinste Gruppe mit $14,1 \%$. Sie sind sehr traditionalistisch, religiös und wertkonservativ eingestellt. Die „fünf Säulen des Islam“ werden vorbehaltslos eins zu eins im eigenen Leben umgesetzt. Sie spalten sich eher von den Säkularisierungstendenzen der Mehrheit der muslimischen Bevölkerung ab und ziehen sich in ihr eigenes religiöses Milieu zurück. Vertreter dieser „bewahrenden Religiosität“ sind tendenziell eher in den Städten vorzufinden als auf dem Land. Zudem sprachen sich viele gegen die in Europa typische Trennung von Staat und Religion aus. 
Außerdem klären die drei Autoren durch ihre Studie auf, dass es nicht "die“ Muslime gibt. Das in den medialen Darstellungen und in politischen Debatten häufige Vorurteil, dass es sich bei der muslimischen Bevölkerung um eine homogene Gruppe von religiös extremen Gläubigen handle, die ihre Religion einheitlich praktiziere, könne nicht weiter aufrechtzuerhalten sein. ${ }^{50}$

Zudem müsse das öffentliche Bild revidiert werden, denn mehr als zwei Drittel der Muslime sind nicht in Moscheegemeinden organisiert bekräftigt Aslan. Im Folgeschritt bilanziert er, dass islamische Institutionen ihre Angebote neu überdenken müssten um die Menschen wieder erneut zu erreichen.

Yildiz fordert eine Stärkung an Demokratie im Kontext von innermuslimischer Diversität mit der Behauptung, dass man ja nicht 24 Stunden am Tag nur Muslim sein würde.

\subsubsection{Konfessionalität und Kirche/Glaubensgemeinschaft}

In Deutschland haben wir einen hohen Anteil an konfessionell Gebundenen: zwei Drittel der Jugendlichen gehören derzeit den Landeskirchen an. Dennoch ist die Teilnahme an kirchlichen Angeboten und die Zustimmung $\mathrm{zu}$ den Glaubensinhalten, zur Bedeutung des Glaubens für die Lebensführung und besonders die religiöse Praxis nur sehr gering. ${ }^{51}$ Wie kommt dieser Widerspruch zustande? Zusammenfassend kann man bilanzieren, dass der aktuelle Trend für zwei Drittel der Jugend folgendermaßen lautet: Kirche als soziale gesellschaftliche Institution wird tendenziell bejaht, der christliche Glaube dahingegen eher weniger. Gleichzeitig sind 64\% der Meinung, dass auch die Kirchen zukunftsfähiger werden müssten und $57 \%$ bestätigen, dass die Kirche keine Antworten auf ihre existentiellen Fragen geben könne. $^{52}$ Auch $42 \%$ der konfessionslosen Jugendlichen finden es gut, dass es die Kirche gibt, wollen aber persönlich eher weniger mit ihr zu tun haben. Die SINUS-Studie bestätigt, dass Jugendliche die Funktion von Kirche und Religion für die Gesellschaft jedoch als äußerst positiv empfinden und schätzen. ${ }^{53}$

\footnotetext{
${ }^{50}$ Zur Illustration ihrer Argumente dient die Zahl an Frauen, die kein Kopftuch trägt. Dies ist bei fast $80 \%$ aller muslimischen Frauen in Österreich der Fall.

${ }^{51} \mathrm{Vgl}$. SHELL-Studie, 157.

${ }^{52}$ Vgl. ebd., 259.

${ }^{53}$ Vgl. SINUS-Studie, 374.
} 
Dahingegen sehen viele muslimische Jugendliche keinen Widerspruch zwischen der Verbindung von der Institution ihrer Religionsgemeinschaft und der religiösen Praxis im alltäglichen Leben. Vielmehr bejahen die meisten die Existenz ihrer religiösen Gemeinschaft und nur 34\% wünschen sich eine Veränderung ihrer Religionsgemeinschaft. ${ }^{54}$ Interessant wird es hier, welches die SINUS-Studie bestätigt, dass christliche Jugendliche vor allem Kirchenmitglieder sind, da sie "hineingeboren" wurden ${ }^{55}$ und muslimische Jugendliche auf Grund ihrer Familien die Moschee besuchen. ${ }^{56}$ Es sind also gesellschaftliche, kulturelle, soziale und traditionelle Gemeinschaftsgründe ausschlaggebend für Kirchenmitgliedschaft, und nicht unbedingt nur die Gründe „religiösen Charakters“.

\subsubsection{Leben und Umgang mit religiöser Vielfalt}

Bei den meisten Befragten besteht der Freundeskreis aus Jugendlichen verschiedener Religionen. Hier steht die religiöse Vielfalt oftmals eng mit der Nation und Kultur der Freundinnen und Freunde in Verbindung und die Einbindung in das familiäre Umfeld des Freundes kann wichtig sein. ${ }^{57}$ Über unterschiedliche Religionen tauschen sie die Jugendlichen aber eher weniger aus. Solange persönlich vertretende Werte wie Toleranz und Respekt nicht in Konflikt mit „anders" Gläubigen treten, zeigt sich der Jugendliche gegenüber seinem Freund offen und interessiert. Außerhalb des eigenen Freundeskreises kommen die Jugendlichen vor allem über die Schule und den Religionsunterricht mit anderen Religionen in Kontakt. ${ }^{58}$

Viele assoziieren religiöse Konflikte mit den aktuellen Auseinandersetzungen rund um den Islam und den gewalttätigen Auseinandersetzungen in Syrien bzw. den IS. Dabei äußern sie ihr Unverständnis bezüglich dieser Konflikte. Zudem vermischen vor allem die Experimentalistischen Hedonisten religiöse und kulturelle Konflikte und können die Gründe für bestimmte Auseinandersetzungen nicht nachvollziehen beziehungsweise differenzierter betrachten. Zumindest versuchen die Jugendlichen zwischen dem Islam als Religion, den verschiedenen Interpretationsmöglichkeiten des Korans und religiös begründeten

\footnotetext{
${ }^{54}$ Vgl. SHELL-Studie, 160.

${ }^{55} \mathrm{Vgl}$. SINUS-Studie, 350.

${ }^{56}$ Vgl. ebd., 355.

${ }^{57}$ Vgl. ebd., 360.

${ }^{58} \mathrm{Vgl.} \mathrm{ebd.,} 363$.
} 
Gewaltausübungen zu differenzieren. ${ }^{59}$ Andere religiöse Konflikte, die weniger mediale Präsens haben, sind den Jugendlichen kaum bekannt. Außerdem lehnt die Mehrheit die religionsbegründete Gewalt aufs schärfste ab. Den KonservativBürgerlichen und Sozialökologischen Jugendlichen sind Werte wie Frieden, Nächstenliebe und gemeinschaftliches Miteinander besonders am Herzen. ${ }^{60}$ Besonders muslimische Jugendliche distanzieren sich von islamistischen gewalttätigen Gruppierungen. Sie grenzen ihren eigenen persönlichen Glauben von den religiösen Konflikten stark ab.

Die Meisten gehen davon aus, dass alle Religionen ein friedliches Miteinander befürworten und Toleranz einen Schlüsselbegriff dafür darstellt.

Die Jugendlichen aus den muslimischen Familien von der Studie zum radikalen Islam im Jugendalter lehnen die Teilnahme am islamistischen Terrorismus einstimmig ab und verurteilen die islamistischen Extremistinnen und Extremisten ${ }^{61}$, da sie von deren Unvereinbarkeit mit dem Islam überzeugt sind.

Die muslimisch-deutsche Jugend ist tendenziell weniger religiös als die erste und zweite Generation an Immigranten und stärker an die deutsche Gesellschaft angepasst, dennoch ist auch für sie die soziale Gemeinschaft der nationalen Herkunftsgruppe und die Gemeinschaft ihrer Geschwister im Glauben scheinbar wichtiger als die deutsche Mehrheitsgesellschaft. ${ }^{62}$ In erster Linie ist ihr Alltag von jugendtypischen Themen dominiert. Die muslimisch-deutschen Jugendlichen sind bikulturell sozialisiert und fühlen einen stärkeren Assimilierungsdruck als ihre Eltern. Zudem sehen sie sich selbst als innerlich zerrissene Jongleure zwischen den Kulturen. Das bedeutet, dass neben den jugendtypischen Herausforderungen der Identitätsfindung noch eine weitere Entwicklungsaufgabe hinzukommt: die Zughörigkeit zu einer kulturellen und auch religiösen Minderheit in der andersartigen Mehrheitsgesellschaft in Deutschland entdecken und verstehen lernen. ${ }^{63}$

Die Studie von Mirjam Schambeck hebt vier Auffälligkeiten besonders hervor:

Die Geflüchteten waren in ihrem Heimatland wegen ihrer Religionszugehörigkeit oftmals Opfer von Diskriminierungen. Im Aufnahmeland schätzen sie deshalb die

\footnotetext{
${ }^{59}$ Vgl. ebd., 368.

${ }^{60}$ Vgl. ebd., 370.

${ }^{61} \mathrm{Vgl}$. Schiefer, Möllering, Geschke, Muslimisch-deutsche Lebenswelten in Zeiten von Terrorismus (-verdacht): Eine Mehrgenerationenfallstudie, 138.

${ }^{62}$ Vgl. ebd., 139.

${ }^{63}$ Vgl. ebd.
} 
Säkularisierung und Privatisierung von Religion und somit Verminderung von potentiellen gesellschaftlichen Konflikten.

Laut dem Bericht einer Geflüchteten spielt die Religion als ein sozialer Ort für sie eine besonders tragende Rolle, um ein Wir-Gefühl in Deutschland aufzubauen und parallel eine Brücke in die Heimat darzustellen.

Einem weiteren jungen Flüchtling hilft während seiner Flucht in Kairo aber auch im für ihn fremden Deutschland das zusammenschweißende Gemeinschaftsgefühl in der Moscheegemeinde. In der Schule wird er mit Mitschülern anderer Religionen konfrontiert und lernt die religiöse Vielfalt als gleichberechtig anzuerkennen.

Ein weiterer Interviewter sieht in seiner Religion den sicheren Hafen in der Fremde und Ausgangspunkt für eine Konfrontation und Bewertung der Kultur des Aufnahmelandes. ${ }^{64}$

Ednan Aslan, der Leiter des Instituts für Islamische Studien, und die Soziologen Jonas Kolb und Erol Yildiz fassen in ihrer Studie zur Religiosität der Muslime in Österreich zusammen, dass jeder dritte Muslim dort eine „hochfundamentalistische“ Einstellung hat. Damit ist einerseits gemeint, dass sich eine große Zahl der Muslime in einem Säkularisierungsprozess befinde, parallel dazu gibt es jedoch auch ein großes Potenzial für Ansichten, die die Autoren als hochfundamentalistisch werten. Gemeint ist damit, dass diese Muslime meinen, dass die eigene Religion recht und andere Religionen unrecht hätten. Ein Drittel der Befragten findet es beispielsweise „sehr bedrohlich“, wenn das eigene Kind einen Partner mit anderer Religionszugehörigkeit heiraten würde. ${ }^{65}$

In der österreichischen Studie wurde den religiösen Selbstbildern, den praktizierten Umgangsformen mit religiösen Pflichten im Alltag, den Zukunftsperspektiven der interviewten Muslime sowie deren Haltung zu den Themen Religion, Staat und Politik Raum gegeben. Als Konsequenz der Ergebnisse fordern die Autoren neue Integrations- und Bildungsmaßnahmen. Als Ausgangspunkt soll hier die muslimische Diversität dienen. Man müsse eine hochwertige religiöse Bildung an den Universitäten etablieren wie es in Wien bereits der Fall ist, so Yildiz. Desweiteren müsste die islamische Theologie im europäischen Kontext neu durchbuchstabiert werden und eine allgemeine Offenheit für den interreligiösen Dialog befürwortet werden.

\footnotetext{
64 Schambeck, Mirjam, Was religiöse Wertebildung zur Integration beitragen kann, 125-129.

${ }^{65} \mathrm{Vgl}$. katholische Nachrichten kath.net, Jeder dritte Muslim hochfundamentalistisch.
} 


\subsection{Eigene empirische Studie mit zwei Jugendlichen pro Religion}

\subsubsection{Zum Forschungssetting}

Im Juni 2017 habe ich eine eigene qualitativ-empirische Untersuchung zur Erforschung der Religiosität christlicher und muslimischer Jugendlicher an der Staudinger Gesamtschule in Freiburg im Breisgau durchgeführt. Grundlage und Orientierung dafür waren vor allem die beiden großen Studien zum selbigen Thema (SHELL- und SINUS-Studie). Der folgende Beitrag dokumentiert die Auswertung meiner Studie zum Thema dieser Arbeit.

Gezielt wurde darauf geachtet einen männlichen und einen weiblichen Jugendlichen der jeweiligen Religion zu befragen. Das Alter der Interviewten liegt zwischen 17 und 18 Jahren. Für die Erstellung meines Interview-Leitfadens habe ich mich erneut an der SHELL- und SINUS Studie orientiert. Somit war das Kernthema die Religiosität der christlichen und muslimischen Jugend in Freiburg zu untersuchen. Thematisch wurden besonders das Leben und der Umgang mit religiöser Vielfalt in den Blickwinkel genommen. Die Meinungen, Wahrnehmungen und Einstellungen dazu sollen dabei vor dem Hintergrund eines Lebens als Christ bzw. Muslim der ersten, zweiten oder dritten Generation in Deutschland betrachtet werden.

Die ersten beiden Interviews wurden am Donnerstag, 1. Juni 2017 gegen 13:15 Uhr in der Staudinger Gesamtschule durchgeführt. Am Folgetag wurden gegen 15:15Uhr die weiteren beiden Interviews vor dem Fitnessstudio Fitness First in der Freiburger Innenstadt durchgeführt. Auffällig ist, dass alle vier Befragten zu Beginn ihren Gottesglauben als wichtig bzw. sehr wichtig für ihr Leben einstuften und dementsprechend ihre Antworten in den Interviews auch relativ religiös konnotiert ausfielen.

\subsubsection{Zur Forschungsmethode}

Die in diesem Abschnitt präsentierten empirischen Ergebnisse beruhen auf einer Befragung von vier Jugendlichen im Alter zwischen 17 und 18 Jahren aus der Staudinger Gesamtschule in Freiburg im Breisgau. Interviewt wurden jeweils zwei christlich und zwei muslimisch Gläubige und mittels Diktiergerät aufgenommen und durch Mitschriften protokolliert. Hier bot sich besonders das qualitativ- 
empirische Verfahren der Sozialforschung als Forschungsmethode an. Eine qualitative Datenanalyse mit dem Ziel, induktiv eigene Theorien zu erstellen, ist von vorneherein jedoch nicht angestrebt worden.

Im Folgenden sollen der angewandte Interviewleitfaden vorgestellt und die Vorgehensweise im Gespräch kurz skizziert werden. Anschließend sollen die Interviews einzeln interpretiert und daraus direkt Rückschlüsse über den Wissensstand bezüglich des Themas gezogen werden.

Der Interview-Leitfaden und die Datenanalyse knüpfen an die vorhergehenden Ausführungen der fünf bereits dargestellten Studien in dieser Arbeit zu Glauben und Religion an, gehen aber über diese hinaus. Ziel ist es, die dort dargestellten Thesen empirisch zu überprüfen, sowie Strukturen und Zusammenhänge aufzudecken, ohne dass der Blick durch jene theoretischen Ergebnisse eingeschränkt wird.

Bei der Interpretation der empirischen Ergebnisse mit Hilfe einer Adaption der Anwendung der Qualitativen Inhaltsanalyse nach Philipp Mayring ${ }^{66}$, soll eine fruchtbare Plattform geschaffen werden, die über den vorhandenen theoretischen Horizont hinaus Anregungen für weitere theoretische und praxisbezogene Überlegungen veranlasst, denen ich in dieser Arbeit Raum geben möchte.

Die Interviews wurden in Deutsch transkribiert. Das so entstandene Textmaterial wurde mit einer Variation des Schemas von Philipp Mayring ausgewertet und in den folgenden Kapiteln dieser Arbeit zu finden sein. Die drei angewandten Techniken bestehen aus Zusammenfassung, Strukturierung und Explikation ${ }^{67}$. Nur durch die Bildung von Kategorien im ersten Schritt, konnte das Material zusammengefasst und im zweiten Schritt strukturiert, sowie anhand der zuvor gebildeten Kategorien eingeschätzt werden. In einem dritten Schritt wurden die Aussagen unter Einbeziehung des Kontextes, in welchem die Aussagen getätigt wurden, und durch einen Vergleich der Aussagen miteinander genauer erläutert. Mehrmals wurde auf die Daten des Interviews zurückgegriffen, sowie alle drei Schritte auch ineinander übergehend angewendet.

Aufgrund der geringen Anzahl der Interviews und ihres eher kleinen Umfangs sind nur Folgerungen aus der je einzelnen Perspektive möglich, ein zusammenfassender Vergleich bringt deshalb sehr unwahrscheinlich neue Ergebnisse im Vergleich zu den bereits fünf großen genannten Studien.

\footnotetext{
${ }^{66}$ Vgl. Mayring, Einführung in die qualitative Sozialforschung, 114-121.

${ }^{67}$ Vgl. ebd., 115.
} 
Selbstverständlich geschieht dies in dem Bewusstsein, dass den Thesen nur eine eingeschränkte Aussagekraft aufgrund der Rahmenbedingungen zukommt.

\subsubsection{Klassifizierung und Interview-Leitfaden}

Die vier befragten Jugendlichen wurden nach folgenden Kriterien unterschieden und klassifiziert:

1. Interview mit $\mathrm{CM}^{68}$ am 2.06.17 (Katholisch, männlich, deutsch, 17 Jahre alt, Abiturient; Gott ist in deinem Leben wichtig: trifft voll zu).

2. Interview mit CW2 ${ }^{69}$ am 2.06.17 (Evangelisch, weiblich, deutsch, 17 Jahre alt, Abiturientin, Gott ist in deinem Leben wichtig: trifft voll zu).

3. Interview mit $M M 3^{70}$ am 01.06.17 (Sunnitisch, männlich, syrisch, 18 Jahre, besondere Eingangsklasse 10; Gott ist in deinem Leben wichtig: trifft voll zu). Er ist vor 4 Jahren mit seiner Familie von Syrien nach Deutschland geflüchtet.

4. Interview mit MW4 ${ }^{71}$ am 01.06.17 (Schiitisch, weiblich, deutsch, 17 Jahre alt, besondere Eingangsklasse 10; Gott ist in deinem Leben wichtig: trifft zu).

Um die Religiosität der Jugendlichen zu vergleichen, wurde der InterviewLeitfaden entsprechend des Gesamtanliegens der Studie folgendermaßen konzipiert:

1. Was für eine Rolle spielen Glaube und Religion für dich?

2. Was ist für dich sinnstiftend? Was gibt dir Sinn im Leben?

3. Gehörst du einer Glaubensgemeinschaft an? Wenn ja, wie stark ist die Bindung daran und worauf stützt sie sich?

4. Wie äußert sich Glaube und Religion konkret in deinem Alltag? Was bedeutet es für dich den eigenen Glauben zu leben/ nicht zu leben?

5. Hast du in deinem persönlichen Umfeld Kontakt zu Menschen anderer Religionen? (z.B. Freundeskreis, Schule, Beruf, Freizeit, etc.)

6. Wie findet der alltägliche Austausch über Religion statt?

7. Gibt es in deinem Alltag konkrete Berührungspunkte mit anderen Religionen?

8. Nimmst du religiöse Konflikte wahr? Wenn ja, wie bewertest du diese?

\footnotetext{
${ }^{68} \mathrm{CM} 1=$ christlicher, männlicher, erster Interviewter.

${ }^{69} \mathrm{CW} 2$ = christliche, weibliche, zweite Interviewte.

${ }^{70} \mathrm{MM} 3$ = muslimischer, männlicher, dritter Interviewter.

${ }^{71}$ MW4 = muslimische, weibliche, vierte Interviewte.
} 
9. Was für einen Einfluss haben diese Konflikte auf deinen persönlichen Glauben und deine grundsätzliche Einstellung zu Glaube und Religion?

Zunächst wurde untersucht, wie die Teilnehmenden zum Thema "Glauben und Religion" reagieren, und was innen Sinn im Leben gibt, und ob für sie ein Zusammenhang zwischen Sinn und Glaube/ Religion besteht. Zum Verständnis dieser subjektiven Einschätzung und Wahrnehmung wurde die Lebenswelt der christlichen und muslimischen Jugendlichen in Freiburg fokussiert und nach Glaubensgemeinschaft und religiöser Praxis im täglichen Leben gefragt. Darauf aufbauend wurden das Leben und der Umgang der Jugendlichen mit religiöser Vielfalt in Anbetracht der aktuellen politischen und gesellschaftlichen Entwicklungen, vor allem bezüglich der aktuellen enormen Einwanderungsswellen besonders thematisiert. Im Vordergrund stand an dieser Stelle die Bindung an Deutschland, wie auch an die (andere) Herkunftskultur und die Wahrnehmung der sogenannten Mehrheitsgesellschaft in Deutschland.

Im Großen und Ganzen kann man sagen, dass die vier Fallbeispiele meiner Studie die tendenziellen Hauptaussagen der fünf repräsentativen Studien im deutschsprachigen Raum widerspiegeln.

Zur besseren Übersicht und Vergleichbarkeit wurden die Ergebnisse meiner Studie in denselben Kapiteln zusammengefasst, wie in den Kapiteln der bereits zuvor betrachteten großen repräsentativen Studien.

\subsubsection{Glaube als Wertorientierung}

Gute Gemeinschaft und Beziehungen sind den meisten Jugendlichen in Deutschland gemäß den beiden großen Studien besonders wichtig. Meine vier Befragten haben dem auch zugestimmt. Zudem nannte alle Vier aber auch noch ihren Glauben bzw. Religion als sinngebend. Der 17-Jährige Katholik findet in Religion, Glaube, Familie und Sport seinen Sinn des Lebens wiedergespiegelt. Der Glaube, Familie und Freunde geben dem christlichen und muslimischen Mädchen Sinn im Leben. Für den Moslem sind Erfolg und Religion maßgebend im Leben. Außerdem zählt er Familie, Freunde und Gott als sinngebende Faktoren auf. Der Katholik bezeichnet seinen Glauben beispielsweise als Stütze in schwierigen Lebensabschnitten. Für die 17-Jährige Christin sind Glaube und 
Religion das Wichtigste im Leben. Der Gottesglaube und das Zusammenleben in Frieden sind für den muslimischen Jugendlichen besonders erstrebenswert.

Für die 17-Jährige Schiitin ist der Glaube erst seit der Jugend wichtiger geworden, da sie bei ihrer christlichen Mutter aufgewachsen ist und ihr muslimischer Vater ihr seine Religion erst mit den Jahren besser vorstellen und erklären konnte.

Auch wurde in meiner Studie bestätigt, dass muslimische Jugendliche besonders nach Gerechtigkeit und moralischem Verhalten $\mathrm{zu}$ streben scheinen. Diesbezüglich äußerte sich MM3 folgendermaßen:

„Also ähm bei uns, im Islam muss man halt fünf Mal am Tag beten und das mache ich auch täglich. Deshalb habe ich viel Kontakt, also sozusagen mit Religion und Gott und so. Ähm und ich find halt wichtig und für mich ist auch gut, dass ich halt mich an die Religionsgesetzte (.) festhalte. Und dass ich auch äh damit was mach“ und alles was ich lerne auch übe in meinem Altag, ausüben. Und ähm dass ich halt (.) so wenig wie möglich Fehler mache. Und ja.....

Auch MW4 sagte dazu:

„Also ich find's eigentlich wichtig meinen Glauben zu leben, weil, also, es gibt halt viele Sachen, die uns vorbeschriftet werden, oder wie sagt man, vorgeschrieben ja. Und ich find's wichtig sich an die Sachen zu halten."

\subsubsection{Gottesglaube}

Drei von vier Jugendlichen sagen, dass ihnen der Glaube an Gott „besonders wichtig“ im Leben ist. Nur die 17-Jährige Muslimin sieht ihn „nur“ als wichtig (ohne Steigerungsform „sehr“) an. Der Protestantin hilft der Glaube an Gott die alltäglichen Probleme zu meistern. Aus der kleinen Studie kann nicht darauf geschlossen werden, dass die beiden christlichen Jugendlichen eher weniger gläubig sind als die beiden muslimischen Jugendlichen, wie es die SHELLStudie $^{72}$ herausgefunden hatte.

Desweiteren tritt der Glaube nicht getrennt von Religiosität bei den drei Jugendlichen auf, sondern gehört zusammen, da sie ihren Gottesglaube und die Teilnahme an einer Glaubensgemeinschaft relativ regelmäßig ausüben. Einzig der christliche Jugendliche CM1 steht diesem Thema differenzierter gegenüber und bestätigt damit indirekt die Aussagen der großen Studien zum Rückgang der

\footnotetext{
${ }^{72}$ Vgl. SHELL-Studie, 254-255.
} 
Notwendigkeit des regelmäßigen Kirchganges und der Privatisierung des Glaubens:

„Ähm also ner Glaubensgemeinschaft direkt nicht, aber ich gehe natürlich ähm ab und zu in die Kirche, aber nicht ähm als Gemeinschaft sonder für mich selbst.“

\subsubsection{Glaube und Religion im Alltag}

Mehrmals am Tag scheint es beiden christlichen Jugendlichen wichtig zu sein zu beten, da das Gebet für sie therapeutische Wirkung hat. Dies widerspricht der Aussage der bereits vorhin genannten Studien, dass die Praxis des Gebets im Durchschnitt weniger als täglich stattfinde. Der 18-Jährige Muslim gehört der sunnitischen Glaubensgemeinschaft an und geht ab und zu in die Moschee. Er hat aber auch zu Moslems anderer Glaubensgemeinschaften Kontakt. Außerdem hält er die 5 Gebetszeiten am Tag ein und versucht die Regeln des Korans so gut wie möglich im Alltag umzusetzen. Sein Alltag wird von der religiösen Praxis relativ stark durchdrungen, so wie es auch die SINUS-Studie über Muslime schreibt. ${ }^{73}$ Die junge Schiitin geht eigentlich nur ab und zu an religiösen Feiertagen in die Moschee. Auch sie versucht im Alltag die Vorschriften des Korans einzuhalten, tut dies jedoch erst seit dem Jugendalter, da sie bei ihrer Mutter aufgewachsen ist und nur ihr muslimischer Vater sie im muslimischen Glauben unterweisen konnte. Dementsprechend hat sich die religiöse Praxis erst ab dem Jugendalter bei ihr entwickelt.

\subsubsection{Konfessionalität und Kirche/Glaubensgemeinschaft}

Die beiden christlichen Jugendlichen besuchen eine ihrer Konfession entsprechende Gemeinde, jedoch der Katholik eher sporadisch und für sich selbst. Die Protestantin geht dahingegen mit ihrer Familie regelmäßig, da sie seit ihrer Kindheit in der Gemeinde aufgewachsen ist und sich dort heimisch fühlt. Beide bejahen den Kirchgang, der Katholik äußert sich jedoch nur mit geringem Interesse gegenüber kirchlichen Angeboten, da er „nur“ für sich die Messe besuche, und dies auch eher sporadisch.

Der sunnitische Jugendliche geht öfters in die Moschee, seine Schwester dahingegen ist bekennende Atheistin. Dies widerspricht dem Ergebnis der SHELL-

\footnotetext{
${ }^{73}$ Vgl. SINUS-Studie, 341.
} 
und

SINUS-Studie,

dass

gesellschaftliche,

gesellige,

soziale

Gemeinschaftsgründe ausschlaggebend für die

Glaubensgemeinschaftsangehörigkeit seien, und nicht unbedingt nur „religiöse“.

\subsubsection{Leben und Umgang mit religiöser Vielfalt}

Im Freundeskreis trifft der katholische Jugendliche auf vorwiegend muslimische und kaum christliche Freunde. Sie tauschen sich manchmal über religiöse Themen aus. Im Ethikunterricht erfährt er die Standpunkte Andersgläubiger über Religionen. Zudem nimmt er persönlich keine religiösen Konflikte wahr, sondern bekommt nur Diskriminierungen gegenüber Moslems über Dritte mit. Anderen Religionen gegenüber sieht er sich als sehr offen an, ist dennoch von seinem eigenen Glauben überzeugt. Die Protestantin hat in ihrem engeren Freundeskreis vor allem christliche Freunde, aber auch ein paar Muslimische. Der alltägliche Austausch über Religion findet in ihrer Gemeinde, dem Freundeskreis und evangelischen Religionsunterricht statt. Auch sie bekommt, wenn überhaupt, nur kleinere Streitgespräche zwischen Atheisten und Gläubigen, unabhängig der Religion, bzw. über das Fernsehen Konflikte rund um den IS mit. Auch sie steht hinter ihrem eigenen Glauben, bloß fragt sie sich, warum so viel Ungerechtes geschieht, obwohl die Religionen Frieden lehren.

Der Sunnit wohnt mit seiner atheistischen Schwester zusammen und kommt mit ihr oft über den Glauben in hitzige Gespräche. Auch in seiner Klasse hat er Kontakte zu Jugendlichen anderer Glaubensausrichtungen und spricht mit ihnen über Religionen. Dabei versucht er zu belehren, aber gleichzeitig auch zu lernen und sich die Meinungsverschiedenheit seines Gegenübers nicht zu sehr zu Herzen zu nehmen. Er legt viel Wert darauf über andere Religionen Bescheid zu wissen, gleichzeitig aber seine festen Gründe zu haben, warum er seine Religion vertritt.

Die Schiitin hat in der Schule, im Freundeskreis, in der Familie und bei ihrem Nebenjob (Eisdiele) Kontakt zu Menschen anderer Religionen. Vor allem in der Schule trifft sie auf gleichgläubige Freundinnen, mit denen sie sich über den Glauben austauschen kann. Dabei kann es auch schon mal zu Diskussionen über die Vereinbarkeit von Koran und gewalttätigem IS kommen, welche sie jedoch ablehnt, da von dem Befehl zu Gewalt im Koran nicht die Rede sein könne. 
Alle vier Befragten haben in ihrem Freundeskreis Jugendliche verschiedener Religionen. Auch hier steht die religiöse Vielfalt oftmals eng mit der Nation und Kultur der Freundinnen und Freunde in Verbindung. ${ }^{74}$ Unterschiedliche Religionen sind eher weniger das Thema in der Clique, aber Toleranz wird erwartet. Außerhalb des eigenen Freundeskreises kommen die Jugendlichen vor allem über die Schule, den Religionsunterricht sowie diverse Nebenjobs und Sport mit anderen Religionen in Kontakt: „Also bei mir eben, manchmal wenn ich in der Kirche, also ich habe ja auch Freunde in der Kirche mit denen ich mich über sowas unterhalt, oder auch privat mit Freunden über sowas, oder halt auch im Religionsunterricht, bin ich ja im evangelischen Religionsunterricht. Da reden wir halt auch, also da reden wir natürlich auch über Religion", berichtet CW2 schmunzelnd.

\section{Kennzeichen/Charakteristika jugendlicher Religiosität}

\subsection{Vorbemerkung}

Aus allen erwähnten Studien lassen sich Basismerkmale der Religiosität christlicher und muslimischer junger Erwachsener ableiten. Nichtdestotrotz muss erwähnt sein, dass der Religionsbegriff in den jeweiligen empirischen Studien unterschiedlich verwendet wurde und Religion funktional, diskursiv oder auch substantial verstanden werden kann. Dennoch wurde der Versuch nicht gescheut, Kennzeichen juveniler Religiosität herauszufiltern und zusammenzufassen. Bei den Ergebnissen ist jedoch nie ein Absolutheitsanspruch dahinter, sondern lediglich von Tendenzen die Rede.

\subsection{Allgemeines Kennzeichen jugendlicher Religiosität}

Kirchlichkeit wird von den christlichen Jugendlichen oft als negativ und altmodisch eingeschätzt, Religion und Glaube jedoch eher positiv. Muslimische Jugendliche dahingegen trennen die Faktoren tendenziell weniger voneinander und stehen ihrer Glaubensinstitution viel weniger kritisch gegenüber, als es bei ihren christlichen Glaubensgeschwistern der Fall ist.

\footnotetext{
${ }^{74}$ Vgl. SINUS-Studie, 360.
} 
Jugendliche Religiosität zeichnet sich nicht unbedingt durch ein konkretes Bekenntnis, sondern tendenziell durch ein allgemein religiös aufgeladenes Weltbild aus. ${ }^{75}$ Den meisten ist der genaue theologische Inhalt und Wahrheitsanspruch ihrer Religion im Einzelnen gar nicht bekannt oder sogar zweitrangig. In Europa ist aber überwiegend das christliche Weltbild und sein kulturelles Erbe entscheidend. Dies bedeutet zum einen, dass christliche junge Menschen keine neue religiöse Sprache kreieren, sondern sich der vorhandenen traditionellen christlichen Sprachmuster bedienen. Auf der anderen Seite bedienen sie sich der christlichen Tradition als Katalysator ${ }^{76}$. Das bedeutet, dass die über die Tradition überlieferten Begriffe, Anregungen, Denkmuster von den Jugendlichen aufgenommen werden und im selben Zuge weiter ausgeformt werden, um ihr religiöses Weltbild zu erweitern. In postmodernen Gesellschaften vollziehen sich demnach weniger Prozesse des Religionsverlustes, als vielmehr „Prozesse des religiösen Formenwandels, in deren Verlauf an die Stelle des institutionell verfassten Modells von Religion religiöse Symbolisierungen des eigenständig agierenden Individuums treten“"77.

Das religionspädagogische Prinzip des „Symbolisieren Lernen“ und „Ästhetischen Lernen“78 im Religionsunterricht kann hier eine tragende Rolle einnehmen, um eine angemessene religiöse Kompetenz der jungen Bürger Deutschlands zu fördern.

\subsection{Funktion und Aneignung von Religiosität}

Jugendliche verorten ihre subjektive Religiosität in der Auseinandersetzung mit objektiver Religion. Das bedeutet laut Sellmann ${ }^{79}$, dass Religiosität hier einen funktionellen Wert hat, beziehungsweise als Strategie dient. Sie wird für die Konstruktion der eigenen Biographie erst dann essentiell, wenn sie hilft Identität zu formen, nämlich durch ein gewisses Zugehörigkeits- und Abgrenzungsgefühl. Außerdem soll Religion in einer globalisierten, sich rasch wandelnden, unüberschaubaren Welt Sicherheit spenden.

\footnotetext{
75 Vgl. Ziebertz, Gesellschaftliche und jugendsoziologische Herausforderungen für die Religionsdidaktik,103.

${ }^{76} \mathrm{Vgl}$. Kropac, Jugendliche Religiosität.

${ }^{77} \mathrm{Vgl}$. Schöll, Religion Jugend.

${ }^{78}$ Vgl. Schambec, unveröffentlichtes Manuskript zur Vorlesung über Religionspädagogik im SS 17.

${ }^{79}$ Sellmann, Jugendliche Religiosität als Sicherungs- und Distinktionsstrategie im sozialen Raum, 46-52.
} 
Interessanterweise verändert sich die Bedeutung von Religion. Sie wird zu einer von biografischen Kontexten abhängigen Größe und für Geflüchtete in Deutschland besonders entscheidend: „Nicht das Subjekt fügt sich ein in den von der Religion aufgespannten ordo; vielmehr wird Religion selbst in einen ordo eingefügt, nämlich den der Biografie ${ }^{\text {“80. }}$. Damit ist Religion also nicht mehr eindeutig bestimmbar, sondern das, was als Religion oder religiös gedeutet wird, muss je nach Lebenslage neu bestimmt werden. Biographische Reflexion setzt jetzt bei bestimmten Lebensübergängen ein und löst institutionell vorgegebene Ablaufmuster ab. In wie weit das auf die Biographien der geflüchteten Jugendlichen hier in Deutschland zutrifft, muss in den kommenden Jahren noch weiterhin erforscht werden.

Viele christliche junge Menschen sind heutzutage nicht mehr unbedingt Mitglied der Kirche, obwohl sie durch die Familie dazu erzogen worden sind und wie die meisten muslimischen Jugendlichen in die Religion hineingeboren wurden. Sie eignen sich Religion vielmehr in einer Weise an, die der Art und Weise der heutigen Kulturaneignung entspricht. Religiöse Inhalte werden für sie vor allem dann wichtig, wenn sie ihre Lebenswelt, ihre Interessen und Gefühle ansprechen, sie sinnlich-ästhetisch konfiguriert sind und genussversprechend wirken. Idealerweise sollten sie auch noch in das persönliche Kreativitätsmuster passen und durch die Welt der Medien zugänglich sein.

Die Option für oder gegen Religion wird gemäß der Klassifizierung jugendlicher Lebenswelten durch die SINUS-Studie im Kontext von (Kommunikations-)Milieus und auch auf Grund lebensgeschichtlich bedeutsamer Ereignisse entschieden.

Auch die Kirchen müssen sich als traditioneller Ort von Religion unter diesen gesellschaftlichen Umständen ändern. Das lebenslange Gemeindemitglied muss einem Typus von Jugendlichem weichen, der nur bei Bedarf zweckgebunden und zeitlich befristet die Kirchenangebote wahrnimmt. Anders hingegen scheint es laut der SHELL-Studie und SINUS-Studie auf muslimischer Seite. Immer noch haben die Vorgaben des Korans sowie der Religionsführer der einzelnen Moscheen etc. einen erheblichen Einfluss auf moralische Fragen und die Lebensführung.

\footnotetext{
${ }^{80}$ Sellmann, Jugendliche Religiosität als Sicherungs- und Distinktionsstrategie im sozialen Raum,
} 48. 


\subsection{Vier spezifische Eigenschaften der Religiosität muslimischer Jugendlicher im Vergleich zu christlichen Jugendlichen}

(1) Für junge Musliminnen und Muslime ist es selbstverständlich, dass ihr Glaube institutionell eingebettet ist, sie sich dem Islam zugehörig fühlen und ihr Glaube im Familienalltag als ein sich ständig wiederholendes Ritual ausgeübt wird. Weitaus weniger vermögen es die christlichen Kirchen die Jugendlichen dauerhaft an sich zu binden und die Sinnfrage durch kirchliche Angebote und Lehre zu beantworten.

(2) Wie auch das Christentum ist der Islam eine öffentliche Religion. Nichtsdestotrotz nehmen muslimische Jugendliche im Vergleich zu ihren christlichen Altersgenossen viel häufiger an den von ihrer Religion vorgeschriebenen öffentlichen religiösen Ritualen und Praktiken, wie z.B. regelmäßigen Gebeten, Koran-Lehren und Ramadan teil. Durch den starken sozialen Zusammenhalt der Familie erleben die Jugendlichen ihre Zugehörigkeit zum Islam und zur religiösen Gemeinschaft noch intensiver. Ihre Religion sehen sie als eine Art moralische Instanz mit religiösen Ge- und Verboten, die sie sehr ernst zu nehmen scheinen. Für sie endet die Sinnfrage in dem Streben nach gerechtem, moralisch richtigem Verhalten. Somit hilft innen der Islam für die Bewältigung des Alltags.

(3) Alle muslimischen Befragten in den Studien lehnen die Anwendung religiöser Gewalt aufs schärfste ab und negieren jegliche legitime Verbindung ihres Glaubens mit Gewalt. Insgesamt stellte sich heraus, dass so gut wie alle Jugendlichen die Teilnahme an Gewalt ablehnen, jedoch muslimische Jugendliche sich aufgrund des vermehrten Auftretens von radikalen islamischen Gruppen noch stärker davon zu distanzieren versuchen.

(4) Einerseits gibt der Islam den Jugendlichen ein kollektives Identitätsgefühl. Andererseits bedeutet dies aber weder, dass sie sich reflektiv mit diesem auseinander setzen müssen, noch dass sie sich eine eigene Meinung bilden brauchen. 


\subsection{Modi der Aneignung von Religion}

Gemeinsam ist allen Jugendlichen, dass sie für die Bewältigung ihrer lebenspraktisch zu lösenden Probleme und Fragen durch Prozesse der (religiösen) Sinnfindung hindurchgehen. Hierbei treten vier Merkmale ${ }^{81}$ bei auf:

(1) Viele eignen sich Religion nur okkasionell an, nämlich dann, wenn ihre Lebenssituation danach verlangt. In Krisen suchen sie beispielsweise danach um lebenspraktische Entscheidungen besser treffen zu können. ${ }^{82}$

(2) Jugendliche müssen sich nicht mehr nur für eine Religion bzw. einen Sinn im Leben entscheiden, sondern können sich mit dem „sowohl-als-auch-Gedanken“ ihre geforderte Stellungnahme frei lassen und selbstständig wählen.

(3) Der Lebenssinn kann nicht von einer göttlichen oder moralischen Instanz abgeleitet werden oder genauso wenig an dritte delegiert werden. Jugendliche müssen damit in direkten Kontakt kommen und eigene Erfahrungen machen, um (religiösen) Sinn zu finden.

(4) Unter den gesellschaftlichen Bedingungen von Pluralisierung und Individualisierung muss sich der einzelne junge Mensch selbst mit der Sinnfindung auseinandersetzen. Dennoch lebt er in keiner Welt mit beliebig vielen offenen Optionen sondern fragt bei lebenspraktischen Entscheidungen nach angemessenen und sozial verbindlichen Möglichkeiten.

In unserer postmodernen Gesellschaft wird heutzutage alles aufgefunden: von institutioneller Steuerung, individualisierten Formen der Gestaltung der eigenen Biographie bis zu hin zu Orientierungen fundamentalistischer Art und Weise, wie wir sie öfter bei muslimischen als bei christlichen Jugendlichen in Deutschland vorzufinden ist. Aus diesem Grund kann man eben nicht nur von der einen Aneignung oder Charakteristika von Religion bzw. Religiosität sprechen, sondern muss die vorherrschende Vielfalt anerkennen, die durch alle fünf betrachteten Studien zum Ausdruck kommt.

\footnotetext{
${ }^{81} \mathrm{Vgl}$. Schöll, Religion Jugend.

${ }^{82}$ Passend dazu die These von Karl Rahner: „die Not lehrt beten“, die er nach dem zweiten Weltkrieg formulierte, in: Schockenhoff, Theologie des geistlichen Lebens in Geschichte und Gegenwart.
} 


\subsection{Identität, Identitätsbildung und religiöse Bildung}

Von religiöser Identität kann laut Stefan Altmeyer also dann gesprochen werden, wenn der theoretische Begriff Identität auf menschliche Identifizierungspraktiken verweist, in die Bezüge zu individueller Religiosität und soziokulturell kodierter Religion eingefügt sind. Bildungsprozesse sind auf diese menschlichen Grundvollzüge in einem wechselseitig kritischen Verhältnis bezogen. Bildung muss zeigen, in wie weit es zur Identitätsentwicklung speziell im Jugendalter, aber auch zur Identitätshinterfragung im Sinne von bereits etablierten Mustern des Identifizierens gegenüber anderen Menschen mit anderer Überzeugung, beitragen kann.

Im Rahmen von religiöser Bildung bedeutet dies, dass religiöse Traditionen so in Lernprozesse eingespielt werden sollen, dass sie auf Relevanz der eigenen Lebensmuster hin geprüft werden und andererseits zur Weiterentwicklung der individuellen religiösen Identitätsmuster angesichts einer multireligiösen und multikulturellen Gesellschaft des 21. Jahrhunderts anregen sollen. Durch den Kontakt mit überlieferter Religion und religiöser Pluralität kann dies beispielsweise im Religionsunterricht geschehen. ${ }^{83}$

Vor dem Verständnis von Identität als Prozess und dem empirisch belegten Wissen der oben genannten Studien, nämlich dass wesentliche religiöse Identifizierungspraktiken bereits im Vorfeld des Religionsunterrichts stattfinden, soll die sinnvolle Auseinandersetzung mit religiöser Verschiedenheit zur Weiterentwicklung der eigenen religiösen Identität der Jugendlichen im Religionsunterricht von Nutzen sein. Gleichzeitig dürfe das Vertrautwerden mit der Heimatreligion im Religionsunterricht nicht vernachlässigt werden. Laut Stefan Altmeyer wäre eine doppelte Hermeneutik aus Korrelation und Konfrontation der eigenen, sowie der anderen Religionen für eine identitätssensible und kritische (religiöse) Bildung besonders hilfreich. Insgesamt plädiert er für die Anerkennung und Förderung des autonomischen, transformatorischen Identifizierungsprozesses eines Anderen auf der Suche nach einer gemeinsamen Welt, in der die Achtung vor der Unterschiedlichkeit des Gegenübers hoch angesehen wird. ${ }^{84}$

\footnotetext{
${ }^{83}$ Weitere Überlegungen zu diesem Thema werden im letzten Kapitel näher erläutert.

${ }^{84} \mathrm{Vgl}$. Altmeyer, religiöse Identität.
} 


\section{Konsequenzen}

\subsection{Aktueller Zustand des christlich-islamischen Dialogs}

Ist es möglich mit dem Islam auf einer Ebene ins Gespräch zu kommen, wenn er jedoch als vernunftfeindlich abgestempelt wird? Kann der Dialog zwischen den beiden großen Weltreligionen auf Augenhöhe stattfinden? Die gemeinsame Basis aller drei Weltreligionen ist das Gebot der Gottes- und Nächstenliebe und wird somit zum Fundament der interreligiösen Dialoge. In wie weit kann die klassische muslimische Lehre die biblischen Texte nicht als Verfälschungen sondern als göttliche Offenbarung tolerieren? ${ }^{85}$ Auf dem zweiten vatikanischen Konzil wurden die anderen Religionen als Inhaber göttlicher Spuren anerkannt und im selben Zuge das Bewusstsein der eigenen Identität betont. Die Würde des vernunftbegabten Menschen und sein freier Wille stehen hier im Mittelpunkt. Aufgrund dieser Eigenschaften wird er zur Verantwortung gezogen in der gemeinsamen Suche nach der Wahrheit. Wie wird das Gottesbild angesichts des gemeinsamen Doppelgebots reflektiert? Welche Konsequenzen haben für uns Christen das trinitarische Gottesverständnis und das Bekenntnis zur Inkarnation? Wie stehen Glaube und Vernunft zusammen? Wie stehen Koran, Tenach und die christliche Bibel zueinander? Ist angesichts der Differenzen von muslimischem und christlichem Glauben religiöse Bildung und ein gemeinsamer Dialog im Religionsunterricht möglich? Diesen Fragen werde ich in den folgenden Kapiteln auf den Grund gehen.

\subsection{Umsetzung der Wünsche der Schülerinnen und Schüler gegenüber religiösen Bildungskonzepten}

In Bezug auf Religion, religiöse Pluralität und Religionsunterricht lassen sich folgende vier Punkte $^{86}$ von den oben genannten empirischen Jugendstudien ableiten:

(1) Religion wird von Schülerinnen und Schülern im Plural wahrgenommen. Bildungspläne und Bildungskonzepte müssen diesem Plural der Religionen gerecht werden und diese verstärkt thematisieren.

\footnotetext{
${ }^{85}$ Vgl. Rahner, „Ein gemeinsames Wort zwischen uns und euch...?“, 157-158.

${ }^{86}$ Vgl. Schambeck, Multi-Kulti?, 189.
} 
(2) Die Pluralität von Religionen wird in einem ambivalenten Spannungsverhältnis erlebt. Die einen sehen darin eine Tür um Neues und Anderes zu erfahren, andere sehen in der Pluralität der Religionen den Auslöser für Unruhe und Verwirrung.

Religiöse Bildung muss die Schülerinnen und Schüler befähigen sich angesichts des Plural der Religionen konstruktiv verhalten zu können.

(3) Menschen identifizieren sich selbst auch über Religion. Die Kenntnis über andere Religionen hilft somit die Menschen dieser Religionen besser zu verstehen. Die Jugendlichen sahen durchaus eine Spannung zwischen der eigenen und der fremden Religion, manche darin sogar ein Konfliktpotential. Im Religionsunterricht müssen die Spannungen zwischen Eigenem und Fremdem aufgegriffen und produktiv sinnvoll umgesetzt und gestaltet werden.

(4) Der Hintergrund der empirischen Jugendstudien ist es vor allem die Jugendlichen in ihrer Individualität und als Subjekte religiösen Lernens wahrzunehmen. Auch in Bezug auf das Thema Pluralität der Religionen muss im Religionsunterricht bei den Subjekten religiöser Bildung angesetzt werden und von ihnen ausgehend neue Bildungskonzepte entwickelt werden.

Nach dem Blick auf die empirischen Vergewisserungen über die Konsequenzen des Plurals der Kulturen und Religionen in Deutschland für die Jugendlichen, sollen die theologischen Herausforderungen, die sich daraus ergeben müssen, näher betrachtet werden.

Die Multi-Kulti-Situation ist schon längst in den Klassenzimmern angekommen, wie man meiner eigenen Studie zum Thema religiöser Vielfalt entnehmen kann. Jetzt liegt es an den Schulen sich dieser Aufgabe zu stellen und den Religionsunterricht als äußerst geeigneten Ort dafür zur Verfügung zu stellen.

\subsection{Religiöse Bildung im Kontext von Integration}

Schambeck vertritt die These, dass es von der Selbst- und Fremdwahrnehmung in der Gesellschaft abhängt, ob Jugendliche offen gegenüber dem Religionsverständnis anderer sind oder sich abkapseln oder/ und fragil verhalten. Integration wird hier zu einem der entscheidenden Faktoren für die Ermöglichung von Selbst- und Fremdwahrnehmung. ${ }^{87}$

Idealerweise soll gelungene Integration die gleichberechtigte Teilhabe aller an den essentiellen Lebensradien der Aufnahmegesellschaft darstellen. Hierbei kommt

\footnotetext{
${ }^{87}$ Vgl. Schambeck, Warum ein religiöses Wir-Gefühl nicht nur beruhigt, 52.
} 
das sogenannte Wir-Gefühl ins Spiel. Es entscheidet über Grad der Integration und ist gleichzeitig auch sein Schlüssel. Dieses Gefühl der Identifikation eines Kollektivs wird unter anderem durch Religion erzeugt.

Das Augenmerk liegt in dieser Arbeit besonders auf muslimischen Jugendlichen in Deutschland, denn sie verkörpern die Mehrheit der Jugend mit Migrationshintergrund.

Ziel des folgenden Beitrages ist es Religion als entscheidenden Faktor im Integrationsprozess darzustellen und gleichzeitig die Ambivalenz des durch Religion erzeugten Wir-Gefühls aufzuzeigen. Außerdem hat der Religionsbedarf der Flüchtlinge in Deutschland in den letzten Jahren durch die bis jetzt andauernden Migrationswellen stetig zugenommen. Es ist entscheidend, dass er für das gesellschaftliche Miteinander ernst genommen wird.

Innerhalb dieses Kontextes werden das Konzept und die Organisation von religiöser Bildung neu durchdacht und reflektiert.

Anhand der genauen Betrachtung der Ergebnisse der Shell und Sinus-Studie und der drei weiteren Studien kann man die Bedeutung und Prägekraft einschätzen, die Religion für christliche und muslimische Jugendliche in dieser Arbeit hat. Für die Konzeptionalisierung religiöser Bildung werden erneut Ergebnisse der Studien ausgewählt. $^{88}$

An dieser Stelle stellt Schambeck erste Überlegungen an, was bei Bildungsprozessen und Integrationsbemühungen auch aufgrund der Ergebnisse aus Kapitel 3 und 4 mit beachtet werden sollte:

Die erste Überlegung bezieht sich auf den intra-religiösen Bildungsaspekt: der Islam muss durch religiöse Bildung auch als Diskurssystem greifbar gemacht werden, damit der einzelne Schüler den Inhalt studieren und das Potential der Religion für sich im hier und jetzt ergründen könne. Denn es bestehe die Gefahr, dass die religiösen Rituale und Moralvorstellungen des Islams von den Glaubensanhängern nicht kritisch reflektiert und adaptiert werden und diese somit leichter manipulierbar werden. Aus diesem Grund müsste eine Instanz bzw. eine Alternative dazu geschaffen werden, die den Inhalt theologisch festlegt, damit die Religion nicht für eigene Zwecke missbraucht werden könne. Ein alleiniges sozial bedingtes Wir-Gefühl würde den Anspruch des Islam sehr eingrenzen und inm nicht gerecht werden. Dringend notwendig wird es daher sein, dass sich

\footnotetext{
${ }^{88}$ Vgl. ebd., 53
} 
Universitäten wissenschaftlich mit dem Islam auseinandersetzen, so wie es auch die drei Autoren der österreichischen Studie zur Religiosität im Alltag von islamisch Gläubigen fordern. Außerdem müssten die Imame akademisch ausgebildet werden und der islamische Religionsunterricht im gesamten Bundesland eingeführt werden. ${ }^{89}$

Die zweite Überlegung betrifft den gesellschaftspolitischen Bildungsaspekt: Der Islam müsse weg von einer Privatisierungstendenz und hin zu einer öffentlichen Größe wieder gestärkt werden, damit eine vernunftbasierte Debatte über die Rolle des Islam an öffentlichen Orten für jeden zugänglich sei. Religiöse Bildung ist dafür verantwortlich, dass der Islam nicht missbraucht wird um andere Gruppen zu diskriminieren oder zu eliminieren (vgl. Fundamentalismus).

Drittens muss religiöse Bildung Möglichkeiten und Begegnungen mit Andersgläubigen schaffen um Vorurteile gegenüber anderen Religionen abzubauen und einen Raum bieten, in welchem eine denkerisch-aufklärerische Auseinandersetzung mit den Inhalten der jeweiligen Religion erfahrbar wird. Gleichzeitig kann ein religiöser Bildungsprozess darauf hinleiten, dass die Menschen ihre Gemeinsamkeiten als Menschen und den einen gemeinsamen Lebensraum für alle anerkennen. Dies wiederum schafft keine Abspaltung der verschiedenen Gruppen, sondern ein Sich-besinnen auf die größere Einheit aller Menschen und fördert den interreligiösen sowie interkulturellen Dialog. Die Voraussetzung wiederum dafür ist, dass religiöse Bildung zu interreligiöser Kompetenz befähigen können muss und daher fast schon automatisch zu interreligiöser Bildung umbenannt werden könne. ${ }^{90}$

\subsubsection{Interreligiöse Kompetenz}

Interreligiöse Kompetenz ist im 21. Jahrhundert zur unabdingbaren Schlüsselqualifikation für gesellschaftliche, politische und ökonomische Zusammenhänge geworden. In einer globalisierten und religionspluralen postmodernen Gesellschaft reicht es nicht mehr aus, sich gegenüber nur einer Religion verhalten zu können. An den Studien kann man ablesen, dass der Religionsplural zu einem alltäglichen Phänomen geworden ist und Menschen vor

\footnotetext{
${ }^{89}$ Vgl. ebd., 54.

${ }^{90}$ Vgl. ebd., 55.
} 
der Herausforderung stehen, ihre Position zu Religion angesichts des Plurals der Religionen herauszufinden.

Besser gesagt, es führt kein Weg an der Ausbildung interreligiöser Kompetenz vorbei bezüglich der Migration, Multikulturalität, Multireligiosität Deutschlands und der Theologie der Religionen insgesamt auf gesellschaftlicher Ebene.

Wie kann interreligiöse Bildung folglich am sinnvollsten gestaltet werden, so dass dadurch interreligiöse Kompetenz erworben werden kann?

Dies versuche im Folgenden zu erörtern.

Hierbei soll die Beschreibung von interreligiöser Kompetenz helfen, religiöse Lernund Bildungsprozesse in diagnostischer, orientierender und didaktischer Hinsicht einzuschätzen und zu begleiten.

Ein religiös kompetenter Jugendlicher muss sich zu diesem Plural begründet und verantwortungsvoll verhalten können. Folglich ist religiöse Kompetenz auf Grund des Religionsplurals nicht anders denkbar denn auch als Vermittlung von interreligiöser Kompetenz im Religionsunterricht als idealen Lernort. $^{91}$ Die begründete Beschreibung interreligiöser Kompetenz nach Mirjam Schambeck (2013) greift die Herausforderungen des Differenzdenkens zwischen eigener und fremder Religion produktiv auf, nimmt den Wahrheitsanspruch der Religionen und damit deren substanziellen Gehalt ernst und ist nicht losgelöst von den Lebensdeutungen der Menschen zu denken. ${ }^{92}$

\subsubsection{Wertebildung nach christlicher und muslimischer Perspektive - Der Beitrag von religiöser Wertebildung zur Integration}

Wertefragen sind laut Mirjam Schambeck auch Religionsfragen und ein zentrales Thema in der Religionspädagogik, besonders im Kontext von zunehmender Religionspluralität und gleichzeitiger wachsender Religionslosigkeit. Angesichts der vielen Geflüchteten, die seit dem Sommer 2015 nach Deutschland ununterbrochen kommen und der damit verstärkten Notwendigkeit von Integration muss eine gemeinsame Wertebildung gedacht werden, die in Unterschiedlichkeit gelebt werden kann. Traditionelle muslimische Werteeinstellungen treffen auf westliche, europäische Wertevorstellungen und bergen mögliches

\footnotetext{
${ }^{91}$ Vgl. Schambeck, Interreligiöse Kompetenz, 159.

92 Vgl. Schambeck, Interreligiöse Kompetenz, 159-184 um eine ausführliche Beschreibung von interreligiöser Bildung und Kompetenz zu erlangen.
} 
Konfliktpotential. Wertebildung und Wertefragen sind also ein wichtiger Faktor im Rahmen von sozialer und kultureller Integration und müssen deshalb in dieser Arbeit auch zu Wort kommen. Durch Migration und Integration gestaltet sich unsere Gesellschaft und Kultur neu, der Wertekanon muss neu durchdacht und transformiert werden. Nach heutigen Erkenntnissen stellt Wertebildung keine bloße Vermittlung von Werten dar, vielmehr muss sie subjektorientiert vorgehen.

Diesen Fragen muss nachgegangen werden um Integration in Deutschland in Bezug auf den Religionsplural sinnvoll durchzuführen.

Josef Freise vertritt die Meinung, dass sich die muslimische Community und andere religiöse Migrantengemeinschaften in die demokratische Zivilgesellschaft in Deutschland nur dann integrieren oder dort beheimaten können, wenn die demokratischen Kräfte in der Mehrheitsgesellschaft den extremistischen Tendenzen wie Pegida oder AfD widerstehen und auf anderer Seite die pluralistisch denkenden Muslime den extremistischen Kräften in ihren eigenen Reihen klar Widerstand leisten. ${ }^{93}$

Aus religionspädagogischer Sicht wird klar, dass die Teilhabe aller Geflüchteten und Migrant/-innen an Bildung, Zugang zum Arbeits-und Wohnmarkt wichtige Indikatoren für gelungene Integration darstellen. Obwohl es viele Jugendliche mit Migrationshintergrund gibt, die diese wichtigen Integrationsindikatoren erfüllen, kann der Staat einige von ihnen nicht daran hindern zu radikalisieren. „Wie können diese Abgrenzungs- und Radikalisierungstendenzen vermieden und Jugendliche zugleich gestärkt werden, Identität und Zugehörigkeit zu gewinnen, und zwar ohne ihre Herkunft(sreligion) ablegen zu müssen?"94 Religiöse Wertebildung müsse an dieser Stelle dazu beitragen, dass diese Radikalisierungstendenzen verhindert werden.

Laut den oben betrachteten Studien sind die meisten Jugendlichen mit Migrationsund Fluchterfahrungen aus muslimisch geprägten Kulturen und selbst muslimischen Glaubens. Religion als Wertequelle und Handlungsmovens spielen für sie eine weitaus wichtigere Rolle als für ihre christlichen Altersgenossen. Sie verschafft ihnen ein Identitätsgefühl und eine Verortung in der Gesellschaft. Mirjam Schambeck unterscheidet drei Gruppen von muslimischen Jugendlichen

\footnotetext{
${ }^{93} \mathrm{Vgl}$. Freise, Religion als portable Heimat, 73.

${ }^{94}$ Schambeck, Was religiöse Wertebildung zur Integration beitragen kann. Überlegungen aus der Religionspädagogik, 118.
} 
und untersucht, wie sie religionsbezogene Merkmale für ihre Identifikationskonstruktion heranziehen.

Die erste Gruppe besteht aus muslimischen Jugendlichen mit Migrationshintergrund, die in der zweiten Generation in Westeuropa leben. Sie kommt zu dem Ergebnis, dass Religion für sie eine Chance bietet Zugehörigkeit zu finden bzw. zu hinterfragen. Gegenseitige Anerkennung ist der Schlüssel für eine offene pluralitätsfähige Haltung zwischen dem eigenen Wir und den anderen Wirs innerhalb einer Gesellschaft. ${ }^{95}$

Die zweite Gruppe formiert sich aus Jugendlichen, die sich radikalislamischen Gruppierungen angeschlossen haben und deren Erzeugung eines Wir-Gefühls sich ausschließlich auf ihre Gruppe bezieht und sich nach außen hin von der Mehrheitsgesellschaft eher abkapselt. Die Zugehörigkeit nach innen hängt nicht von der ethnischen Herkunft ab, da auch Konvertit/-innen als gleichberechtigte Mitglieder gelten. Jugendlichen in diesen Gruppen erlangen nicht nur ein Zugehörigkeitsgefühl, sondern auch Aufmerksamkeit vonseiten der Medien, Politik und Gesellschaft. ${ }^{96}$

Die Jugendlichen, die in den letzten fünf Jahren in Deutschland angekommen sind, weil sie aus ihren Heimatländern fliehen mussten, bilden die letzte Gruppe. Dieser Bereich ist jedoch erst sehr anfänglich erforscht. Das Forschungsprojekt „Tell me your story“ kam bereits zu folgenden Auffälligkeiten bezüglich der Rolle von Religion für die Identitätskonstruktion der befragten Jugendlichen:

Erstens werden die Privatisierung von Religion und damit das Verschwinden eines Konfliktfaktors begrüßt. Im Heimatland war Religion teilweise der Grund warum sie nach Deutschland flüchten mussten oder heftigen Diskriminierungen ausgeliefert waren. Umso leichter gestaltet sich ihr Leben in diesem Aspekt in Deutschland. Zweitens dient Religion als Wir-Gefühl und als Brücke in die Heimat (Das ExilsWir). Die Gebetspraxis kann beispielsweise eine Verbindung in die Heimat zu den Verwandten sein, gleichzeitig aber auch ein Wir-Gefühl im Ankunftsland Deutschland darstellen.

Drittens ist Religion ein Ort des Wir-Gefühls inmitten anderer gleichberechtigter Wirs. Die Moscheegemeinde und die Schule können Orte für neue Freundschaften zwischen den Jugendlichen werden.

\footnotetext{
${ }^{95}$ Vgl. ebd., $121 \mathrm{f}$.

${ }^{96}$ Vgl. ebd., 124.
} 
Eine weitere Auffälligkeit ist, dass Religion als Wir-Gefühl im Gegenüber zur Aufnahmegesellschaft eine wichtige Rolle spielt. Die Religion des Heimatlandes kann hier zum Maßstab werden, um die Gepflogenheiten im Ankunftsland zu taxieren. ${ }^{97}$

Gemäß der empirischen Vergewisserungen geht es anschließend darum, Wertebildung daran zu bemessen, inwieweit sie die Jugend befähigt, Zugehörigkeit und Anerkennung zu finden und gleichzeitig bei ihnen eine Offenheit für die Mehrheitsgesellschaft zu fördern. Zudem solle sie bei innen eine reflexive und eigenverantwortete Durchdringung der Spannung zwischen dem eigenen Wir und den anderen Wirs hervorrufen. ${ }^{98}$

Das Ziel von Wertebildung im Kontext von Integration müsse sein, dass die Lernenden sich einen eigenen reflexiven Standpunkt erarbeiten können. Dieser müsse sich nach ihren eigenen Wertevorstellungen, sowie nach denen der Gesellschaft richten. Zuerst müsse danach geschaut werden, was die Jugendlichen bewegt und daran der Schwerpunkt der Wertebildungsprozesse orientiert werden. Folglich würde die Wertebildungsarbeit mit der ersten Gruppe der Jugendlichen anders ausfallen als mit der zweiten und dritten Gruppe. „Je weniger anerkannt sich Jugendliche fühlen, je stärker sich diese fehlende Anerkennung in Abkapselung oder sogar rigider Abgrenzung ausdrückt, desto intensiver ist Sorge für die konstruktive Ich-Stärkung der Jugendlichen zu

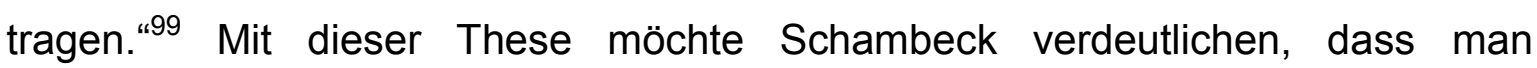
radikalisierte Jugendliche nur zurückgewinnen kann, wenn zuvor Beziehungen aufgebaut und innen dadurch gezeigt wird, „dass sie anerkannt sind und die Flucht in radikale Ideologien nicht nötig haben, um sich ihrer selbst zu vergewissern. “100 Außerdem darf die essentielle Rolle der Religionen bei der Anerkennung und Zugehörigkeit des Einzelnen zur Gruppe nicht außer Acht gelassen werden. Die Religionen müssen selbst aktiv werden und nicht nur den gesellschaftlichen und staatlichen Institutionen den Aufklärungsprozess überlassen. Nicht nur die muslimischen Religionsgemeinschaften, sondern auch die christlichen Kirchen müssen sich für Jugendliche mit Migrations- und Fluchterfahrungen einsetzen, damit diese wiederum die Religionen als Transporteure von Zugehörigkeit,

\footnotetext{
${ }^{97}$ Vgl. ebd., 120-127.

${ }^{98}$ Vgl. ebd., $129 f$.

99 Ebd., 135.

${ }^{100}$ Ebd., 136.
} 
Anerkennung und Ich-Stärke erleben. Abschließend plädiert Schambeck für folgende Punkte: „Die Einführung des islamischen Religionsunterrichts ist dafür ein wichtiger Weg, die Etablierung einer wissenschaftlichen islamischen Theologie an staatlichen Universitäten und die Akademisierung der Imane auch. Es ist von daher höchste Zeit, dass die islamischen Verbände ihr Verhältnis zum Grundgesetz und ihre Repräsentanzfunktion von muslimischen Gläubigen klären lassen, um als verlässlicher Kooperationspartner in den „res-mixtaeAngelegenheiten" zu fungieren. “101 Demnach müsse der Islam sich von Einflüssen trennen, die mit dem Grundgesetz unvereinbar sind. Die Umsetzung dieses Vorschlages würde für muslimische und christliche Kooperationen in unserer Gesellschaft nur von Vorteil sein.

\subsubsection{Didaktische Überlegungen und ein Beispiel für die praktische Umsetzung im Religionsunterricht}

Anhand des folgenden Beispiels „Kennen sich Gott und Allah“? - Annäherungen an das islamische Gottesverständnis über die Gebetspraxis ${ }^{102}$ kann interreligiöse Kompetenz im Schulunterricht erworben werden.

Der Islam klärt die Frage nach der Orthodoxie vornehmlich über die Frage nach dem rechten Handeln (Orthopraxie). Das unaussprechliche Geheimnis des Namens des allerhöchsten Gottes ist nach muslimischem Verständnis eher in der Gebetspraxis als in der spekulativen Durchdringung zu erahnen. Aus diesem Grund lohnt es sich das Gottesbild in der muslimischen Gebetspraxis näher zu betrachten und Parallelen bzw. Differenzen zwischen Christ/innen und Muslim/innen in ihrer Anbetung des Allerhöchsten zu entdecken und einen Raum für gegenseitige Bereicherung zu schaffen.

Der Einstieg über den fremden Text "Lobpreis Gottes“ von Franz von Assisi von 1224 zeigt, wie Franziskus Gott versteht und am Ende seines Lebens besingt. Vielen Jugendlichen fehlt die Sprache um ihr Gottesbild näher zu beschreiben. Deshalb bietet sich der Einstig über den litaneiförmigen Gebetstext von Franziskus dafür an weitergeschrieben, mit eigenen Fragen und Gedanken ergänzt zu werden. Der Text aus einer weit entfernten Zeit spiegelt die Erfahrung eines Dritten und bietet den Schülerinnen und Schülern „die Möglichkeit, diese Distanz

\footnotetext{
101 Ebd., 137.

102 Vgl.ebd., $212 f f$.
} 
zu nutzen, um für sich selbst zu klären, ob sie den Duktus des Textes aufgreifen und eine eigene Du-Formulierung anfügen wollen, oder ob sie den Text als Folie verstehen, von der sie sich absetzen, die sie bezweifeln oder auch dezidiert ablehnen“103. Der Textauszug aus dem Lobpreis Gottes wird auf vorbereiteten Blättern an die Lerngruppen ausgeteilt und lädt durch gezogene Linien zwischen den Zitaten zum Weiterschreiben ein. Nachdem die Jugendlichen ihre bearbeiteten Texte freiwillig vorgetragen haben, wird der Autor des Gebetstextes als Christ vorgestellt, welcher sich schon damals mit dem Islam und deren Gebetspraktiken beschäftigte.

In einem zweiten Schritt werden die Schülerinnen und Schüler aufgefordert Sure 57, 1-6.9 zu lesen und zu analysieren. Auf der einen Seite beschäftigt sich eine Gruppe damit Überschriften zu finden und das Gottesverständnis zusammenfassen. Die andere Gruppe sucht nach Unterschieden zwischen den Anrufungen des Lobpreises Gottes bei Franziskus und den Psalmen in Sure 57 und arbeitet diese heraus. Eine dritte Gruppe konzentriert sich auf die Gemeinsamkeiten zwischen den beiden Texten in Bezug auf das Gottesverständnis und artikuliert diese. Die Arbeitsschritte münden in einem Unterrichtsgespräch über das Gottesverständnis des Islam, die Wichtigkeit der Gebetspraxis als Zugang zum Gottesbild und die Barmherzigkeit als besonderes Gottesprädikat.

Laut meiner eigenen empirischen Studie zur Einstellung der christlichen Jugendlichen gegenüber dem Islam ist die ungerechtfertigte Identifizierung des Islam mit Terror und Fundamentalismus erkennbar. Deshalb ist es an dieser Stelle wichtig die Weite und Tiefe des islamischen Gottesverständnisses zu betrachten. Die Barmherzigkeit Gottes wird hier als paralleler Punkt beider Texte aufgegriffen und bearbeitet.

Eine lediglich analytische und literaturwissenschaftliche Auseinandersetzung mit den Koranversen reicht jedoch nicht aus, um die Besonderheit des Psalms in Sure 57 zum Ausdruck zu bringen, welcher für gläubige Muslim/innen das Wort Gottes an die Menschen wiederspiegelt. Aus diesem Grund wird ein muslimischer Experte in den Unterricht eingeladen, der authentisch darüber erzählt, was ihm die Sure bedeutet, wie sie seine Gebetspraxis beeinflusst, was für inn der wichtigste Teil der Sure darstellt (vgl. existentielle Erfahrungsweise von Religion). 
Entscheidend ist im Anschluss, was die Schülerinnen und Schüler aus den kennengelernten Verehrungsweisen Gottes für ihre eigenen Lebensdeutungen, Haltungen und Handlungen fruchtbar werden lassen.

Die Jugendlichen lernen innerhalb dieser Unterrichtssequenz, wie andere Menschen Gott verstehen und in ihr Leben einbeziehen sowie die Bedeutsamkeit dieses Wissens für andere anzuerkennen. Genauso liegt es in der Freiheit jedes einzelnen Schülers die Gebetspraxis der Muslim/innen und des Franz von Assisi für ihr eigenes Leben anzunehmen oder abzulehnen. Dies darf nicht im Radius des überprüfbaren Lernens liegen. ${ }^{104}$

\subsubsection{Pluralitätsfähige religiöse Erziehung im Islamischen \\ Religionsunterricht. Grundlagen und Perspektiven.}

Wie kann und muss der Religionsunterricht sich verändern lassen angesichts der in dieser Arbeit beschriebenen gesellschaftlichen, politischen und religiösen Herausforderungen des 21. Jahrhunderts: dem demographischen Wandel, Religionsplurals und der auf der anderen Seite zunehmenden Religionslosigkeit der Kinder und Jugendlichen. Gleichzeitig ist Religion als Thema wieder mehr in den öffentlichen Blick gerückt und auf gesamtgesellschaftlicher Ebene wird diskutiert, wie das Zusammenleben von Menschen mit unterschiedlichen kulturellen, religiösen und weltanschaulichen Hintergründen in friedlicher Weise gelingen kann.

Diese Frage stellt sich unter anderem Ednan Aslan und gibt dazu Impulse aus der islamischen Religionspädagogik.

Er plädiert für eine pluralitätsfähige religiöse Erziehung im islamischen Religionsunterricht, damit muslimische Kinder „die Pluralität aus ihrem kulturellen, religiösen Standpunkt heraus deuten und mit den Verhältnissen einer pluralen Gesellschaft umgehen können. “105 Heutzutage konfrontiert sich der Islam seiner Meinung nach nicht mehr mit dem Grund, warum die Religionen einander tolerieren sollten, sondern mit der Frage, wie die Pluralitätsfähigkeit der Religionen ausgestaltet werden kann, damit ein „friedliches Zusammenleben ohne

\footnotetext{
${ }^{104}$ Vgl. ebd., 216.

${ }^{105}$ Aslan, Pluralitätsfähige religiöse Erziehung im Islamischen Religionsunterricht, 411.
} 
Absolutheitsanspruch einer bestimmten Religion oder Weltanschauung und ohne Identitätsverlust gewährleistet ist. “106

$\mathrm{Ihm}$ ist es wichtig theoretische Grundlagen zu schaffen, damit muslimische Kinder und Jugendliche zwischen religiöser Tradition und individueller Perspektive eine eigene religiös-islamische Identität in der Praxis begründen lernen. ${ }^{107}$

Hierbei gilt es bei der Entwicklung der pluralistisch-islamischen Erziehung drei Felder zu berücksichtigen, die miteinander in Verbindung stehen: das Thema, die Lernsubjekte und das Lernmilieu. ${ }^{108}$ Nur unter diesen Voraussetzungen werden die Grundlagen für eine islamische Religionspädagogik geschaffen.

Die Religion bildet den Kern der islamischen Erziehung, da sie die Normen für den Umgang mit der Gesellschaft festlegt. Schülerinnen und Schüler müssen dementsprechend lernen ihre Umgangsformen aus ihren Wertevorstellungen heraus zu begründen. ${ }^{109}$

Die Begründung der Pluralität aus dem Koran heraus ist nicht nur möglich, sondern auch notwendig, da Aslan die These vertritt, dass der gläubige Mensch einerseits ein Mitglied der islamischen Gemeinschaft ist, sein bewusstes Bekenntnis inn jedoch als Individuum über die Stammeszugehörigkeit hinaus erhebt und in die Lage versetzt selbstbestimmt eine Entscheidung zu treffen. ${ }^{110}$ Somit erkennt er Pluralität als ein Gesellschaftskonzept des Islam an und religiöse Vielfalt sei der Wille Gottes. ${ }^{111}$ Dies müsse unterrichtet werden, da pluralistisches Denkvermögen ein Zeichen für geistige Reife und Selbstreflexion ist und somit auch dem gesellschaftlichen Fortschritt dienlich, weil dem Menschen Eigenverantwortung zugeschrieben wird. ${ }^{112}$

Im nächsten Schritt stellt er sich die Frage, wie man diesen Ansatz den muslimischen Schülerinnen und Schüler beibringt und kommt zu den Überlegungen, dass der Lehrkörper auf den Unterschied von horizontal und vertikal konkurrierenden theologischen Positionen hinweisen und dadurch einen Raum für unterschiedliche Wahrheitsansprüche schafft. Außerdem sollte auf eine

\footnotetext{
${ }^{106}$ Ebd., 412.

107 Vgl. ebd., 413.

${ }^{108}$ Vgl. ebd., 413.

${ }^{109}$ Vgl. ebd., 414.

${ }^{110}$ Vgl. ebd., 418.

111 Vgl. ebd., 419 für den ausführlichen Argumentationsgang seiner Thesen anhand bestimmter Koranauslegungen.

${ }^{112}$ Vgl. ebd., 420.
} 
Pluralität der Form und Sprache, in der sich die Wahrheit offenbart hat, geachtet werden, damit Vielfalt zur Selbstverständlichkeit werden kann. ${ }^{113}$

Natürlich kann dies im Religionsunterricht zu Verunsicherungen auf Seiten der Schülerinnen und Schüler führen. Gleichzeitig werden sie jedoch herausgefordert sich eine eigene Meinung anhand der innerislamischen Pluralität zu bilden. Aufgrund dessen dient pluralistische Erziehung der Persönlichkeitsentwicklung, der Schulung des Gewissens und der Begegnung mit Herausforderungen. ${ }^{114}$ Der islamische Religionsunterricht wäre laut Aslan der geeignete Ort, um bei den muslimischen Kindern und Jugendlichen die ernsthafte Auseinandersetzung mit der eigenen Tradition, dem eigenen Umfeld und mit sich selbst zu fördern. Gleichermaßen ist sich Aslan bewusst, dass sich der Religionsunterricht der Spannung zwischen der Individualität und Gemeindezugehörigkeit der jeweiligen Lernenden stellen muss und hier sich auf den Weg machen muss eine Balance zwischen beidem in einer pluralistischen Atmosphäre zu schaffen. ${ }^{115}$

\subsubsection{Konstruktiver Vorschlag an die Bildungspolitik}

Nach der Auswertung der fünf Studien und meiner eigenen Studie zum Thema Religiosität Jugendlicher komme ich zu folgendem Fazit und Stimme Schambeck darin zu, dass die Bindekraft des Islams für muslimische Jugendliche bzw. Jugendliche mit Migrationshintergrund an ihre Religion viel stärker ausgeprägt ist als es bei in Deutschland geborenen christlichen Jugendlichen der Fall ist.

Religion dient in einem ambivalenten Sinn als Ort und Praxis des sogenannten "Wir-Gefühls" ${ }^{\text {"116 }}$. Auf der einen Seite erlaubt es Religion den MigrantInnen und Flüchtlingen sich ihres Ortes in Deutschland bewusst zu werden und sich auf die Andersgläubigen selbstsicher und reflektiert einzulassen. Auf der anderen Seite besteht jedoch die Gefahr der Isolierung und Abgrenzung durch das erzeugte religionsspezifische Wir-Gefühl. An diesem Punkt müssen laut Mirjam Schambeck religiöse Bildungsprozesse und Integrationsmaßnahmen ansetzen, um das Verhältnis von Religion und dem starken Wir-Gefühl reflektiert zu durchdenken und gegebenenfalls neu zu definieren.

\footnotetext{
${ }^{113}$ Vgl. ebd., 420.

${ }^{114} \mathrm{Vgl}$. ebd., 422.

${ }^{115}$ Vgl. ebd., 424.

${ }^{116}$ Vgl. Schambeck, Warum ein religiöses Wir-Gefühl nicht nur beruhigt, 56 .
} 
Die folgenden sieben Punkte sind nach dem Schema von Mirjam Schambeck herausgearbeitet worden und ein Sieben-Punkte-Vorschlag an die Bildungspolitik um Maßnahmen für neue religiöse Bildungsprozesse anzuregen. Sie verdeutlichen, wie Religion als Faktor von Integration ins Spiel kommen kann und werden an dieser Stelle besonders passend hervorgehoben und betont.

Punkt 1: Zunächst muss Religion als wichtiger Faktor von Integrationsprozessen anerkannt und ernst genommen werden. Es reicht nicht aus den Flüchtlingen Sprachunterricht zu erteilen und sie in die kulturellen Gewohnheiten Deutschlands einzuweisen. Vielmehr müsse Religion als entscheidende Rolle thematisiert und in konkrete Bildungsprojekte integriert werden. Das Ziel ist es hierbei über Religion ein „offenes Wir-Gefühl zu ermöglichen, das die eigene Religionszugehörigkeit für andere (religiöse) Wirs öffnet" ${ }^{\text {"117 }}$ und sich nicht mit Vorurteilen gegenüber den Anderen verschließt.

Zum einen müsse man diskursiv-informativ seine eigene Religion und die der Mehrheitsgesellschaft behandeln. Das bedeutet zum Beispiel, dass die religiösen Praktiken, Weltanschauungen, Inhalte kritisch-kontrovers diskutiert werden müssten. Damit könnten Vorurteile abgebaut werden, die oft die größten Hürden für interreligiöses Lernen darstellen.

Des Weiteren müsste Religion existentiell-vertiefend betrachtet werden. Dazu ist es hilfreich Orte zu schaffen, an denen Menschen über die Relevanzfrage ihrer eigenen Religion für sich selbst und in der Verortung einer religiösen Gemeinschaft nachsinnen und diese vertiefen können.

Außerdem sollte Religion als orientierend-interaktive Dimension ins Spiel gebracht werden. Der Religionsplural in Deutschland schreibt den religiösen Bildungsprozessen quasi vor, die eigene Religion als Deutepotenzial neben anderen Deuteangeboten zu betrachten. Interreligiöse Lernprozesse können konsequenterweise nur dann stattfinden, wenn die Auseinandersetzung mit anderen Religionen und deren Weltanschauungen stattfindet. Einer der sinnvollsten Wege dies zu erreichen, wäre den direkten Kontakt mit Menschen, die lebendige Zeugen der anderen Religion darstellen, zu suchen.

${ }^{117}$ Ebd., 57. 
Punkt 2: Um Religion als Faktor von Integration thematisieren zu können, werden unterschiedliche Lernorte und Akteure von Nöten sein, damit Religion angesichts des religionspluralen Kontextes Deutschlands gelebt und vertieft werden kann. Beispielsweise kann dies im Integrationsunterricht erfolgen. Indem religionskundliches Wissen, gepaart mit didaktischen Fähigkeiten, unterrichtet wird, wird ein gewinnbringender Dialog ermöglicht. In der Schule könnte ein sinnvoller Lernort der konfessionelle Religionsunterricht sein. Die Etablierung von islamischem Religionsunterricht würde den Islam nicht nur als Diskurssystem vorstellen, sondern als Lebensüberzeugung aus der „Ersten-PersonPerspektive" ${ }^{\text {"118 }}$ durch die Lehrperson authentisch darbringen. Nur so kann der Unterricht über Religion der Religion selbst gerecht werden und den Anspruch erfüllen, den die Religion in all ihren Dimensionen diesem vorschreibt. Laut Schambeck sind konfessionsbezogene mit dialogischen Organisationsformen im Religionsunterricht besonders ertragreich, da sie einerseits die angemessene Beheimatung des Glaubens garantieren und gleichzeitig zur Interaktion mit Menschen anderer Religionszugehörigkeiten motivieren.

Punkt 3: Mit Religion müsse man als Fremdheitsfaktor umzugehen lernen. Denn den einen Islam gibt es nicht. Vielmehr verschiedene Ausprägungen des Islams und des Christentums in Syrien, oder auch in Deutschland beispielsweise. Für Flüchtlinge kann deshalb die eigene Religion, aufgrund der unterschiedlichen kontextuellen Ausformulierungen von Religionen, im Aufnahmeland befremdlich wirken. Dies gilt es innerhalb religiöser Bildungsmaßnahmen zu beachten. Westeuropa ist zudem von der Privatisierung von Religion sowie einem säkularisierten Staatsbild geprägt. Neben der intra-religiösen Fremdheit sind die Geflüchteten auch einer kulturell-kontextuellen Fremdheit ausgesetzt. Den ankommenden MigrantInnen muss die Möglichkeit gegeben werden, „sich mit atheistischen und agnostischen Positionen auseinanderzusetzen als auch zumindest die wesentlichen Elemente des Christentums kennenzulernen. Das ist einerseits wichtig, um die Kultur Europas zu verstehen [...]. Das hat andererseits aber auch theologische und gesellschaftspolitische und das heißt vor allem religionszivilisierende Gründe“"119.

118 Ebd., 57.
119 Ebd., 58. 
Punkt 4: Zwischen Religion und dem Wir-Gefühl besteht, wie bereits erwähnt, ein ambivalentes Verhältnis. Dies gilt es innerhalb des religiösen Bildungsprozesses aufzudecken und zu bearbeiten. Einerseits kann Religion als sozialer Ort für junge Menschen dienen, an welchem sie sich ihrer Identität bewusst werden und ihr Verhalten moralisch prüfen. Um aber einen Missbrauch des Wir-Gefühls gegenüber den Andersgläubigen zu verhindern, muss dafür Sorge getragen werden, dass Religionen in all ihren Seiten befragt und dadurch kritisch-kontrovers sowie vernunftbezogen durchdacht und reflektiert werden.

Punkt 5: Außerhalb des Familienalltags müssen für Jugendliche Räume geschaffen werden um das eigene Wir zu stärken und es gleichzeitig für andere Wirs offen zu lassen. Religiöse Bildungsarbeit verhindert dadurch, dass dieses Wir-Gefühl sich nicht vom Rest der Gesellschaft abkapselt und isoliert. Gleichermaßen sorgen die vielfältigen Wirs für eine tolerantere gesellschaftliche Pluralität. Als Beispiele wären organisierte interreligiöse Lernorte mit anderen Religionsgruppen zu nennen, oder das Verständnis für atheistische Meinungen, sportliche Aktivitäten unabhängig von der Religionszugehörigkeit etc.

Punkt 6: Religiöse Bildungsangebote sollten nicht nur auf Jugendliche beschränkt werden, sondern sich auf wenn möglich alle Altersgruppen von MigrantInnen und Flüchtlingen ausdehnen. Je zufriedener und integrierter die Elterngeneration in dem Aufnahmeland lebt, desto weniger schwer fällt es ihren Kindern ihren eigenen Weg zu finden, ohne innerlich zwischen zwei Kulturen hin und her gerissen zu sein. Dies wird wiederum Konsequenzen für das gesellschaftliche Wohlbefinden haben.

Punkt 7: Religion braucht für eine gelungene Auseinandersetzung ein öffentliches Forum. Außerdem wird Religion nicht nur wegen dem demographischen Wandel bezüglich der Flüchtlingswellen, dem sich Deutschland aktuell aussetzen muss, ein wichtiges Thema, sondern ist für den gesamten öffentlichen Diskurs nicht wegzudenken. Postmoderne Gesellschaften dürfen die „sprachliche Kraft und inhaltliche Schärfe"120 nicht verlieren, um angemessen und vernünftig im öffentlichen Raum über Religion sprechen zu können und die enorme Kraft und

${ }^{120}$ Ebd., 59. 
den Einfluss der Religionen auf Menschen nicht nur im Privaten zu belassen. Alle repräsentativen Religionen bräuchten akademisierte Ausbildungen, „denn erst die interreligiöse Bezüglichkeit kann eine religionsplurale Gesellschaft mit ihren Erfordernissen der Verständigung verschiedener Positionen abbilden“121. Dies bedeutet nicht, dass die Trennung von Staat und Kirche aufgehoben werden soll. Vielmehr soll die Wirkkraft der Religionen zivilisiert werden. Öffentliche Stätten der Religionsausübung werden somit als Teil von einer pluralen und offenen Gesellschaft ermöglicht. Möglicherweise kann somit ein besserer öffentlicher Diskurs des Friedens stattfinden, den eigentlich alle Religionen zutiefst als Botschaft in sich tragen. Europa muss die Auseinandersetzung mit Religion öffentlich machen, damit interreligiöse Bildung geschieht, welche die Religion auf Deutepotenzial für die Lebensüberzeugung hin erschließt und entsprechende religiöse Bildungsorte ausbaut.

\section{Schlussbetrachtung}

„So dient Religion der Kontingenzbewältigung [...], der gesellschaftlichen Integration [...], als Grundlage des sozialen Handelns [...], der Welterklärung, der Orientierung und Identitätsgewinnung, der Affektbewältigung und auch der Gemeinschaftsbildung [...] und nicht zuletzt der Sinngenerierung. Das Problem funktionaler Bestimmungsversuche liegt vor allem darin, dass religiöser Inhalt und religiöse Funktion auseinanderzufallen drohen und nicht-religiöse Inhalte die Funktion religiöser Inhalte übernehmen können, wobei funktionale Bestimmungen teilweise implizit substantiale Bestimmungen voraussetzen [...].“122

Mit diesem Zitat fasst Könemann stichwortartig zusammen, was die eben betrachteten Studien als Ergebnisse über die Funktion der Religion und Religiosität Jugendlicher herausgefunden haben.

Religion und religiöse Bildung spielen angesichts des demographischen Wandels in Europa erneut eine wichtige öffentliche Rolle in der Integrationsdebatte, da Religion unter anderem für Integration und Orientierung sorgt.

\footnotetext{
${ }^{121}$ Ebd., 59.

122 Könemann, Religion.
} 
Spezifisch der Religionsunterricht sollte es sich laut Schambeck zum Ziel machen, die Schülerinnen und Schüler in, von, durch und über Religion zu unterrichten. ${ }^{123}$ Wie kann dies erreicht werden, damit die Jugend sich angesichts des Multikulti in Deutschland zu verhalten weiß?

Zuallererst müsse Religion immer als Deuteangebot ins Spiel gebracht werden und nie als Grund für einen Katechismusunterricht an der öffentlichen Schule. Erst dann lernen Schülerinnen und Schüler sich zu Religion angemessen zu verhalten und sich selbst sowie den Anderen eine begründete Auskunft über die eigene Meinung zu Religion zu geben.

Dies kann nur dann der Fall sein, wenn Korrelation und Positionalität des Lehrers im Unterricht stattfinden. Eine wechselseitige Durchdringung und kritischproduktive Wechselbeziehung zwischen religiösen Traditionen und den Lebenswelten der Lernenden ist anzustreben, damit kognitive und existentielle Korrelationsprozesse ermöglicht werden und die Relevanzfrage von christlichen, aber genau so auch muslimischen Jugendlichen im Religionsunterricht gestellt werden kann. Wenn über Religion nur in dritter Person-Perspektive erzählt wird, dann liegt immer nur ein verkürztes Verständnis von Religion vor.

Aus diesen Gründen unterstütze ich Schambecks These zu einem konfessionellen Religionsunterricht für jetzt und zukünftig.

Im heutigen Religionsunterricht wurden folgende Defizite erkannt: religiöse Themen werden immer mehr nur noch zu Randthemen im Unterricht. Zudem wird meist nur noch die kognitive Ebene von Religion behandelt und die Relevanzfrage so gut wie vermieden. Gleichzeitig tritt die konfessorische Rede und theologische Expertise der Lehrpersonen zurück.

An Berufsschulen ist der Religionsunterricht meist mit jungen Leuten aller Religionszugehörigkeiten gemischt. Hier ist es wichtig Lehrkräfte zu haben, die bekenntnisorientiert ihren Unterricht gestalten und für Muslime/ Juden/ Buddhisten u.a. einen religiösen Vertreter einladen, der von seiner Religion berichtet, damit die Vieldimensionalität von Religion zum Tragen kommt.

Wie muss allgemein der Religionsunterricht in Deutschland verändert werden, damit er für die jetzige und die kommenden Generationen aktuell bleibt und die aufgeführten Kriterien unterstütz?

\footnotetext{
${ }^{123}$ Vgl. Schambeck, unveröffentlichte Manuskripte. Vorlesung zu religiösem Lernen im RU. Konzeptionelle Entwicklungslinien und religionsdidaktische Prinzipen.
} 
Die programmatischen Leitbegriffe „konfessionell - kooperativ - kontextuell“ treffen die Debatte um die Zukunft des konfessionellen Religionsunterrichts ziemlich klar. Mit dem zusammenfassenden Beitrag von Henrik Simojoki und Konstantin Lindner und dem Positionspapier vieler Religionswissenschaftler und Religionspädagogen wird die gegenwärtige Diskussion um einen zukunftsfähigen Religionsunterricht deutlich vorangebracht. Dabei gilt, dass die drei Leitbegriffe des Religionsunterrichts in ihrem wechselseitigen Zusammenhang wahrgenommen und verstanden werden. Außerdem spielt religiöse Bildung in diesem Zusammenhang eine besonders wichtige Rolle, da den Schulen durch interkulturelles und interreligiöses Lernen eine besondere Verantwortung übertragen wird:

„Der Religionsunterricht hält die Frage nach Gott wach, bietet Identifikationsmöglichkeiten in der jeweils eigenen Tradition, ist dialogisch ausgerichtet und trägt durch die vernunftbasierte Auseinandersetzung mit Religionen dazu bei, Schülerinnen und Schüler zu einem reflektierten Verhalten zu Religion zu befähigen und fundamentalistischen Tendenzen entgegenzuwirken. “124

Der Religionsunterricht ist der Ort, an dem dargestellt wird, wie in aufgeklärter Weise Menschen heutzutage mit Religion und Glauben leben können. Er schafft einen Raum für die Schülerinnen und Schüler sich mit Anderen und Andersgläubigen über religiöse Fragen bezüglich religiöser, kultureller und sozialer Vielfalt auszutauschen. Hierbei werden Schülerinnen und Schüler auf ihrer Suche nach Sinn und Glück ernst genommen, unterstützt und begleitet. Der Ort des Religionsunterrichts bietet innen Orientierungshilfen und Befähigung zur eigenen Positionierung in einer zunehmend globalisierten, pluralen Welt.

Um diese Errungenschaften des Religionsunterrichts weiterhin zu gewährleisten,, wurden empirische Vergewisserungen zur Verfügung gestellt und im folgenden Positionspapier vom 19. Dezember 2016 gebündelt wiedergegeben.

Es beinhaltet drei Thesen ${ }^{125}$, die im Folgenden kurz erläutert werden:

(1) Der Religionsunterricht der Zukunft ist konfessionell Nur in einem bekenntnisbezogenen, konfessionellen Religionsunterricht können religiöse Fragen und Themen so bearbeitet werden, so dass sie

\footnotetext{
${ }^{124}$ Lindner u.a., Zukunftsfähiger Religionsunterricht, 445.

${ }^{125}$ Vgl. Schambeck u.a. (Hg.), Positionspapier, 446-447.
} 
den Religionen in ihrer Eigenart gerecht werden. Erst indem die Lehrpersonen ihre religiöse Position in das Unterrichtsgeschehen mit einbringen, beginnen die Lernenden sich mit dem Christsein angesichts postmoderner Lebensbedingungen genauer auseinanderzusetzen. Der christliche Glaube als mögliche Sinndeutung kann innen helfen ihre eigene religiöse Positionierung dazu zu hinterfragen und ihre Lebensfragen zu bearbeiten. In dieser Art des Unterrichts wird deutlich, dass das Christentum aus Konfessionen besteht, die einen Reichtum an Vielfalt bilden. Individuelle Bezüge auf das Christentum greifen diesen in konfessionellen Akzentsetzungen auf.

(2) Der Religionsunterricht der Zukunft ist kooperativ An vielen Schulen in Deutschland wird bereits die Notwendigkeit einer dialogischen Zusammenarbeit der Religionen und des religiösen Wandels in konfessioneller Zusammenarbeit im Religionsunterricht ernst genommen und weiter ausgebaut. In den verschiedenen kooperativen Lernformaten ist es das Ziel, die partnerschaftlichen und dialogischen Lernprozesse einzuleiten und im interreligiösen Horizont Themen $z u$ durchdringen. Voraussetzung dafür sind die Vernetzung und Zusammenarbeit mit den Alternativfächern Ethik, Philosophie etc. und dem Unterricht weiterer Religionen.

(3) Der Religionsunterricht der Zukunft ist kontextuell

Abhängig von Ort, Region, Schulform oder sogar Schule gestaltet sich der Religionsunterricht oftmals sehr unterschiedlich. Aus diesem Grund müsse man auf bereits existierende regionale Konzepte zurückgreifen, die bereits kontextbezogene Antworten auf die vielgestaltige Situation bergen. Dabei geht es nicht um die optimale Bildung großer Konfessionsgruppen, sondern um die Entwicklung von religionsunterrichtlichen Konzepten und Organisationsformen, die sich an den örtlichen Gegebenheiten orientieren.

Die Umsetzung dieses konfessionellen Religionsunterrichts in kooperativer Orientierung und kontextueller Abstimmung ist nur möglich, wenn die Kirchenleitungen sowie die staatlichen und schulischen Behörden, die wissenschaftliche Religionspädagogik und die Lehrkräfte, Lernenden und ihre 
Eltern gemeinsam dahinter stehen und mitgestalten. Der Religionsunterricht muss auf die steigende Zahl an muslimischen Kindern und Jugendlichen in Deutschland, der gleichzeitig zunehmenden Konfessions- und Religionslosigkeit sowie Religionspluralität reagieren und diese Schüler nicht ausschließen, sondern beachten und gemäß ihrer Bedürfnissen agieren.

Das am 19. Dezember 2016 veröffentlichte Positionspapier haben über 170 Religionspädagoginnen und Religionspädagogen aus Forschung und Lehre bisweilen unterschrieben und stehen somit hinter folgenden Aussagen ${ }^{126}$ :

(1) Förderung der Weiterentwicklung und bildungspolitischen Starkmachung unterschiedlicher Modelle eines konfessionell-kooperativen Religionsunterrichts, welcher die kontextuellen Gegebenheiten ernst nimmt

(2) Erforschung religionsdidaktischer Eckpunkte und Standards in Bezug auf die Konzeption und Organisation eines konfessionellen, kooperativen und kontextuellen Religionsunterrichts und deren Etablierung in der Lehrer- und Lehrerinnenbildung sowie schulischen Praxis.

(3) Verstärkte Kooperation in der Anfangsphase der Lehrer- und Lehrerinnenbildung an den Hochschulen und Universitäten, wenn möglich mit den Fachvertreterinnen und -vertretern der jeweils anderen Konfessionen und Religionsgemeinschaften sowie der Alternativfächer Ethik, Philosophie etc.

(4) Anbahnung und Vertiefung der Wege der Zusammenarbeit mit der islamischen und jüdischen Religionspädagogik und den sich etablierenden Religionspädagogiken anderer Religionen sowie der Pädagogik und Fachdidaktik der jeweiligen Alternativfächer Ethik- und Philosophieunterricht, etc.

(5) Konstruktive Berücksichtigung der wachsenden Anzahl von Schülerinnen und Schülern, die keiner Konfession oder Religion angehören bei der Entwicklung eines konfessionellen, kooperativen und kontextuellen Religionsunterrichts.

Mein Berufswunsch ist es nach dem Staatsexamen an beruflichen Schulen Religionsunterricht erteilen zu können. Heutzutage wird dort der Religionsunterricht in der Praxis längst in religiös-heterogenen Lerngruppen des 
Klassenverbandes erteilt, ohne dass dieser konzeptionell fundiert oder didaktisch begleitet wäre. Im Schulalltag werde ich mich sicherlich mit vielen heterogenen Klassen mit Migrationshintergrund an den beruflichen Schulen konfrontieren müssen. Nach der genaueren Betrachtung der Religiosität christlicher und muslimischer Jugendlicher in Deutschland, sowie der Bilanzierung eines zukunftsfähigen Religionsunterrichts, stütze ich die These von Simojoki und Lindner, frage ich mich jedoch, wie die Theorie konkret in die Praxis umgewandelt werden kann und sich für die kommenden Jahre bewähren wird. Das Positionspapier ${ }^{127}$ als Konzept von Schambeck u.a. steht hinter einer Theologie der Pluralität und gegenseitigen Wertschätzung des Gegenübers. Diese Grundvoraussetzung ist entscheidend, um die Forderungen umsetzen zu wollen.

${ }^{127}$ Vgl. Schambeck u.a. (Hg.), Positionspapier, 445-448. 


\section{Literaturverzeichnis}

Allenbach, Brigit/Goel, Urmila/Hummrich, Merle/Weissköppel, Cordula (Hg.): Jugend, Migration und Religion. Interdisziplinäre Perspektiven, Zürich 2011.

Altmeyer, Stefan, religiöse Identität, in: WiReLex - Das wissenschaftlichreligionspädagogische Lexikon im Internet 3 (2017) [https://www.bibelwissenschaft.de/stichwort/100197/; letzer Abruf am 23.01.2018].

Aslan, Ednan, Pluralitätsfähige religiöse Erziehung im Islamischen Religionsunterricht. Grundlagen und Perspektiven, in: Lindner, Konstantin/Schambeck, Mirjam/Simojoki, Henrik/Naurath, Elisabeth (Hg.), Zukunftsfähiger Religionsunterricht. Konfessionell - kooperativ - kontextuell, Freiburg i. Br. 2017, S. 411-428.

Aslan, Ednan/Kolb, Jonas/Yildiz, Erol, Muslimische Diversität. Ein Kompass zur religiösen Alltagspraxis in Österreich, Wiesbaden 2017.

Calmbach, Marc/Borgstedt, Silke/Borchard, Inga u.a., Wie ticken Jugendliche 2016? Lebenswelten von Jugendlichen im Alter von 14 bis 17 Jahren in Deutschland, Berlin 2016.

Freise, Josef. Religion als portable Heimat? Religiöse Werteentwicklung in Migrationsprozessen, in: Schambeck, Mirjam/Pemsel-Maier, Sabine (Hg.), Welche Werte braucht die Welt? Wertebildung in christlicher und muslimischer Perspektive, Freiburg 2017, S. 58-78.

Herrmann, Rainer, Terror und Islam, in: Frankfurter Allgemeine Zeitung vom 27.05.17, S. 1.

Katholische Nachrichten kath.net, Jeder dritte Muslim hochfundamentalistisch, vom 13.06.17., in: http://www.kath.net/news/mobile/59895; letzter Abruf am 24.01.2018. 
Könemann, Judith, Religion, in: WiReLex - Das wissenschaftlichreligionspädagogische Lexikon im Internet [http://www.bibelwissenschaft.de/stichwort/100075/; letzer Abruf am 24.01.2018].

Kropac, Ulrich, Jugendliche Religiosität, in: WiReLex - Das wissenschaftlichreligionspädagogische Lexikon im Internet 3 (2017) [http://www.bibelwissenschaft.de/stichwort/100087/; letzter Abruf am 24.01.18].

Kuckartz, Udo/Dresing, Thorsten/Rädiker, Stefan/Stefer, Claus, Qualitative Evaluation. Der Einstieg in die Praxis 2., aktualisierte Auflage, Wiesbaden 2008.

Lindner, Konstantin/Schambeck, Mirjam/Simojoki, Henrik/Naurath, Elisabeth (Hg.), Zukunftsfähiger Religionsunterricht. Konfessionell - kooperativ - kontextuell, Freiburg i. Br. 2017, S. 445-448.

Mazière, Thomas de, Rede beim 2. Zukunftskongress „Integration und Migration“ vom 20. September 2016, in: IRP Impulse Herbst 2016 „Dem Menschen zugewandt", Freiburg 2016, S.4.

Mayring, Philipp, Einführung in die qualitative Sozialforschung. Eine Anleitung zu qualitativem Denken, 5., überarbeitet und neu gestaltete Aufl., Weinheim/ Basel 2002.

Mecheril, Paul/Thomas-Olalde, Oscar, Die Religion der Anderen, in: Allenbach, Brigit; Goel, Urmila; Hummrich, Merle; Weissköppel, Cordula (Hg.): Jugend, Migration und Religion. Interdisziplinäre Perspektiven, Zürich 2011, S. 35-68.

Oertel, Holger, „Gesucht wird: Gott?" Jugend, Identität und Religion in der Spätmoderne, in: Gräb, Wilhelm/Meyer-Blanck, Michael (Hg.): Praktische Theologie und Kultur PThK 14, Gütersloh 2004.

Rahner, Johanna: „Ein gemeinsames Wort zwischen uns und Euch..."? Eine kritische Rückfrage zum aktuellen Stand des christlich-islamischen Dialogs und der Suche nach einer angemessenen hermeneutischen Basis, in: 
Dies./Schambeck, Mirjam(Hg.), Zwischen Integration und Ausgrenzung. Migration, religiöse Identität(en) und Bildung - theologisch reflektiert, Münster 2011, S. 157176.

Schambeck, Mirjam, Integration als Frage des Diskurses über Grundwerte?, in: Dies./Pemsel-Maier, Sabine (Hg.), Welche Werte braucht die Welt? Wertebildung in christlicher und muslimischer Perspektive, Freiburg i. Br. 2017, S. 235-259.

Schambeck, Mirjam, Interreligiöse Kompetenz. Basiswissen für Studium, Ausbildung und Beruf, Göttingen 2013.

Schambeck, Mirjam, Multi-Kulti? Kulturtheoretische, theologische und religionspädagogische Überlegungen, in: Dies./Rahner, Johanna (Hg.), Zwischen Integration und Ausgrenzung. Migration, religiöse Identität(en) und Bildung theologisch reflektiert, Münster 2011, S. 177-214.

Schambeck, Mirjam, unveröffentlichtes Manuskript: Vorlesung zu religiöses Lernen im RU. Konzeptionelle Entwicklungslinien und religionsdidaktische Prinzipen, Albert-Ludwigs-Universität Freiburg, Sommersemester 2017.

Schambeck, Mirjam, Warum ein religiöses Wir-Gefühl nicht nur beruhigt. Religionspädagogische Orientierungen in der aktuellen Integrationsdebatte, in: ÖRF 24 (2016) H. 2, S. 51 - 60 und in: Österreichisches Religionspädagogisches Forum ÖRF http://unipub.uni-graz.at/oerf/periodical/titleinfo/1646710; letzter Abruf am 30.01.2018.

Schambeck, Mirjam, Was religiöse Wertebildung zur Integration beitragen kann. Überlegungen aus der Religionspädagogik, in: Dies./Pemsel-Maier, Sabine (Hg.), Welche Werte braucht die Welt? Wertebildung in christlicher und muslimischer Perspektive, Freiburg i. Br. 2017, S. 118-138.

Schambeck, Mirjam/Schröder, Bernd, Auf dem Weg zu einer Didaktik konfessionell-kooperativer Lernprozesse, in: Lindner, Konstantin/Schambeck, Mirjam/Simojoki, Henrik/Naurath, Elisabeth (Hg.), Zukunftsfähiger 
Religionsunterricht. Konfessionell - kooperativ - kontextuell, Freiburg i. Br. 2017, S. 343-363.

Schiefer, David/Möllering, Anna/Geschke, Daniel, Muslimisch-deutsche Lebenswelten in Zeiten von Terrorismus (-verdacht): Eine Mehrgenerationenfallstudie, in: Herding, Maruta (Hg.), Radikaler Islam im Jugendalter. Erscheinungsformen, Ursachen und Kontexte, Halle (Saale) 2013, S. 125-139, in:

\section{http://www.dji.de/fileadmin/user upload/bibs2014/1461 DJI Radikalerlslam.pdf;} letzter Abruf am 30.01.2018.

Schockenhoff, Eberhard, Theologie des geistlichen Lebens in Geschichte und Gegenwart, unveröffentlichtes Manuskript zur Vorlesung vom Wintersemester 2016/17 an der Albert-Ludwigs-Universität Freiburg.

Schöll, Albrecht, Religion Jugend, in: WiReLex - Das wissenschaftlichreligionspädagogische Lexikon im Internet 3 3 (2017)

[http://www.bibelwissenschaft.de/stichwort/100085/; letzter Abruf am 24.01.2018].

Sellmann, Matthias, Jugendliche Religiosität als Sicherungs- und Distinktionsstrategie im sozialen Raum, in: Kropač, Ulrich/Meier, Uto/König, Klaus (Hg.), Jugend, Religion, Religiosität. Resultate, Probleme und Perspektiven der aktuellen Religiositätsforschung, Regensburg 2012, S. 25-55.

Shell Deutschland Holding (Hg.), Jugend 2015. Eine pragmatische Generation im Aufbruch (17. Shell Jugendstudie), Frankfurt a. M. 2015.

Simojoki, Henrik/Lindner, Konstantin, in: Dies./Schambeck, Mirjam/Naurath, Elisabeth (Hg.), Zukunftsfähiger Religionsunterricht. Konfessionell - kooperativ kontextuell, Freiburg i. Br. 2017, S, 429-444.

Weissköppel, Cordula, Die Kultur der Väter verstehen. Ethnoreligiöse Sozialisation von Jugendlichen im transnationalen Beziehungsgefüge der koptisch-orthodoxen 
Kirche in der Schweiz, in: Allenbach, Birgit u.a. (Hg.), Jugend, Migration und Religion. Interdisziplinäre Perspektiven, Zürich 2011, S. 159-195.

Wippermann, Carsten, Religion, Identität und Lebensführung. Typische Konfigurationen in der fortgeschrittenen Moderne. Mit einer empirischen Analyse zu Jugendlichen und jungen Erwachsenen, Opladen 1998.

Yildiz, Erol, Ein Ausflug in die Altagspraxis migrantischer Jugendlicher, in: Allenbach, Birgit (Hg.) u.a., Jugend, Migration und Religion. Interdisziplinäre Perspektiven, Zürich 2011, S. 115-133.

Ziebertz, Hans-Georg, Gesellschaftiche und jugendsoziologische Herausforderungen für die Religionsdidaktik, in: Hilger, Georg/Leimgruber, Stephan/Ziebertz, Hans-Georg, Religionsdidaktik. Ein Leitfaden für Studium, Ausbildung und Beruf, München 7. Aufl. 2012, 76-105.

Alle Internetseiten wurden zuletzt im Januar 2018 überprüft. 


\section{Anhang}

a) Transkription der vier Interviews:

-zwei Interviews am Donnerstag, 1.Juni 2017 gegen 13:15 Uhr in der Staudinger Gesamtschule.

-zwei Interviews am Freitag, 2. Juni 2017 gegen 15:15Uhr vor dem Fitnessstudio Fitness First in der Freiburger Innenstadt.

- alle vier transkribierten Interviews wurden anonymisiert.

Vorbemerkung: Die folgenden beiden zu Interviewenden sitzen neben einander und hören, was der andere für Antworten gibt. Vermutlich haben die Antworten des ersten Befragten einen Einfluss auf die Antworten der zweiten Befragten gehabt, da sie immer wieder zu ihrem Sitznachbarn schauen und den Blickkontakt suchen. Ausdrücklich wollten beide Befragten neben einander sitzen und das Interview des anderen mitbekommen.

Interview mit CM1 am 2.06.17 (Katholisch, männlich, deutsch, 17 Jahre alt, Abiturient; Gott ist in deinem Leben wichtig: trifft voll zu)

Nora: „Was für eine Rolle spielen Glaube und Religion für dich?“

CM1: „Also Religion spielt in meinem Leben ne große Rolle, ähm vor allem als Stütze, wenns mir ähm nicht so gut geht, und ich würd auch sagen, dass Gott ähm so ziemlich das wichtigste mit in meinem Leben ist.

Nora: „Dankeschön. Ähm Frage Nummer zwei: was ist für dich sinnstiftend? Was gibt dir Sinn überhaupt in deinem Leben?"

CM1: „Mmh ja wie schon gesagt auf jeden Fall die Religion, mein Glaube, aber natürlich auch Familie und ähm Sport vor allem.“

Nora: „Mhm, gehörst du einer Glaubensgemeinschaft an? Wenn ja, wie stark ist die Bindung daran und worauf stützt sie sich?“

CM1: „Ähm also ner Glaubensgemeinschaft direkt nicht, aber ich gehe natürlich ähm ab und zu in die Kirche, aber nicht ähm als Gemeinschaft sonder für mich selbst."

Nora: „Mhm, in welche Kirche gehst du, wenn ich fragen darf?“ 
CM1: „Ähm des ist ganz unterschiedlich, aber meistens ähm, in die, wie heißt die denn in unserer Schule, in die ZZZ Kirche in YYY."

Nora: „Alles klar. Frage Nummer vier: wie äußert sich Glaube und Religion konkret in deinem Alltag? Was bedeutet es für dich den Glauben zu leben oder auch nicht zu leben?!“

CM1: „Ähm also, ja konkret im Alltag ist es ähm für mich auf jeden Fall wichtig ähm mehrmals am Tag zu beten, weil man finde ich so auch vieles loswerden kann, was man sonst ähm nicht los wird."

Nora: „Mhm. Ähm Frage Nummer fünf: hast du in deinem persönlichen Umfeld Kontakt zu Menschen anderer Religionen? Zum Beispiel im Freundeskreis, Schule, Beruf, Freizeit?"

CM1: „Mh ja also im Freundeskreis sehr viel, da ich äh habe ich kaum christliche Freunde, überwiegend ähm muslimische Freunde, und ähm mit dem iss' es, mit denen ist es eigentlich auch immer gut, vor allem weil man sich auch manchmal austauschen kann."

Nora: „Mhm, das ist eigentlich auch schon die Frage Nummer sechs: wie findet der alltägliche Austausch über Religionen statt?"

CM1: „Mh ja da kann ich nur noch hinzufügen, auch natürlich ähm im Religionsunterricht, da bin ich nämlich im Ethikunterricht, weil ichs' ähm auch spannend find von anderen Religionen mitzubekommen."

Nora: „Ja. Und für den ähm katholischen Religionsunterricht wolltest du dich nicht entscheiden?"

CM1: „Ähm ja das war irgendwie halt in der Grundschule hatte man das schon immer und da habe ich mir so gedacht, ja meine eigene Religion, da könnte ich mich selber drüber informieren. Und ich fands' da eher spannender mit anderen Religionen in Kontakt zu kommen."

Nora: „Mhm. Alles klar. Frage Nummer sieben: gibt es in deinem Alltag konkret Berührungspunkte mit anderen Religionen?"

CM1: „Ja, überwiegend nur über Freunde.“

Nora: „Mh. Und da eben muslimische Freunde und im Ethikunterricht, wo du auch über andere Religionen sprichst. Also ihr behandelt nicht nur philosophische Themen im Ethikunterricht sonder auch..."

CM1: „Nee, vor allem sind es auch die Ansatzpunkte von ähm denen aus meiner Klasse dann mit anderen Religionen, wie die das im Gegensatz zu mir sehen." 
Nora: „Cool. Frage Nummer acht: nimmst du religiöse Konflikte wahr? Wenn ja, wie bewertest du diese?"

CM1: „Also ich persönlich jetzt nicht, aber man bekommt natürlich immer mal wieder mit, ähm Diskriminierungen gegen vor allem Muslime, wegen dem was alles passiert ist, aber von mir persönlich jetzt nicht, weil ich da eher offener bin." Nora: „Mhm. Frage Nummer neun: was für einen Einfluss haben diese Konflikte auf deinen persönlichen Glauben und deine grundsätzliche Einstellung zu Glaube und Religion?"

CM1: „Ja wie gesagt einfach auch schon direkt, dass ich ähm von Grund aus offener bin anderen Religionen gegenüber, weil ich ähm mit anderen Religionen vor allem kein Problem habe."

Nora: „Mhm. Aber sie überzeugen dich auch nicht, beziehungsweise du kriegst jetzt nicht Zweifel im eigenen Glauben, wenn du dich mit anderen Religionen beschäftigst."

CM1: „Nee, des auf keinen Fall, weil ich find meine Religion ist die beste, die es gibt."

Nora: „Okay, sehr cool. \{schmunzelt\} (1) Und Frage Nummer zehn: gibt es noch etwas, was dir auf dem Herzen liegt und wichtig scheint zu sagen."

CM1: „Nein gibt es nicht.“

Nora: „Alles schon gesagt! Vielen Dank fürs Interview!“

CM1: „Bitte! (4) \{Geflüstert\} Mein Glaube ist der Beste.“/Humor/

Interview mit CW2 am 2.06.17 (Evangelisch, weiblich, deutsch, 17 Jahre alt, Abiturientin, Gott ist in deinem Leben wichtig: trifft voll zu)

GL: „Wir fangen an mit der ersten Frage: was für eine Rolle spielen Glaube und Religion für dich?"

CW2: „Ja also Glaube und Religion spielen für mich ne' sehr wichtige Rolle, weil also schon seit ich klein bin ist es eigentlich relativ wichtig für mich, oder was heißt sehr wichtig für mich. Und ja also es ist auch eigentlich so das Wichtigste in meinem Leben so (.).“

GL: „Was ist für dich sinnstiftend. Also was gibt dir Sinn im Leben?"

CW2: „Ähm, (.) auch mein Glaube, meine Familie, aber auch Freunde, und keine Ahnung, ja des eigentlich." 
GL: „Mhm. Frage Nummer drei: gehörst du einer Glaubensgemeinschaft an? Und wenn ja, wie stark ist die Bindung daran und worauf stützt sie sich?“

CW2: „Mhm ja! Also ich gehe jeden Sonntag in die Kirche, ähm mit meiner Familie und ähm die Bindung ist daher auch sehr stark, weil ich da eben schon bin seit dem ich klein bin und des ist auch eigentlich wie so eine Familie für mich dort."

GL: „Frage Nummer vier: wie äußert sich Glaube und Religion konkret in deinem Alltag? Was bedeutet es für dich den Glauben zu leben oder auch nicht zu leben?"

CW2: "Ähm also es äußert sich halt dadurch, dass wenn ich zum Beispiel Probleme habe im Alltag, ich das, also ich, natürlich es beschäftigt mich schon, aber ich gebe es halt meistens einfach so an Gott ab, und also deswegen wenn irgendwas ist, also dann kann ich, habe ich das Gefühl dann kann ich besser damit umgehen eben dadurch dass ich eben an Gott glaub " und wenn ich halt bet" generell."

GL: „Mhm. Frage Nummer fünf: hast du in deinem persönlichen Umfeld Kontakt zu Menschen anderer Religionen?"

CW2: „Mhm, ja! Also halt ähm mit Muslimen. Aber (.) ähm es ist eigentlich weniger geworden, also weil in meinem engeren Freundeskreis hauptsächlich Christen sind."

GL: „Mhm. Ähm Frage Nummer sechs: wie findet der alltägliche Austausch über Religion statt?"

CW2: „Also bei mir eben, manchmal wenn ich in der Kirche, also ich habe ja auch Freunde in der Kirche mit denen ich mich über sowas unterhalt', oder auch privat mit Freunden über sowas, oder halt auch im Religionsunterricht, bin ich ja im evangelischen Religionsunterricht. Da reden wir halt auch, also da reden wir natürlich auch über Religion." \{schmunzelt\}

GL: „Mhm. Frage Nummer sieben: gibt es in deinem Alltag konkrete Berührungspunkte mit anderen Religionen?"

CW2: „Ähm ja eben. Ähm wenn ich privat mit ähm Andersgläubigen zu tun hab؛ Ähm aber des ist eigentlich, ähm also, des ist gar nicht sooo, spielt keine so große Rolle eigentlich dann."

GL: „Okay. Ähm Frage Nummer acht: nimmst du religiöse Konflikte wahr? Wenn ja, wie bewertest du diese?" 
CW2: „Ja also ich selber bekomme jetzt nicht, also nicht so viele religiöse Konflikte mit. Also höchstens glaube ich sogar eher, dass manchmal so eher zwischen Atheisten und Gläubigen, und dann egal welcher Religion, und dass die dann oftmal' irgendwas dummes sagen oder so was. Aber so zwischen Religion eigentlich nicht außer halt was man halt so im Fernsehen mit bekommt, so IS und so was."

GL: „Mhm: Frage Nummer neun: was für einen Einfluss haben diese Konflikte auf deinen persönlichen Glauben und deine grundsätzliche Einstellung zu Glaube und Religion?"

CW2: „Ähm es hat eigentlich gar keinen Einfluss auf meinen Glauben! (.) Weil also es ist eigentlich so, des egal ist was kommt. Ich bleib“ bei meinem Glauben. \{lacht\} Da kann mich dann auch nichts umstimmen. Deswegen also is (.) is also, manchmal, wenn man sowas hört, ähm fragt man sich halt so, wo halt der Sinn hinter ner Religion steckt, die eigentlich Frieden lehrt, dass dann irgendwelche schlimmen Sachen so passieren. Aber so an sich an meinem eigenen Glauben ändert des nichts."

GL: „Mhm. Und die letzte Frage: gibt es noch etwas, was dir auf dem Herzen liegt und wichtig scheint zu sagen?"

CW2: „Nee, ich hab“ alles gesagt!“

GL: „Vielen Dank!“

CW2: „Kein Problem!“ $\{$ lachend\}

Vorbemerkung: Das Interview fand in einer Gesamtschule in Freiburg, konkret in einer Art öffentlichen Vorraum der schulinternen Bibliothek, statt. Aus diesem Grund sind Geräusche im Hintergrund der Audiodatei unausweichlich vorhanden.

Interview mit MM3 am 01.06.17 (Sunnitisch, männlich, syrisch, 18 Jahre, besondere Eingangsklasse 10; Gott ist in deinem Leben wichtig: trifft voll zu). Er ist vor 4 Jahren mit seiner Familie von Syrien nach Deutschland geflüchtet.

GL: „Wir fangen mit der ersten Frage an: was für eine Rolle spielen Glaube und Religion für dich?"

MM3: „Also Religion spielt für mich eine wichtige Rolle! Denn, ähm also, ich hab jeden Tag halt, ich hab', ich hab“ mit Religion und ich beschäftig, beschäftige mich 
auch damit und ich finde halt ähm es ist wichtig für das Leben. Und ja sonst mehr (.)."

GL:"Was ist für dich sinnstiftend? Was gibt dir Sinn im Leben?"

MM3: „Also mir gibt Sinn im Leben, wenn man äh etwas macht, was am Ende auch etwas bringt \{kurze Pause\} Also was mir Sinn im Leben gibt ist (.) äh halt (.) meine Familie, Freunde und so und auch Gott spielt auch eine Rolle in meinem Leben. Ähm also dass halt alle, dass wir halt zusammen friedleben und so, des finde ich wichtig in meinem Leben. Und sonst ähm ja (.).

GL: „Dritte Frage: gehörst du einer Glaubensgemeinschaft an? Wenn ja, wie stark ist die Bindung daran und worauf stützt sie sich?"

MM3: „Also ja ich bin ein Muslim, ich bin ein Sunnite, also ein sunnitischer Muslim, also ich hab' nicht viel Kontakt mit Anderen, die halt äh gleiche Glaubensgemeinschaft haben. Ähm aber ich hab, habe auch viel zu tun mit Leuten, die was anderes, die zu einer anderen Glaubensgemeinschaft gehören, ähm aber ja manchmal gehe ich auch in die Moschee und dort gibts auch Leute, die wie ich sind, und auch Sunnitische."

GL: „ist die Moschee hier in XXX, in die du gehst?" MM3: „Ja genau, ist in XXX.

GL: „Wie äußert sich Glaube und Religion konkret in deinem Alltag? Was bedeutet es für dich den eigenen Glauben zu leben oder auch nicht zu leben?“

MM3: „Also ähm bei uns, im Islam muss man halt fünf Mal am Tag beten und das mache ich auch täglich. Deshalb habe ich viel Kontakt, also sozusagen mit Religion und Gott und so. Ähm und ich find halt wichtig und für mich ist auch gut, dass ich halt mich an die Religionsgesetzte (.) festhalte. Und dass ich auch äh damit was mach' und alles was ich lerne auch übe in meinem Alltag, ausüben. Und ähm dass ich halt (.) so wenig wie möglich Fehler mache. Und ja..."

GL: „Danke. Frage Nummer fünf: hast du in deinem persönlichen Umfeld Kontakt zu Menschen anderer Religionen? Zum Beispiel im Freundeskreis, in der Schule, Freizeit?"

MM3: „Ja. Also halt ähm in der Familie habe ich meine Schwester. Sie ist äh Atheistin. Und ich äh find halt so sozusagen dass sie eine andere Religion, oder gar keine Religion hat. Und in der Schule gibt's auch welche, also es gibt in meiner Klasse gibt's viele Muslime, aber auch so wie andere Muslime, äh zum 
Beispiel Christen oder irgend'was anderes. Und ja dann, direkt also ich habe auch Kontakt mit anderen, die halt keinen, eine andere Religion haben.“

GL: „Mhm. Frage Nummer sechs: wie findet der allägliche Austausch über Religionen statt? Also wie ähm täuschst du dich ähm über deine Religion aus mit anderen Menschen oder auch über andere Religionen? Deine eigene aber auch andere Religionen?"

MM3: „Also ja manchmal rede ich auch mit Leute, mit andere Leute, die eine andere Glaube haben, Religion und ich frage sie halt an was sie glauben. Und manchmal wenn jemand halt äh mit mir über meinen Glauben redet, dann versuche ich halt ihm also wenn er was falsches hat im Kopf oder Gedanken, dass ich das korrigier' und manchmal lerne ich auch von anderen, die halt mir was erzählen, was ich nicht weiß, und ja (.).“

GL: „Mhm. Ähm Frage Nummer acht nee Frage Nummer sieben: gibt es in deine Alltag konkrete Berührungspunkte mit anderen Religionen? Also ähm wahrscheinlich..."

MM3: „Nee, eigentlich nicht. So indirekt nich'. Eigentlich nich““

GL: „Okay mhm. Nummer acht: nimmst du religiöse Konflikte wahr und wenn ja, wie bewertest du diese? Also sind sie schlimm, oder wenig schlimm?"

MM3: „Also ja, ich nehm sie schon wahr. Aber (.) es ist halt so, also wenn man mit mir, also wenn ich mit jemand debattiere über eine bestimmte Religion, meine Religion, dann nehme ich sie halt so, (2) wie sagt man, sportliche Seele halt so. Nur das halt so (.) dass man halt drüber diskutiert und so, aber nicht gegenseitig schlagen oder so. Aber wenn, manchmal gibt's auch, könnte auch Stress sein, weil ähm wenn die andere, weil wenn der ander' sagt ihre Meinung, auf mich das sozusagen, ähm (.) also wenn sie halt sagt, dass ich halt komplett falsch bin und so und schlecht verhält, dann ja dann könnte auch zu Konflikt entstehen ja.“

GL: „Aber würdest du dann auch (.) ähm nur verbaler Konflikt, oder Gewalt, nein, oder?!“

MM3: „Nein, Gewalt nicht, aber halt mit Reden halt, mit Diskutieren!“

GL: „Ja! Alles klar! Frage Nummer neun: was für einen Einfluss haben diese Konflikte auf deinen persönlichen Glauben und deine grundsätzliche Einstellung zu Glaube und Religion? Also beeinflussen Konflikte mit Andersgläubigen deinen eigenen Glauben, dass du zum Beispiel zweifelst oder dass du noch stärker im Glauben bist?“ 
MM3: „Also, also eigentlich zu anderen Religionen eigentlich nicht, weil ähm ich, also ich für mich ich informiere mich auch über andere Religionen und ich habe auch meine Zeugen (.) also Gründe, warum ich mich fest an meine Religion halte. Aber Zum Beispiel äh zu Hause habe ich wie gesagt meine Schwester und manchmal wir diskutieren über Religion und Atheismus. Und äh manchmal stellt sie Fragen dar, die ich nicht beantworten kann und dann habe ich selber Zweifel dran, aber ich versuche so weit wie möglich, so gut wie möglich drüber zu informieren und recherchieren. Und dann finde ich die halt die passende Antwort und dann ist nicht mehr in meinen Gedanken, dann also ist weg dann.“

GL: „Joa, oh okay. Gibt es noch etwas, was dir auf dem Herzen liegt und wichtig scheint zu sagen? Also möchtest du noch irgend'was sagen?"

MM3: „Nee, weiß ich nicht (.).“ $\{$ lächelnd\}

GL: „Okay! Dann vielen Dank! Dann bedanke ich mich herzlich für das Interview!“ MM3: „Kein Problem!“

Interview mit MW4 am 01.06.17 (Schiitisch, weiblich, deutsch, 17 Jahre alt, besondere Eingangsklasse 10; Gott ist in deinem Leben wichtig: trifft zu)

Vorbemerkung: Die Teilnehmerin MW4 ist in Deutschland geboren, ihr Vater ist Libanese (Muslim) und ihre Mutter Deutsche (Christin).

GL: „Die erste Frage: was für eine Rolle spielen Glaube und Religion für dich?“

MW4: „Also für mich spielen Glaube und Religion eigentlich schon ne große Rolle. Aber is zwar, bei mir isses halt so, dass ich ähm eher bei meiner Mutter aufgewachsen bin und sie Deutsche is. Und wir, ich halt deswegen nicht so viel damit in Kontakt gekommen bin am Anfang, aber jetzt halt umso älter ich werd", versuche ich halt immer mehr mich damit zu beschäftigen."

GL: „Mhm. Was ist für dich sinnstiftend? Also was gibt dir Sinn im Leben?“ MW4: „Mmm. Meine Familie und meine Freunde und auch mein Glaube.“

GL: „Mhm. Also du bist muslimisch obwohl deine Mama nicht Muslimin ist?! Und hast du dich dann selber dafür entschieden oder dein Vater, der dir da geholfen hat?"

MW4: „Also mein Vater, mein Vater hat immer versucht uns so in die Richtung zu bringen." 
GL: „Hast du noch Geschwister?“

MW4: „Ja!“

GL: „Und die sind auch muslimisch?“

MW4: „Ja!“

GL: „Ok. Alles klar! Ähm dritte Frage: gehörst du einer Glaubensgemeinschaft an? Wenn ja, wie stark ist die Bindung dazu und worauf stützt sie sich? Also wie kann man sehen, dass du aktiv in dieser Glaubensgemeinschaft Teil davon bist?"

MW4: „Also is‘ jetzt mit Glaubensgemeinschaft so was wie Moschee und...“

GL: „Genau!“

MW4: „Ähm, also. Ich gehe zwar ab und zu in die Moschee, aber nich so oft. Und wenn halt so Trauertage sind und so, dann muss man halt in die Moschee gehen, und des mach ich dann halt auch.“

GL: „Mhm. Und Feiertage, so festliche Tage auch? Geht ihr da auch in die Moschee, oder?“

MW4: „Joa, ab und zu. Also nicht regelmäßig aber (.) ab und zu.“

GL: „Okay. Und ist das die gleiche Moschee wie er in XXX?“

MW4: „Mhm. Ich gehe in ZZZ.“

GL: „Ahja, okay! Danke! Ähm vierte Frage: wie äußert sich Glaube und Religion konkret in deinem Alltag? Was bedeutet es für dich den eigenen Glauben zu leben oder auch nicht zu leben?“

MW4: „Also ich find's eigentlich wichtig meinen Glauben zu leben, weil, also, es gibt halt viele Sachen, die uns vorbeschriftet werden, oder wie sagt man, vorgeschrieben ja. Und ich find's wichtig sich an die Sachen zu halten."

GL: „Mhm, alles klar. Ähm fünfte Frage: hast du in deinem persönlichen Umfeld Kontakt zu Menschen anderer Religionen?“

MW4: „Ähm, ja, eigentlich überall! Bei der Arbeit, in der Schule, in meinem Freundeskreis."

GL: „Wo arbeitest du?"

MW4: „Auch in der Familie. In ner Eisdiele.“

GL: „Ah ok. Wo?“

MW4: „In CCC.”

GL: „Ah cool. Ok. Und in der Familie, deine Mama ist welcher...“

MW4: „Sie ist christlich.“

GL: „Welches? Welche christliche (.) ?“ 
MW4: „Evangelisch.“

GL: „Evangelisch. Und sie toleriert es, oder? Für sie ist es okay, dass du muslimisch bist?

MW4: „Ja!“

GL: „Aber sie würde nicht mit dir zu Allah beten?“

MW4: „Nein!“

GL: „Ok! Lebt sie auch ihren Glauben? Ist sie sehr religiös?“

MW4: „Nich (.) ganz. Also nicht so arg, aber ein bisschen.“

GL: „Okay. Also sie betet auch, aber...?"

MW4: „Ja, ab und zu.“

GL: „Ok. Ähm Frage Nummer sechs: Wie findet der alltägliche Austausch über Religion statt?"

MW4: „Also eigentlich in der Schule. Meistens mit meinen Freundinnen, die auch muslimisch sind."

GL: „Betet ihr auch ähm in der Schule zusammen? Habt ihr so nen Raum, wo ihr hin gehen könnt?“

MW4: „Nein!“

GL: „Oder, also redet ihr einfach über den Glauben, ähm über Allah?

MW4: „Wenn zum Beispiel. Oft gibt es halt mal so Sachen, dass die Eine ner anderen Meinung is als die Andere und dann reden wir darüber."

GL: „Ok! Also auch über den Koran, über irgendwelche Gesetze. Schwierige Momente, Situationen, so?"

MW4: „Mhm!“

GL: „Ok. Danke! Ähm Frage Nummer sieben: gibt es in deinem Alltag konkrete Berührungspunkte mit anderen Religionen?"

MW4: „Wie isses gemeint?"

GL: „Also im Alltag zum Beispiel jetzt in der Eisdiele. Dass du da irgendwie Christen auch triffst und dann redet ihr über den Glauben. Oder ähm dass du auch schon mal mit Christen zusammen gebetet hast oder irgendwie den Glauben gelebt hast?"

MW4: „Eher nich'.“

GL: „Eher nich‘. Mhm. Nummer acht: nimmst du religiöse Konflikte wahr? Wenn ja, wie bewertest du diese?" 
MW4: „Also ich nehm' sie schon wahr. Un' (.) Wie ich sie bewerte? Es kommt halt drauf an, wie schlimm es is'."

GL: „Hast du ein Beispiel für einen religiösen Konflikt, was dir schon mal passiert ist?"

MW4: „Ähm (4) Mir fällt jetzt grad nichts ein.“ /lacht verlegen/

GL: „Oder dass jemand irgendwie schlecht über den Islam gesprochen hat, oder?“ MW4: „Ja, also es ging halt um das Thema IS, und...“

GL: „War das im Unterricht, oder?“

MW4: „Nee, des war im Freundeskreis. Und da war halt ähm eine Freundin der Meinung, dass die, also dass die nach unserem Koran leben sozusagen, dass dort im Koran steht, dass man Leute töten soll und so was, aber dabei stimmt des gar nich'. Und dann haben wir halt auch darüber diskutiert, gestritten.“

GL: „Mhm. Ok. Danke. Ähm Frage Nummer neun: was für einen Einfluss haben diese Konflikte auf deinen persönlichen Glauben. Also kriegst du Zweifel, wenn du mit (.) Leuten irgendwie über deinen Glauben sprichst oder religiöse Konflikte hast? Und deine grundsätzliche Einstellung zu Glaube und Religion? Verändert sich des durch die Konflikte?"

MW4: „Also jetzt zum Beispiel bei diesem Konflikt war es dann halt so, weil sie hat mir so nen YouTube Video gezeigt von so nem Mann, der des halt gesagt hat und so. Da hab ich mir dann gedacht, häh??? Stimmt des und so was. Aber dann habe ich halt nochmal nachgedacht und dann ist mir, also habe ich mir selber gedacht, des gibt's bei uns nicht. Also des steht bei uns nich“ im Koran.“

GL: „Mhm. Ok. Danke. Gibt's als letzte Frage: gibt es noch etwas, was dir auf dem Herzen liegt und wichtig ist zu sagen?"

MW4: „ähm (3).“

GL: „Alles gesagt.“

MW4: „Ja!“

GL: „Ok. Vielen Dank für das Interview!“

MW4: „Bitteschön!“ 
b) Erste Seite der Internetquellen

Schambeck, Mirjam, Art. Warum ein religiöses Wir-Gefühl nicht nur beruhigt. Religionspädagogische Orientierungen in der aktuellen Integrationsdebatte, in: Österreichisches Religionspädagogisches Forum ÖRF: http://unipub.unigraz.at/oerf/periodical/titleinfo/1646710, letzter Abruf am 30.01.18.:

Mirjam Schambeck

Warum ein religiöses Wir-Gefühl nicht nur beruhigt Religionspädagogische Orientierungen in der aktuellen Integrationsdebatte

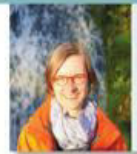

Dr. ${ }^{\text {in }}$ Mirjam Schambeck sf, Professorin fûr Religionspasdagogik an der Katholisch-Theologischen Fakultăt der Universităt Freiburg

\begin{abstract}
In Migrationsstudien und Integrationsdebatten herrscht Obereinkunft darüber, dass die Teilhabe an zentralen Bereichen von Gesellschaft wie Bildung, Zugang zum Arbeits- und Wohnmarkt ausschlaggebend fûr das Gelingen von Integration ist. Damit kann aber nicht die Frage beantwortet werden, warum sich Jugendliche, die sozio-ökonomisch abgesichert sind und über einen

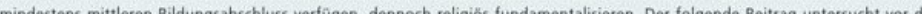

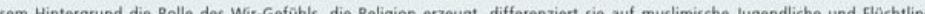
hin und entwickelt Oberlegungen, wie religiöse Bildung konzeptioniert und organisiert werden soll, um einen Beitrag für eine gelingende Integrationsarbeit zu leisten.

Schlagworte: Religion, Wir-Gefühl, Pluralität, Religionsplural, Interreligiöses Lernen, Integrationsmaßnahmen, Religose Bildung im Kontext von Integration
\end{abstract}

Remarks about religion and the "feeling of togetherness" and why this relationship not only calms. Orientations in the current debate about integration

In studies and debates about migration and integration there is a wide agreement on how the access to central areas of society such as education, housing or the employment market is pivotal for successful integration. However, this doesn't explain why adolescents who are economically secure and educated at least on an intermediate level still turn towards religious radicalism. The following contribution explores the role of a feeling of togetherness that is created by religion and then specifically focuses on Muslim adolescents and refugees. Furthermore, ideas are developed on how religious education can be conceptualised and organised in order to sustainably contribute to integration.

Keywords: Religion, Wir-Gefühl (feeling of togetherness), plurality, plurality of religions, interreligious education measures of integration, religious education in contexts of integration

o unterschiedlich Migrationsstudien konzipiert sind und in so unterschiedlicher Differenziertheit Integrationsdebatten laufen, so herrscht dennoch in folgen den Punkten Obereinstimmung: Die Teilhabe an zentralen Bereichen von Gesellschaft wie Bildung, Zugang zum Arbeits- und Wohnmarkt sind entscheidende Kriterien für das Gelingen von Integration. ${ }^{1}$ Detlef Pollack konnte in seiner Studie "Grenzen der Toleranz"2 diesen Befund noch konkretisieren, indem er den Faktor des Religionspluralismus' angesichts auszuhandelnder Gesellschaftspraxen ins Spiel brachte und auf folgende Abhängigkeiten hinwies:
1. Je gebildeter Menschen sind, desto größer ist die Akzeptanz der Gleichbehandlung unterschiedlicher religiöser Gemeinschaften. ${ }^{3}$

2. Je ökonomisch abgesicherter Menschen sind, desto eher befürworten sie die religionsrechtliche Gleich. stellung von Religionen. ${ }^{4}$ D.h., dass materielle Sicherheit die Toleranzbereitschaft erhöht.

3. Je mehr Menschen sog. Werte der westeuropäischen Gesellschaft bejahen wie Meinungsfreiheit, Redefreiheit, Glaubensfreiheit und die Garantie von Minderheitenrechten, desto eher befürworten sie die Gewährung gleicher Rechte für alle und 
Altmeyer, Stefan, religiöse Identität, in: WiReLex:

https://www.bibelwissenschaft.de/stichwort/100197/; letzer Abruf am 23.01.2018.:

Das Wissenschaftlich-

Religionspädagogische Lexikon

UtberWireles

Die Autoren/inner

(a)

Anmeldung

Benutzemame

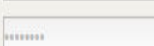

Jetzt anmelden

1 Passwort vergessen?

1. Neu registrieren!

\section{(1) FGefallt mir}

(1) $8+1$

(1) Y Y Tweet
Identität, religiöse

Stefan Altmeyer

(erstellt: Febr. 2016)

Permanenter Link zum Artike:

http://www.bibelwissenschaft.delstichwort 100197]

Digital Object Identifier:

https://doi.org/10.23768/wirelex.Identitt _eligise.100197

1. Problemstellung

2. Koordinaten von Identität

2.1. Die Frage nach Identitat

2.2. Begriff und Perspektiven der Identitatt

2.3. Grundmuster des Identifizierens

3. Identität und Religion, religiöse Identität

3.1. Die Frage nach religiöser Identitatit

3.2. Identifizierungsmuster religioserer Identität

4. Identiät, Identitätsbildung und religiöse Bildung

Literaturverzeichnis

Abbildungsverzeichnis

\section{Problemstellung}

Religöse Identitati ist ein theoretisches Konstrukt, das in

religionspädagogischen Zusammenhängen gleichermaßen allgegenwärig wie zugleich schwer zu fassen ist. So zentral es für das Verstännnis und die Orientierung $\rightarrow$ religiöser Bildungsprozesse ist, so wenig scheint geklärt, was damitj jeweils gemeint sein soll (Pirker, 2013, 11-17, bes. 13; Schweitzer, 2012, 112). Denn zu vieffiltig und teilweise divergierend sind die theoretischen Positionen, die phänomenologischen Bezüge und methodischen Zugänge. Dies gilt für jeden einzelnen der hier zusammengebundenen Begriffe $\rightarrow$ Religion und Identiata wie für die Begriffsverbindung religiose Identitat selbst (Englett, 2014). Zugleich ist auch

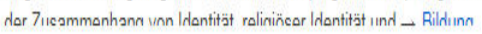

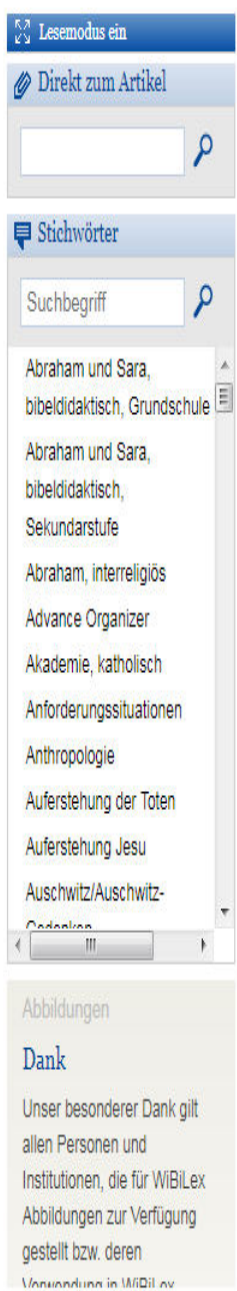


Katholische Nachrichten kath.net, Jeder dritte Muslim hochfundamentalistisch, vom 13.06.17., in: http://www.kath.net/news/mobile/59895; letzter Abruf am 24.01.2018:

\section{'Jeder dritte Muslim hochfundamentalistisch'}

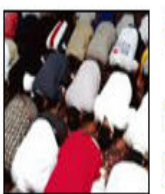

Der Religionspädagoge Ednan Aslan ist allerdings säkular

Wien (kath.net)

In Österreich hat jeder dritte Muslim eine "hochfundamentalistische" Einstellung. Dies geht aus einer Studie von Ednan Aslan, dem Leiter des Instituts für Islamische Studien, und den Soziologen Jonas Kolb und Erol Yildiz hervor, wie "Die Presse" berichtet. Werbung

Die Studie ergibt zwei zentrale Erkenntnisse: Einerseits befinde sich eine große Zahl der Muslime in einem Säkularisierungsprozess, andererseits gibt es auch ein großes Potenzial für Ansichten, die die Autoren als hochfundamentalistisch werten. Gemeint ist damit, dass diese Muslime meinen, dass die eigene Religion recht und andere Religionen unrecht hätten. Ein Drittel der Befragten finde es "sehr bedrohlich", wenn das eigene Kind einen Partner mit anderer Religionszugehörigkeit heiraten würde.

kath.net ist Teilnehmer des Partnerprogramms von Amazon EU, das zur Bereitstellung eines Mediums für Webseiten konzipiert wurde, mittels dessen durch die Platzierung von Werbeanzeigen und Links zu Amazon.de Werbekostenerstattung verdient werden kann.

\section{Lesermeinungen zu diesem Artikel anzeigen und Kommentar schreiben}

Sie können nur die Lesermeinungen der letzten sieben Tage einsehen.

\section{ZUR KATH.NET STARTSEITE}

ZUM SEITENANFANG 

Könemann,
Judith,
Religion,
in:
WiReLex:

http://www.bibelwissenschaft.de/stichwort/100075/; letzer Abruf am 24.01.2018.:

Das Wissenschaftlich-

Religionspädagogische Lexikon

Über WiReLex

Die Autoren/innen

Anmeldung

Benutzernam

Bunn

- Jetzt anmelden

- Passwort vergessen?

- Neu registrieren!

(f) Gefällt mir

$\infty+1$

\% Tweet

\section{Religion}

Judith Könemann

(erstellt: Jan. 2015)

Permanenter Link zum Artikel:

http://www.bibelwissenschaft.de/stichwort/100075/

Digital Object Identifier: https://doi.org/10.23768/wirelex.Religion.100075

1. Aufkommen der Frage nach Religion und etymologische Bestimmung

2. Bestimmungsversuche von Religion

3. Begriffsunterscheidungen: Religion, Religiosität, Spiritualität

4. Religion in der Moderne - zur gesellschaftlichen Situation von Religion

5. Offene Fragen, Desiderate, Perspektiven der Forschung

Literaturverzeichnis

1. Aufkommen der Frage nach Religion und etymologische Bestimmung

In einem ersten allgemeinen Zugang zu den Begriffen Religion und

Religiosität wird unter Religion in der Regel ein mehr oder weniger verfasstes

System von Glaubenssätzen und -lehren verstanden, religionspädagogisch

oftmals als "gelehrte Religion" bezeichnet, während Religiosität

demgegenüber die subjektive Aneignung dieses Systems der Religion meint, religionspädagogisch oftmals als "gelebte Religion" bezeichnet. Diese sehr

allgemeine Bestimmung ist bereits eine moderne, insofern bereits die Frage danach, was Religion sei und wie sie zu bestimmen sei, ein Phänomen der Moderne ist, da sie sich erst zu einem recht späten Zeitpunkt im Laufe des 18. Jahrhunderts stellte (Kaufmann, 1989, 23-31). Das Zerbrechen des umfassenden christlichen Sinn- und Kommunikationszusammenhangs im europäischen Kontext, die Anfragen der Aufklärung und französischen

Revolution, das Wahrnehmen anderer religiöser, nicht-christlicher Traditionen, das Aufkommen des Gedankens religiöser Toleranz als auch die
Kᄌ Lesemodus ein

Direkt zum Artikel

\section{$\rho$}

早 Stichwörter

Suchbegriff

$\rho$

Abraham und Sara,

bibeldidaktisch, Grundschule

Abraham und Sara,

bibeldidaktisch,

Sekundarstufe

Abraham, interreligiōs

Advance Organizer

Akademie, katholisch

Anforderungssituationen

Anthropologie

Auferstehung der Toten

Auferstehung Jesu

Auschwitz/Auschwitz-

4 Tndanionn III

Abbildungen

Dank

Unser besonderer Dank gilt allen Personen und

Institutionen, die für WiBiLex Abbildungen zur Verfügung gestellt bzw. deren 
Kropac, Ulrich, Jugendliche Religiosität, in: WiReLex:

http://www.bibelwissenschaft.de/stichwort/100087/; letzter Abruf am 24.01.18.:

Möchten Sie das Passwort für www bibelwissenschaft de im Passwort-Manager speichern?

Das Wissenschaftlich-

Religionspädagogische Lexikon

Über WiReLex

Die Autoren/innen

\section{Anmeldung}

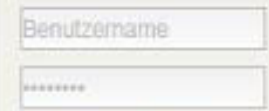

- Jetzt anmelden

- Passwort vergessen?

- Neu registrieren!

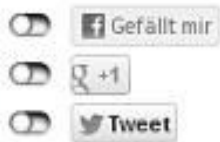

Religiosität, Jugendliche

Uirich Kropac

(erstellt. Jan, 2015)

Permanenter Link zum Artikel:

hittp///www bibelwissenschaft de/stichwort/100087/

Digital Object Identifier:

https://doi.org/10.23768/wirelex.Religiositt_Jugendliche. 100087

1. Empirische Studien zut Religiosităt Jugendlicher

1.1. Differente Ansatze

1.2. Ausgewahlte Studien

1.2.1. Shell Jugendstudie 2010

1.2.2. Untersuchungen von Hans-Georg Ziebertz u.a.

1.2.3. Heinz Streib und Carsten Gennerich: Analysen juveniler

Religiositat

1.2.4. U27- und U17-Studie, Wie ticken Jugendliche?

1.2.5. Religionsmonitor 2013: Religiositāt im internationalen Vergleich

2. Jugendliche Religiositat: eine Charakteristik

2.1. Kennzeichen jugendlicher Religiositāt

2.2. Funktionen von Religiositat und Aneignung von Religion

3. Herausforderungen für Religionsunterricht und Jugendpastoral

3. Biografie

32. Ästhetik

33. Multimedia

Literaturverzeichnis

Antworten auf die Frage, was Jugendreligiositat ist und durch welche Eigenschaften sie sich auszeichnet, führen unmittelbar in das Feld der empirischen Jugendforschung. Jugendreligiosität kann also zunächst nicht anders bestimmt werden als durch eine Auswertung jener empirischer
Lesemodas ein

Direkt zum Artikel

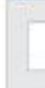

目 Stichwörter

Suchbegriff

Abraham und Sara. bibeldidaktisch, Grunc Abraham und Sara, b beididaktisch.

Sekundarstufe Abraham, interreligiōs Advance Organizer Akademie, katholisch Antorderungssituation Anthropologie Auferstehung der Tote Auferstehung Jesu Auschwitz/AuschwitzAndonienn.

Abbildungen

Dank

Unser besonderer Dan allen Personen und 
Schiefer, David/Möllering, Anna/Geschke, Daniel, Muslimisch-deutsche Lebenswelten in Zeiten von Terrorismus (-verdacht): Eine Mehrgenerationenfallstudie, in: Herding, Maruta (Hg.), Radikaler Islam im Jugendalter. Erscheinungsformen, Ursachen und Kontexte, Halle (Saale) 2013, S. 125-139, in:

http://www.dji.de/fileadmin/user upload/bibs2014/1461 DJI Radikalerlslam.pdf, letzter Abruf am 31.01.18.:

\section{Dرl lugendastitite}

Radikaler Islam im Jugendalter

Erscheinungsformen, Ursachen und Kontexte

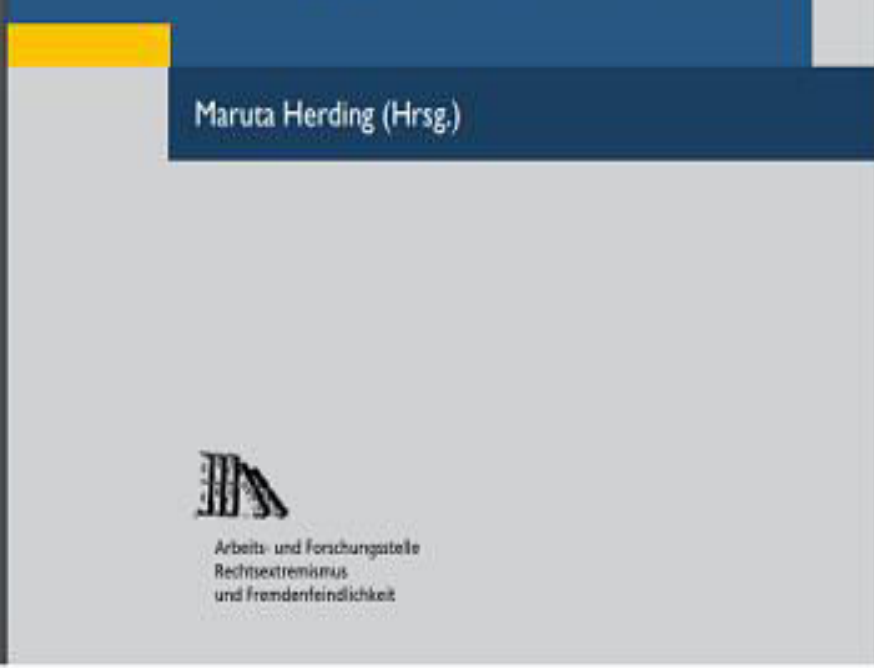


Und:

Dano Scherer, Annu Moulerang, Daniel Geschet

Muslimisch-deutsche Lebenswelten

in Zeiten von Terrorismus(-verdacht):

Eine Mehrgenerationenfallstudie

\section{Einloitung}

Rund funf Prozent der Blevolkerung in Deutschland sind muslimischer Glaubens (Haug u.2. 200\%). Dicse gröbte religiōse Minderheit wat in den letzten Jahren Mittelpankt einet Reihe gesellschaftliches Debarten. The matisiert wurde dabci immer wicder das Zusammenspict von Religiosität, Integration und Radikalisierung, Dies schlaggt sich wach in einer verstark. ten wissenschaftlichen Beachtung dieser Thematik nicder (vgl. Brettfeld/Wetzels 2007; Religoonsmonitor 2008; Gallup-Institut 2009; Li.jeberg Rescarch Internatiotal 2010, 2012; Goh/Rexaci 2010). Thematiscrt wird dabei ebenfalls die zum Teil auspepragt ablehnende Haltung der nichtmuslimischen deutschen Bevölkerung gegenuiler Mludiminnen und Muslimen, eine Haltung, die spàtestens seit dem 11 . September 2001 mit einem gencralisierten latenten Terronismusverdacht verbunden ist (vgl. Decker u.a. 2012: Zick u.1. 2011).

Das komplexe Zusammenspicl von Intcgration, Diskriminierung und Radikalisierung bildete den Hintengrund der Strudic „Isbenswelten junger Muslime in Deutschland" (Friodte u. a. 2012). Der folgende Bcitrag dokumentiert ein Teilmodul dieser Studie: eine qualitative Interview. studie mit Mitgliedern dreicr (ienerationen aus sechs muslimischen Familien (Schiefer/Mollering 2012). Kernthema der Interviers wa dic Wahrnchmung und Finstellung won in Deutschland Icbenden Musliminnen und Muslimen zum islamistischen Termorismus soxie allge. mein zur Hexichung xwischen der (sogenannten), westlichen' und , muslimischen Welt'. Diese subjektiven Wahenchmungen und Einstellungen sollien dabei voe dem Hintergrund cines Lebens als muslimische familic in Deutschland hetrachtet werden. Durch die Finbezichung mehrere Gencrationen in den jewoligen Familien wurde besonders auf intergenerationale Dynamiken sowie Transmissionsprozesse fokussiert. 


\section{Schöll, Albrecht, Religion Jugend, in: WiReLex: \\ http://www.bibelwissenschaft.de/stichwort/100085/; letzter Abruf am 24.01.2018.:}

\section{$\langle>$ C 8 \& hittp://mw.bibelwissenschat.de/stichwort/200085/}

Das Wissenschaftlich.

Religionspäa agogische lexikon

ther WiRelex

Die Autoren/innen

Anmeldung

- Jetzt anmelden

1 Passwort vergessen?

s. Neu registrieren!
Jugend, Religion

Albrecht Schōll

(erstellt Jan, 2015)

Permanenter Link zum Artikel:

hitto:/Www bibelwissenschat delstichwort 100085/

Digital Object Identifier:

https://doi.org/10.23768 iwirelex.Jugend_Religion. 100085

1. Begrifisbestimmung

2. Geschichte def Jugend

3. Jugend als Statuspassage

4. Entstrukturierung der Jugendphase - Jugend als offenes Projekt

5. Religion in der Adoleszenz

5.1. Ausgewathite Ergebnisse der Shell.Jugendstudien und

Kirchenmitgliedschaftsuntersuchung

5.2. Neuartiger Umgang mil Religion

53. Modi der Aneignung von Reilgion

Literaturverzeichnis

\section{Begriffsbestimmung}

Aus biologisch-enturicklungspsychologischer Perspekttve bezeichnet Jugend eine Zeit der Relfung und Entwicklung. In der Pubertat machen Heranwachsende wesentliche korperiche Entwicklungen durch, insbesondere die Entwicklung der sekundàren Geschlechtsmerkmale, der Gebăr und Zeugungsfathigkeit Diese Entwicklung ist mit psychischen, emotionalen und sozialen Veranderungen verbunden, die haufig noch andauem, wenn die Zeit der eigentlichen Geschlechtsreife schon beendet ist.

Kulturell ist Jugend ene Lebenslage innerhalb der Gesellschaft und in der Zwischenstellung zwischen Kindheit und Erwachsenensein ein soziales Phanomen, Diese Lebenslage von Jugend wird als Adoleszenz bezeichnet und hat die Funktion, uber Qualifizierungsppozesse auf die Anforderungen
Mi Lesamodas eil

Direkt zum Artikel

\section{b}

Pr Stichwoiter

\section{Suchbegiff}

Abraham und Sara

bibeldidakisch, Grundeschule

Abraham und Sara

bibeldidakitisch,

Sekundarstute

Abraham, interreligios

Aovance Organizer

Akademie, katholsch

Antorderungssituatonen

Anthropologie

Auterstehung der Toten

Auterstehung vesu

Auschwitz/Auschwitz

nomen

1) III

Abbidungon

Dank

Unser besonderer Dank gitt

allen Personen uno

Insttutionen, de fir WB L Lex

Aboliloungen zur Verfigung

gestelt bzw. deren

Verwendung in WBiLex 


\section{Eigenständigkeitserklärung}

Ich erkläre, dass ich die Arbeit selbstständig angefertigt und nur die angegebenen Hilfsmittel benutzt habe. Alle Stellen, die dem Wortlaut oder dem Sinn nach anderen Werken, gegebenenfalls auch elektronischen Medien, entnommen sind, sind von mir durch Angabe der Quelle als Entlehnung kenntlich gemacht. Entlehnungen aus dem Internet sind durch Angabe der Quelle und des Zugriffsdatums sowie dem Ausdruck der ersten Seite belegt; sie liegen zudem für den Zeitraum von 2 Jahren entweder auf einem elektronischen Speichermedium im PDF-Format oder in gedruckter Form vor.

Freiburg, den 16.02.2018 